\title{
EVAPOTRANSI'IRAÇÃO DE REFERÊNCIA OBTIDA COM A RAZÃO DE BOWEN, LISÍMETRO DE PESAGEM \\ E EQUAÇÃO DE PENMAN-MONTEITH \\ UTILIZANDO SISTEMAS AUTOMÁTICOS
}

\section{BENITO MOREIRA DE AZEVEDO}

Engenheiro Agrônomo

Orientador: Prof. Dr. Marcos Vinícius Folegatti

Tese apresentada à Escola Superior de Agricultura "Luiz de Queiroz", Universidade de São Paulo, para obtenção do título de Doutor em Agronomia, Área de Concentração: Irrigação e Drenagem.

P I R A C I C A B A

Estado de São Paulo - Brasil

Janeiro - 1999 
Dados Internacionais de Catalogação na Publicação (CIP)

DIVISÃO DE BIBLIOTECA E DOCUMENTAÇĀO - Campus "Luiz de Oueiroz"/USP

Azevedo, Benito Moreira de

Evapotranspiração de referência obtida com razāo de Bowen, lisimetro de pesagem e equação de Penman-Monteith utilizando sistemas automáticos / Benito Moreira de Azevedo. - - Piracicaba, 1999.

81 p. : il.

Tese (doutorado) - - Escola Superior de Agricultura Luiz de Queiroz, 1999. Bibliografia.

1. Balấ̧̧o de energia 2. Evapotranspiração 3. Grama-batatais 4. Lisimetro 5. Meteorologia agricola 6. Modelo de Penman-Monteith 7. Relação solo-agua-plantaatmosfera I. Título

CDD 551.572 
À minha esposa,

LORENA,

e às minhas fillhas,

MARIANA E MADIANA,

DEDICO. 
Ao povo do Brasil, ao qual tento retribuir, pelo financiamento direto e indireto dos meus cursos de graduação e pós-graduação

e

A todos os professores que, passo a passo, tempo a tempo, ministram-me valiosos ensinamentos, 


\section{AGRADECIMENTOS}

À LORENA, minha querida esposa, por ter se desdobrado, possibilitando minha dedicação ao curso e às minhas filhas, MARIANA e MADIANA, pelos momentos de separação e de silêncio que souberam compreender e proporcionar.

À Universidade Federal do Ceará, pelo alicerce da minha formação profissional e permissão para realizar o curso de doutorado.

À Escola Superior de Agricultura "Luiz de Queiroz" / USP, através do Departamento de Engenharia Rural, pela oportunidade, facilidade e acolhida para realização deste trabalho.

Ao Prof. Dr. Marcos Vinícius FOLEGATTI, pelas orientações, amizade e, principalmente, apoio concedido em todos os momentos.

Aos professores dos Departamentos de Engenharia Agrícola e de Física e Meteorologia da ESALQ/USP, pela amizade e ensinamentos, em especial, ao NILSON, FRIZZONNE, LIBARDI, PEREIRA, VETTORAZZI e TARLEI.

À Coordenação de Aperfeiçoamento de Pessoal de Nível Superior (CAPES), através do Programa Institucional de Capacitação Docente e Técnica (PICDT), pela bolsa de estudo concedida.

Aos colegas de curso, pelo convívio, amizade e colaboração, em especial, ao THALES, ALEXANDRE, CHICO, ZOCOLER, MAURÍCIO, OSVALDO, RAQUE1, FERNANDO, VIRGÍLIO, FRANCISMAR, LÁZARO, FABIANO, AXEL, SERGIO e tantos outros.

Aus funcionários da ESALQ/USP, CÉSAR, HÉLIO, GILMAR, ZEZINHO, ELIANI: E ROBERTA, pela cooperação.

A todos que, direta ou indiretamente, contribuíram para o êxito deste trabalho, principalmente aqueles que, mesmo sem ter seus nomes citados, apoiaram-me ou, simplesmente, estão felizes com esta realização.

A lodos, muito obrigado. 


\section{SUMÁRIO}

Página

LISTA DE FIGURAS ….............................................. vi

LISTA DE TABELAS _..............................................................

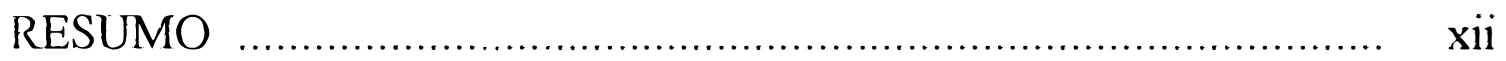

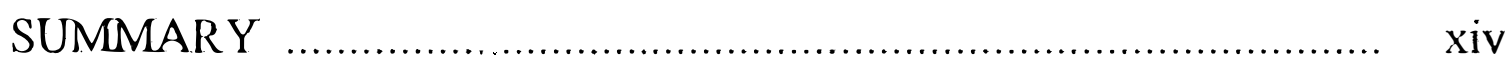

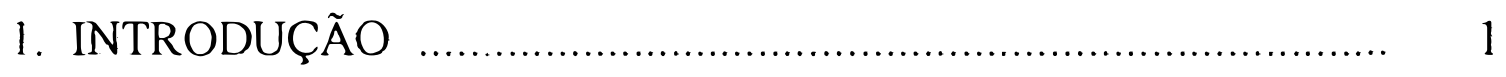

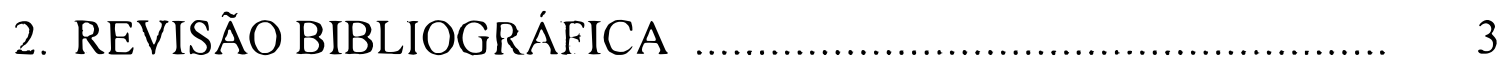

3. MATERIAL E MÉTODOS …............................................. 17

4. RESULTADOS E DISCUSSÃO _.......................................... 34

5. CONCLUSÕES …........................................................ 53

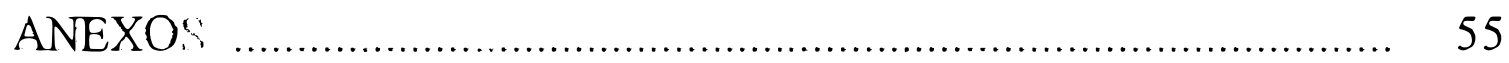

REFER NCIAS BIBLIOGRÁFICAS ….................................... 73 


\section{LISTA DE FIGURAS}

Figura

Página

1 - Área experimental

18

2 - Equipamento automático da razão de Bowen

19

3 - Braço metálico superior com entrada de ar e termopares do equipamento razão de Bowen

4 - Higrômetro, controlador do fluxo de ar e sistema de aquisição de dados do equipamento razão de Bowen

5 - Instalação da placa de fluxo de calor de solo e termopares de solo .....

6 - Vista superior da instalação do lisímetro de pesagem (parte inferior da figura)

8 - $\mathrm{ETo}_{\mathrm{L}}(\mathrm{mm})$ observada no lisímetro de pesagem, $\mathrm{ETo}_{\mathrm{BR}}(\mathrm{mm})$ observada no equipamento razão de Bowen e $\operatorname{EToPM}_{\mathrm{PM}}(\mathrm{mm})$ estimada pela metodologia da FAO/1991, no período de $1^{\circ}$ de novembro a 10 de dezembro de 1996 
$9-\mathrm{ETo}_{\mathrm{BR}}$ ( $\mathrm{mm}$ ) observada no equipamento razão de Bowen versus $\mathrm{ETo}_{1}$ $(\mathrm{mm})$ observada no lisímetro de pesagem, no período de $1^{\circ}$ de novembro a 10 de derembro de 1996

$10-\mathrm{ETO}_{\mathrm{BR}}(\mathrm{mm})$ observada no equipamento razão de Bowen versus ETOpm (mm) estimada pela metodologia da $\mathrm{FAO} / 1991$, no período de $1^{\circ}$ de novembro a 10 de dezembro de 1996

11 - $\mathrm{ETo}_{\mathrm{pM}}(\mathrm{mm})$ estimada pela metodologia da $\mathrm{FAO} / 1991$ versus $\mathrm{ETo}_{\mathrm{L}}$. $(\mathrm{mm})$ observada no lisímetro de pesagem, no período de $1^{\circ}$ de novembro a 10 de dezembro de 1996

$12-\mathrm{ETo}_{\mathrm{BR}}(\mathrm{mm})$ versus $\mathrm{ETo}_{\mathrm{L}^{+}}(\mathrm{mm})$ considerando os valores positivos, para os dias com precipitaçăo inferior a $1 \mathrm{~mm}$

13 - $\operatorname{ETO}_{B R}(\mathrm{~mm})$ observada no equipamento razão de Bowen versus Elopm (mm) estimada pela metodologia da FAO/1991, nos dias com precipitação inferior a $1 \mathrm{~mm}$

$14-\mathrm{ETo}_{1,-}(\mathrm{mm})$ observada no lisimetro de pesagem considerando os valores positivos versus ETO $_{\mathrm{PM}}(\mathrm{mm})$ estimada pela metodologia da $\mathrm{FAO} / 1991$, nos dias onde não ocorreram precipitações

15 - Velocidade média diária do vento $(\mathrm{m} / \mathrm{s})$ versus total diário das diferenças lisimétricas positivas $(\mathrm{mm})$

16 - Variação de $\mathrm{ETo}_{\mathrm{I} .}, \mathrm{E}^{\prime} \mathrm{O}_{\mathrm{I},+}, \mathrm{ETo}_{\mathrm{BR}}$ e ETopm no dia 05 de dezembro de 1996, em mm 
17 - Valores de $\mathrm{ETo}_{\mathrm{I}}$, versus $\mathrm{ETo}_{\mathrm{PM}}, \mathrm{ETo}_{\mathrm{I}}$, versus $\mathrm{ETo}_{\mathrm{BzR}}$ e $\mathrm{ETo}_{\mathrm{PM}}$ versus $\mathrm{ETo}_{\mathrm{BR}}$, estimadas no período de 21 de novembro a 10 de dezembro de 1996

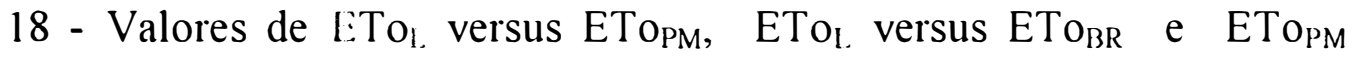
versus $E \mathrm{CO}_{\mathrm{BR}}$, estimadas no período de $1^{\circ}$ a 10 de dezembro de $1996 \ldots .$.

19 - Valores de $\mathrm{ETo}_{\mathrm{L}}$ versus $\mathrm{ETo}_{\mathrm{PM}}, \mathrm{ETo}_{\mathrm{L}}$ versus $\mathrm{ETo}_{\mathrm{BR}}$ e ETopM versus $\mathrm{ETo}_{\mathrm{BR}}$, estimadas para o dia 2 de dezembro de 1996

20 - Valores de $\mathrm{ETo}_{\mathrm{L}}$, versus ETopm, ETo $\mathrm{E}_{\mathrm{L}}$ versus $\mathrm{ETo}_{\mathrm{BR}}$ e ETopM versus $\mathrm{ETo}_{\mathrm{BR}}$, estimadas para o dia 5 de dezembro de 1996

21 - Valores de $\mathrm{ETo}_{\mathrm{L}}$ versus ETo $\mathrm{PM}_{\mathrm{P}}, \mathrm{ETo}_{\mathrm{L}}$ versus $\mathrm{ETo}_{\mathrm{BR}}$ e $\mathrm{ETo}_{\mathrm{PM}}$ versus $\mathrm{ETo}_{\mathrm{BR}}$, estimadas para o dia 6 de dezembro de 1996

22 - Valores de $\mathrm{ETo}_{\mathrm{I}}$ versus $\mathrm{ETo}_{\mathrm{PM}}, \mathrm{ETo}_{\mathrm{L}}$ versus $\mathrm{ETo}_{\mathrm{BR}}$ e $\mathrm{ETo}_{\mathrm{PM}}$ versus $\mathrm{ETo}_{\mathrm{BR}}$, estimadas para o dia 8 de dezembro de 1996

23 - Valores de $\mathrm{ETo}_{\mathrm{L}}$ versus ETo $\mathrm{PM}_{\mathrm{PM}}, \mathrm{ETo}_{\mathrm{L}}$ versus $\mathrm{ETo}_{\mathrm{BR}}$ e ETopM versus $\mathrm{ETo}_{\mathrm{BR}}$, estimadas para o dia 9 de dezembro de 1996

24 - Valores de $\mathrm{ETo}_{\mathrm{L}}$ versus $\mathrm{ETo}_{\mathrm{PM}}, \mathrm{ETo}_{\mathrm{L}}$ versus $\mathrm{ETo}_{\mathrm{BR}}$ e $\mathrm{ETo}_{\mathrm{PM}}$ versus $\mathrm{ETo}_{\text {13R }}$, estimadas para o dia $1^{\circ}$ de dezembro de 1996

25 - Valores de $\mathrm{ETo}_{\mathrm{L}}$ versus $\mathrm{ETo}_{\mathrm{PM}}, \mathrm{ETo}_{\mathrm{L}}$ versus $\mathrm{ETo}_{\mathrm{BR}}$ e $\mathrm{ETo}_{\mathrm{PM}}$ versus $\mathrm{ETo}_{\mathrm{BR}}$, estimadas para o dia 3 de dezembro de 1996 
26 - Valores de $\mathrm{ETo}_{\mathrm{l}}$ versus ETopm, ETo, versus $\mathrm{ETo}_{\mathrm{BR}}$ e ETopM versus ETo $\mathrm{O}_{1 \leqslant R}$, estimadas para o dia 7 de dezembro de 1996

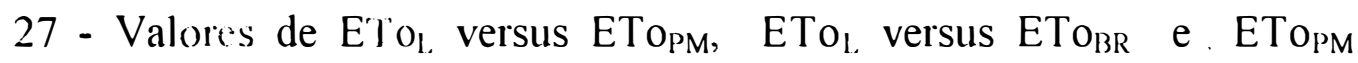
versus ETo $\mathrm{O}_{\mathfrak{s},}$, estimadas para o dia 10 de dezembro de 1996

28 - Valores de $\mathrm{ETo}_{\mathrm{l}+\text { versus }} \mathrm{ETo}_{\mathrm{PM}}$ e $\mathrm{ETo}_{\mathrm{L}+\text { versus }} \mathrm{ETo}_{\mathrm{BR}}$, estimadas para o dia 2 de dezembro de 1996

29 - Valores de $\mathrm{ETo}_{\mathrm{L},+}$ versus $\mathrm{ETo}_{\mathrm{PM}}$ e $\mathrm{ETo}_{\mathrm{L},+}$ versus $\mathrm{ETo}_{\mathrm{BR}}$, estimadas para o dia 5 de dezembro de 1996

30 - Valores de $\mathrm{ETo}_{\mathrm{l}++}$ versus $\mathrm{ETo}_{\mathrm{PM}}$ e $\mathrm{ETo}_{\mathrm{l+}}$ versus $\mathrm{ETo}_{\mathrm{BR}}$, estimadas para o dia 6 de dezembro de 1996

31 - Valores de ETo $\mathrm{L}_{1+}$ versus ETopm e ETo $\mathrm{ET}_{\mathrm{L}+}$ versus ETo $\mathrm{BR}_{\mathrm{BR}}$, estimadas para o dia 8 de dezembro de 1996

32 - Valors; de $E \mathrm{Lo}_{\mathrm{L}^{+}}$versus ETo $\mathrm{PM}_{\mathrm{PM}}$ e ETo $\mathrm{O}_{\mathrm{l}_{+}}$versus $\mathrm{ETo}_{\mathrm{BR}}$, estimadas para o dia 9 de dezembro de 1996 


\section{LISTA DE TABELAS}

Tabela

Página

1 - Valores da evapotranspiração de referência $(\mathrm{mm})$ estimados para o

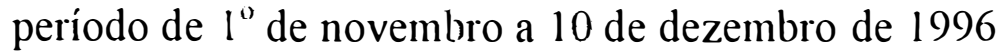

2 - Valores de $\operatorname{ETo}_{\mathrm{BR}}(\mathrm{mm}), \mathrm{ETo}_{\mathrm{PM}}(\mathrm{mm})$ e $\mathrm{ETo}_{\mathrm{L}-\text { - }}(\mathrm{mm})$, nos dias com precipitação inferior a $1 \mathrm{~mm}$

3 - Valores de id e de $r^{2}$ obtidos relacionando-se os valores de $\mathrm{ETo}_{\mathrm{L}}$ versus ETopm, $\mathrm{ETo}_{\mathrm{L}}$ versus $\mathrm{ETo}_{\mathrm{BR}}$ e ETopm versus $\mathrm{ETo}_{\mathrm{BR}}$, para o período tolal, para os 20 dias finais e 10 dias finais do experimento

4 - Valores positivos das diferenças lisimétricas $(\mathrm{mm})$ e velocidade média diária do vento $(\mathrm{m} / \mathrm{s})$ a $2 \mathrm{~m}$ de altura

5 - Valores de id e de $\mathrm{r}^{2}$ calculados com a comparação de $E T \mathrm{o}_{\mathrm{L}}$ versus $\mathrm{ETo}_{\mathrm{p} \mathrm{M}}, \mathrm{ETo}_{\mathrm{I}}$ versus $\mathrm{ETo}_{\mathrm{BR}}$ e $\mathrm{ETo}_{\mathrm{PM}}$ versus $\mathrm{ETo}_{\mathrm{BR}}$, nos dias 02, 05, 06, 08 e 09 de dezembro de 1996

6 - Valores de iil e de $r^{2}$ calculados com a comparação de $E \mathrm{~T}_{\mathrm{I}}$. versus ETopm, ETo $_{1}$ versus ETo $_{\text {BR }}$ e ETopm versus ETo $_{\mathrm{BR}}$, nos dias $1^{\circ}, 03,07 \mathrm{e}$ 10 de dezembro de 1996 
7 - Valores de id e de $\mathrm{r}^{2}$ para as comparações de $\mathrm{ETo}_{\mathrm{L} .+}$ versus $\mathrm{ETo}_{\mathrm{PM}}$, $\mathrm{ETo}_{\mathrm{L}}$ versus $\mathrm{ETo}_{\mathrm{PM}}, \mathrm{ETo}_{\mathrm{L}}$, versus $\mathrm{ETo}_{\mathrm{BR}}$ e $\mathrm{ETo}_{\mathrm{I}}$, versus $\mathrm{ETo}_{\mathrm{BR}}$, nos dias 02, 05, 06, 08 e 09 de dezembro de 1996

8 - Dados climáticos, evapotranspiração de referência e componentes do balanço de energia do dia 05 de dezembro de 1996 


\section{EVAPOTRANSPIRAÇÃO DE REFERÊNCIA OBTIDA COM A RAZÃO DE BOWEN, LISÍMETRO DE PESAGEM E LQUAÇÃO DE PENMAN-MONTEITH UTILIZANDO SISTEMAS AUTOMÁTIĆOS}

Autor: BENITO MOREIRA DE AZEVEDO

Orientador: Prof. Dr. MARCOS VINÍCIUS FOLEGATTI

\section{RESUMO}

Este trabalho foi desenvolvido na área experimental de irrigação, do Departamentı de Engenharia Rural, da Escola Superior de Agricultura "Luiz de Queiroz", na Fazenda Areão, situada no município de Piracicaba, estado de São Paulo, com os objetivos de estimar a evapotranspiração de referência (ETo), em superficie vegetada com grama (Paspalum nolatum flïgge), com um lisímetro de pesagem, com a equação de Penman-Monteith parametrizada pela FAO/1991 e com o bil anço de energia, utilizando-se da razão de Bowen $(\beta)$.

Os dados analisados neste trabalho foram obtidos no período de $1^{\circ}$ de novembro a 10 de dezembro de 1996, utilizando-se de uma estação agrometeorológica automática para coleta de dados climáticos, de um lisímetro de pesagem e de um sistema automático para estimativa da razão de Bowen. Os valores 1 ETo estimados pelas três metodologias adotadas foram comparados estatisticamente, nas escalas horária e diária, com finalidade de estudar a aderência dos resultados alcançados nas escalas propostas. 
Foram obtidos os seguintes valores de evapotranspiração de referência (ETo), para o período total de estudo: com o lisímetro de pesagem a $\mathrm{ETo}_{\mathrm{L}}$ foi de $177,37 \mathrm{~mm}$; empregando-se a parametrização proposta pela $\mathrm{FAO} / 1991$ para a equação de Penman-Monteith alcançou-se um valor de $172,91 \mathrm{~mm}$ para a EToPM e com o equipamento automático razão de Bowen a $E T o_{B R}$ foi estimada em $166,77 \mathrm{~mm}$.

Analisando-se os resultados alcançados para ETo diário, pelo coeficiente de determinação da regressão linear simples e pelo índice de concordância proposto por Willmott (1981), é possível afirmar que as maiores correlações foram obtidas quando se comparou a ETo estimada pela metodologia FAO/1991 com as respostas lisimétricas. O coeficiente de determinação $\left(\mathrm{r}^{2}\right)$ médio dessa análise foi de 0,91 e o índice de concordância (id) médio foi de 0,97 .

Entretanto, para a escala horária, as maiores correlações foram obtidas quando se comparou a ETo estimada pela metodologia FAO/1991 com a estimativa realizada com o método da razão de Bowen. Obtendo-se $r^{2}$ médio de 0,96, para os dias 02,05,06, 08 e 09 de dezembro de 1996, quando as interferências pluviométricas foram reduzidas e o equipamento foi manuseado mais adequadamente. Os valores de id para esses dias apresentaram média de 0,98 . 


\section{REFERENCE EVAPOTRANSPIRATION OBTAINED BY \\ BOWEN RATION SYSTEM, WEIGHING LISYMETER \\ AND PENMAN-MONTEITH MODEL}

Author: BENITO MOREIRA DE AZEVEDO

Adviser: Prof. Dr. MARCOS VINÍCIUS FOLEGATTl

\section{SUMMARY}

This work was carried out at the irrigation experimental area, Fazenda Areão, the Department of Rural Engineering - "Luiz de Queiroz" College of Agriculture, at Piracicaba State of São Paulo - Brazil. The aim of this work was to estimate the reference evapotranspiration (ETo), the Bowen Ratio $(\beta)$, on grass surface (Paspalum notatum flïgge), and compare to the results obtained by a weighing lysimeter and Penman-Monteith model suggested by FAO/1991.

The data analyzed were collected from November first to December tenth, using an automatic Bowen Ration system, weather station and a weighing lysimeter. The values estimated by these three systems were compared, at hourly and daily basis, in order to study the correlation among them at the scales proposed.

It was observed that, during the period that the reference evapotranspiration (ETo) of 177,37 mm measured by the weighing lysimeter, using the methodology suggested by FAO/91, the ETo was $172,91 \mathrm{~mm}$ and the Bowen Ration system estimated ETo was $166,77 \mathrm{~mm}$. 
The highest values of coefficient of determination and Willmott coefficient were observed when the ETo estimated by the FAO/1991 methodology was compared with the lysimeter measurements. The average coefficient of determination $\left(\mathrm{r}^{2}\right)$ was 0,91 and the Willmot coefficient was 0,97 .

For the hourly scale, the highest correlations were obtained when the ETo estimated by the FAO/1991 methodology was compared with the Bowen ratio measurements. The average $r^{2}$ of 0,96 , for the days 02, 05, 06, 08 and 09 December of 1996, when the influence of the rain was reduced and the equipment was used more properly, was found. The average values of id for those days was 0,98 . 


\section{INTRODUÇÃO}

A irregularidade das precipitações pluviométricas tem ocasionado, ao longo dos anos, perdas significativas na produção agrícola. Por outro lado, a irrigação tem sido adotada para corrigir esta deficiência hídrica. Em diversas situações, esta prática vem sendo realizada sem obedecer recomendações técnicas adequadas, o que tem proporcionado um aproveitamento inadequado de áreas cultivadas e dos recursos hídricos disponíveis.

Um dos fatores que determinam o bom desenvolvimento das culturas é a disponibilidade hídrica no solo, daí a importância dos métodos utilizados para estimar os componentes do balanço hídrico. A evapotranspiração é o componente de grande importância por permitir definir a quantidade de água a aplicar-se nos cultivos. Vários são os métodos de medida e estimativa da evapotranspiração de diferentes superficies vegetadas. Dentre eles, o método do balanço de energia tem sido utilizado para tal finalidade. Ele permite estimar as necessidades de água de comunidades vegetais, através da quantidade de energia disponível para o processo de evapotranspiração.

Um fator complicador na estimativa da evapotranspiração, que algumas vezes é negligenciado, é o efeito advectivo, sua amplitude e intensidade, numa determinada condição de área irrigada. O processo de amostragem, através da localização adequada dos equipamentos, também pode comprometer as estimativas, devido a divergência horizontal, principalmente, em situações onde o efeito oásis é expressivo. A evapotranspiração precisa ser conhecida e quantificada, de forma mais precisa possível, proporcionando assim a 
possibilidade de se estimar o volume e intensidade de água a aplicar-se em uma comunidade vegetal, resultando em otimização de lâminas e redução nos custos de produção.

O correto manejo da irrigação implica na utilização racional dos recursos hídricos. Sistemas de irrigação automáticos são caros, e sua justificativa econômica é o incremento da produção resultante de uma alta freqüência de irrigação, principalınente em culturas de elevado valor econômico.

A estimativa diária do consumo de água pelas culturas pode ser obtida baseando-se em mensurações relativamente simples e realizáveis em campo, e as estimativas meteorológicas do fluxo de água na atmosfera podem prover facilmente valores representativos da evapotranspiração. É verdade que ainda existem obstáculos a serem superados para se obter este tipo de estimativa, como: a disponibilidade de equipamento adequado; custos elevados; a baixa mobilidade da instrumentação; entre outros. Com o recente desenvolvimento da tecnologia de sensores e sistemas de aquisição de dados, é possível estimar muito mais facilmente, de forma direta e cun tempo real a evapotranspiração, e com um custo relativamente baixo.

Este trabalho tem como objetivos estimar a evapotranspiração de referência (ETo), em superfície vegetada com grama (Paspalım notatım flïgge), a razão de Bowen ( $(3)$, o fluxo de calor latente pelo balanço de energia e comparar os resultados obtidos com os alcançados através de método lisimétrico e com o mítodo combinado de Penman-Monteith, parametrizado pela Food and Agriculture Organization (FAO/1991), avaliando a utilização de cada uma das metodologias de estimativa de ETo na escala horária e diária. 


\section{REVISÃO DE LITERATURA}

O balanço de energia em superfícies vegetadas permite dimensionar as trocas de massas e energia no sistema solo-planta-atmosfera, através do estudo da partição do saldo de radiação nos diversos processos que ocorrem na superfície. O método permite avaliar as alterações no microclima da vegetação em função dos estágios de desenvolvimento da cultura e em função das condições do solo e da atmosfera. Ele pressupõe que a energia líquida disponível, na superfície da terra, se reparte em Muxo de calor sensível no solo $(G)$, fluxo de calor sensível no ar $(H)$, fluxo de calor latente de evaporação (LE), energia utilizada na fotossíntese (F) e em trocas devidas as atividades metabólicas e armazenamento nos tecidos das plantas $(\mathrm{P})$. A energia média utilizada na atividade fotossintética não supera $3 \%$ do saldo de radiação, sendo esse valor relativamente maior para períodos curtos de tempo, como pela manhã ou tarde, dependendo ainda do estágio de desenvolvimento da cultura, porém não excede $5 \%$ da radiação solar incidente. $O$ termo $\mathrm{P}$, também, é quantitativamente pequeno, com exceção para vegetação de grande porte. Devido ao erro associado as estimativas e aos baixos valores alcançados, os termos $\mathrm{F}$ e $\mathrm{P}$ podem ser considerados negligíveis. Então, no balanço de energia pode-se considerar apenas os três primeiros processos (Sellers, 1965; Fuchs \& Tanner, 1970; Villa Nova, 1973; Rosenberg, 1974; Alfonsi et al., 1986; Fontana et al., 1991; André, 1996; Pereira et al., 1997).

O ganho de energia por advecção é, geralmente, omitido em função das dificuldades de quantificá-lo, podendo causar incorreções na aplicação do método do balanço de energia e, conseqüentemente, na estimativa do volume de água 
consumido por uma comunidade vegetal. Entretanto, a advecção pode ser minimizada quando as medidas são realizadas próximas da superfïcie da cultura e com uma adequada bordadura, de altura uniforme, a barlavento (Chang, 1971; Pereira, 1996).

Berlato \& Molion (1981), salientam que a advecção representa a troca de energia em uma superfície evaporante, através de contribuição horizontal. Embora possa ter importância significativa em certas condições, como para culturas irrigadas de pequena extensão em regiões semi-áridas, este termo é, em geral, desprezado. Em diversas pesquisas agrícolas o efeito da troca de energia (umidade ou momentum devido a heterogeneidade horizontal) tem sido usualmente negligenciado, assumindo-se, desta forma, a uniformidade do microclima e do fluxo evaporativo (Silva, 1989). Isto, de alguma forma, pode ter reflexo negativo na avaliação de alguns métodos, pois eles podem estar sendo utilizados e avaliados de maneira diversa da qual foram propostos pelos autores.

O conceito de evapotranspiração potencial (ETP) foi introduzido por Thornthwaite (1948), e pode ser definido como sendo a perda d'água por uma superfície de solo úmido suficientemente grande, com suprimento contínuo e adequado de água, coberto completamente por vegetação de baixo porte em crescimento ativo, de tal modo que possa tornar desprezível o efeito advectivo. A evapotranspiração depende, de forma significativa, da capacidade do ar em remover vapor d'água, da natureza da vegetação, da natureza do solo, especialmente da disponibilidade de água na zona do sistema radicular e do suprimento externo de energia para a superfície evaporante, principalmente pela radiação solıır.

O consumo de água numa comunidade vegetal pode ser totalizado pela componente evapotranspiração. Segundo Tanner (1960), Chang (1971), Rosenberg (1974), Ometto (1981) e Sediyama (1988), evapotranspiração é a soma dos processos de evaporação da água de uma superfície com a transpiração pelas 
plantas em uma área cultivada, sendo praticamente impossível separar os dois fenômenos. Com exceção de uma desprezível quantidade de água utilizada pelas plantas nos processos metabólicos, os termos evapotranspiração e uso consuntivo podem ser considerados sinônimos. Blaney \& Criddle (1952), definiram o termo uso consuntivo como sendo a soma dos volumes de água consumido na transpiração e formação de tecidos da planta com aquele evaporado, sendo normalmente expresso em milímetros de altura de água, e relacionado aos estágios da cultura.

A ETP pode ser considerada um parâmetro climático, sendo assim dependente exclusivamente do clima. Desta forma, Hargreaves (1974), definiu a evapotranspiração real (ETR) como o uso real de água pelas culturas, incluindo a evaporaçĩo direta a partir da umidade do solo e da vegetação. Ela depende do clima, do solo, da cultura e da umidade do solo na zona do sistema radicular. Enquanto os fatores climáticos determinam a taxa de ETP, os fatores da cultura são influe iados pela percentagem da cobertura vegetal, altura da cultura, área foliar, estígio de desenvolvimento, albedo, resistência estomática ao fluxo de vapor d'água, entre os principais. Assim sendo, durante períodos de total cobertura vegetal e máximo crescimento vegetativo, a maioria das culturas evapotranspira mais que as gramíneas de pequeno porte.

Segundo Aubertini \& Peter (1961), a taxa de evapotranspiração é governada, principalmente, pelo saldo de radiação e pela quantidade de água presente no solo. Os autores observaram ainda, que para maiores densidades de plantio de milho, em condições de deficiência hídrica, uma eficiente captação de radiação solar polte conduzir a um aumento da transpiração e, conseqüentemente, a um murchamento das plantas.

Mukand \& Bruce, citados por Chang (1971), apresentam que a importância relativa da radiação sobre a evapotranspiração potencial é de $80 \%$, da umidade do ar é de $6 \%$ e da velocidade do vento é de $14 \%$, aproximadamente. 
Em uma lavoura irrigada, a água contida no solo está em movimento constante, em vários regimes e direções, e de maneira similar há um fluxo constante de energia. Assim, como a lei da conservação de massa permite calcular o balanço de água no campo, a lei da conservação de energia pode ser aplicada para calcular o balanço de energia no campo. Os dois balanços não são interdependentes, pois o destino da energia que atinge o solo é fortemente influenciado pelo conteúdo de água, pelo seu estado e pelo seu movimento, e vice-versa. O processo afetado de maneira mais significativa é a evaporação, sendo o principal consumidor, no campo, tanto de energia quanto de água. Como a evaporação é, basicamente, um processo de transferência de energia, é possível a aplicação do princípio da conservação de energia para estimar a transferência de água para a atmosfera em forma de vapor, Berlato \& Molion (1981). Uma grande quantidade de calor é absorvida pela água que evapora do solo e da vegetação, sendo chanado de calor latente, estimando esta quantidade de calor, ter-se-á a noção do regime evapotranspirativo, sem que seja necessário medir diretamente o teor de água do solo e os seus fluxos.

A evapotranspiração é menor em uma área seca que circunda uma área irrigada, sendo que na interface destas superficies a evapotranspiração é representativa de uma situação de oásis. Esta situação representa o efeito varal, onde a evapolranspiração aumenta exageradamente (Pereira et al., 1997).

Priestley \& Taylor (1972), propuseram um parâmetro $(\alpha)$ para corrigir o efeito advectivo, sendo expresso pela razão entre a taxa de evapotranspiração potencial e a de equilíbrio. Eles encontraram alta relação entre o parâmetro $\alpha$ e a razão de Bowen ( $\beta$ ), em condições imigadas na cultura do arroz (Oryza sativa).

Bowen (1926), assumiu que os transportes de calor sensivel e de vapor d'água são similares, concluindo que a razão entre os coeficientes de difusividade turbulenta de calor sensível $(\mathrm{Kh})$ e latente $(\mathrm{Ke})$ é igual à unidade. Ele relacionou 
os fluxos de calor sensível (H) e calor latente (LE) da maneira como pode ser visto na equação (01). Esta relação tornou-se conhecida como razão de Bowen $(\beta)$, e tem sido largamente utilizada em estudos de fluxo de calor, estimativas de evapotranspiração e, também, para estimar a resistência imposta pelo sistema planta-atmosfera ao fluxo de vapor d'água (Fontana et al., 1991).

$$
\beta=\frac{H}{L E}
$$

A condição hídrica da superfície evaporante afeta diretamente o valor de $\beta$, interferindo assim na partição da radiação líquida $(R n)$. Desta maneira, quando a superfície apresentar restrição hídrica o valor de $\beta$ será elevado, devido a maior parte de Rn ser utilizada no aquecimento do ar $(\mathrm{H})$. Caso a umidade da superfície seja elevada, uma parte maior de $\mathrm{Rn}$ será destinada para a evaporação de água (LE), e conseqüentemente o valor $\beta$ será reduzido.

Valendo-se do mesmo raciocínio, Pereira et al. (1997), concluíram que o sinal de $\beta$, em uma superfície evaporante, depende apenas do sinal do calor sensível (II), pois considera-se como negativo os fluxos da superfície para a atmosfera que a envolve, e positivo no sentido inverso. Portanto, quando $\beta$ é negativo o valor $\mathrm{H}$ é positivo, significando que está ocorrendo transporte de calor sensível do ar mais quente para a superfície mais fria, caracterizando uma condição de advecção. Nesta situação, Rn pode, até mesmo, ser superado pelo valor de LE, pois o calor sensível transportado representa um acréscimo na energia disponível para o processo de evaporação.

A estimativa dos fluxos turbulentos de calor latente (LE) e sensível (H), sobre uma superfície pode ser realizada, caso se conheça: 
$\mathrm{Rn}=$ radiação líquida;

$\mathrm{G}=$ fluxo de calor sensível no solo;

$\Delta \mathrm{T}^{\prime}=$ diferença entre as temperaturas indicadas nos termômetros de bulbos úmidos de dois níveis $\left(\mathrm{T}^{\prime}{ }_{2}-\mathrm{T}^{\prime}{ }_{1}\right)$;

$\Delta \mathrm{T}=$ diferença entre as leituras dos termômetros de dois níveis $\left(\mathrm{T}_{2}-\mathrm{T}_{\mathrm{l}}\right)$;

$\mathrm{S}=$ tangente à curva de tensão de saturação de vapor d'água no ponto de temperatura média úmida, i.e., o valor médio de $\mathrm{T}_{2}{ }_{2} \mathrm{e} \mathrm{T}{ }_{1}$;

$\gamma=\frac{c_{p} \cdot P}{0,622 \cdot \lambda}$, é o coeficiente psicrométrico;

$\mathrm{P}=$ pressão atmosférica local;

$\mathrm{c}_{\mathrm{p}}=$ calor específico do ar seco a pressão constante $\left(1.005 \mathrm{~J} \cdot \mathrm{kg}^{-1} \cdot \mathrm{K}^{-1}\right)$;

$\lambda=$ calor latente de evaporação $\left(2,45 \mathrm{MJ} \cdot \mathrm{kg}^{-1}\right)$;

$\rho=$ massa específica do ar seco $\left(1,26 \mathrm{~kg} \cdot \mathrm{m}^{-3}\right)$.

É comum e aceito admitir-se que, durante o tempo de medida, $\lambda$ e $\rho$ permanecem constantes numa pequena camada de ar estudada.

Embora Brutsaert (1982), recomende utilizar o gradiente vertical da temperatura potencial $\left(\delta T_{\theta} / \delta z\right)$, é possível empregar o gradiente vertical da temperalura do ar $(\delta T / \delta z)$, sem que se cometa erro significativo. Realizou-se cálculos comparativos, entre a utilização da temperatura potencial e do ar, com os valores normais de pressão, temperatura e umidade do ar, para a cidade de Piracicaba-SP, e as diferenças obtidas foram desprezíveis. Webb (1965); Villa Nova (1973); Pereira et al. (1997), apresentam a equação (02) que permite a estimativa direta de $\beta$ com base no gradiente vertical da depressão psicrométrica $\left(\Delta T^{\prime} / \Delta \mathrm{T}\right)$, corrigida pelo fator de ponderação $((\mathrm{S}+\gamma) / \gamma)$. Isto permite, de forma segura e rápida, estimar o fluxo de calor latente com base no balanço de energia, equação (03). 


$$
\begin{aligned}
& \beta=\left[\left(((S+\gamma) / \gamma) \cdot\left(\Delta T^{\prime} / \Delta T\right)\right)-1\right]^{-1} \\
& L E=(R n-G) /(1+\beta)
\end{aligned}
$$

$O$ valor de $\beta$ deve ser diferente de -1 , e a medida que ele se aproxima deste valor a equação (03) torna-se indefinida. Tanner (1960), acredita que $-0,5$ seja o limite de confiabilidade para $\beta$, quando se utiliza esta equação. Em outro momento, o autor recomenda que ela não seja empregada, caso se encontre no intervalo $-1,25<\beta<-0,75$ (Tanner, 1988). O autor aconselha a realização dos cálculos dos fluxos de calor sensível e latente, e também recomenda não se trabalhar om outros dados associados ao valor de $\beta$, do intervalo mencionado.

Os métodos de estimativa da evapotranspiração que se baseiam no balanço de energì são dos mais confiáveis. A metodologia consiste em determinar o balanço de energia sobre a superfície, depois procura-se avaliar a fração da energia que é utilizada no processo de evapotranspiração. Desde que os fluxos verticais de calor sensível, calor latente e de momento sejam do tipo convectivo forçado (fluxo turbulento em condições de atmosfera neutra), Villa Nova (1973) e Pereira (1996) consideram que eles podem ser calculados em função dos gradientes médios da: temperatura do ar $(\mathrm{T})$, umidade específica do ar (q) e velocidade de vento (u), de acordo com as equações (04), (05) e (06), respectivamente.

$$
H=-\rho \cdot c_{p} \cdot K h \cdot \frac{\delta T}{\delta z}
$$




$$
\begin{aligned}
& \mathrm{LE}=-\rho \cdot \lambda \cdot \mathrm{Ke} \cdot \frac{\delta \chi_{1}}{\delta z} \\
& \tau=\rho \cdot \mathrm{Km} \cdot \frac{\delta u}{\delta z}
\end{aligned}
$$

Em condições de advecção, Blad \& Rosenberg (1974), observaram que o balanço de energia subestimou em até $20 \%$ a evapotranspiração medida em lisímetro, concluindo que os coeficientes de difusividade turbulenta de calor sensível $(\mathrm{Kh})$ e latente $(\mathrm{Ke})$ não são iguais, então a relação $\mathrm{Kh} / \mathrm{Ke}>1$. Vários pesquisadores demonstraram, que em condições atmosféricas estáveis, causadas por advecção local, Kh e Ke são diferentes (Verma et al. 1978; Motha et al. 1979). Entretanto, é comum e aceito considerar-se Kh igual a Ke, sem que se cometa erros significativos nas estimativas de fluxos de calor sensível e latente.

Ainda segundo Villa Nova (1973); Pereira (1996), é lógico assumir-se que o coeficiente de difusividade turbulenta para uma propriedade da atmosfera pode ser considerado igual ao coeficiente de difusividade de transporte de momento, supondo que todas as propriedades são igualmente transportadas pelo mesmo turbilhão. Assim, com base na hipótese da similaridade, e com a atmosfera próxima das condições de neutralidade, admite-se que: $\mathrm{Km} \cong \mathrm{Ke} \cong \mathrm{Kh}$.

O valor de $\beta$, também, pode ser obtido utilizando-se a relação entre as equações (04) e (05), considerando que o coeficiente de transporte turbulento de calor latente (Ke) é igual ao coeficiente de transporte turbulento de calor sensível $(\mathrm{Kh})$ :

$$
\beta=c_{p} \frac{\frac{\delta l}{\delta z}}{\lambda \cdot \frac{\delta l}{\delta z}}
$$


Considerando a umidade específica (q) igual a 0,622.ea / $P$, a equação (07) resulta na seguinte equação:

$$
\beta=\gamma \cdot \frac{\delta T^{r}}{\delta^{\prime} a}
$$

onde:

$\mathrm{T}=$ temperatura do ar;

ea $=$ pressão parcial ou atual de vapor d'água.

Em situações de campo, é comum medir-se a temperatura do ar e a pressão parcial de vapor d'água em apenas duas alturas acima da superfície estudada. Desta maneira, $\delta \mathrm{T}$ e $\delta$ ea são igualados as diferenças $\Delta \mathrm{T}$ e $\Delta \mathrm{ea}$, respectivamente. Essas medidas, quando realizadas em superfícies heterogêneas, devem representar fielmente os parâmetros dir superfície estudada. Para tal, Bausch \& Bernard (1992), esludando a culturá (lo milho (Zea mays, L.) na fase de desenvolvimento, utilizaram um equipamento móvel para coleta de dados, assim o sistema pôde representar a superfície composta pela cultura e pelo solo nu.

No Boletim n" 24 da FAO, Doorenbos \& Pruitt (1990) consideraram o modelo de Penman como o mais preciso na estimativa da ETo, seguido do método do Tanque Classe A. O método de Penman foi amplamente empregado, graças as lacilidades apresentadas para a compreensão dos processos físicos da evaporação de água em superficies naturais. Além disso, é um método que requer informações meteorológicas de apenas um nível acima da superfície evaporante (Thom \& Oliver, 1977; Brutsaert, 1982; Luchiari Jr, 1988).

Smith (1991), apresenta os objetivos e procedimentos propostos, após ampla revisão realizada pela FAO. É uma proposta que demandará tempo e trabalho para ser alcançada, devendo ser implementada em duas etapas. Na 
primeira, a grande inovação será a utilização do modelo de Penman-Monteith (Monteith, 1965) como padrão na estimativa da evapotranspiração de referência (ETo), mas a evapotranspiração das culturas continuaria sendo estimada através de coeficientes de cultura e da ETo. Na segunda etapa, a evapotranspiração das culturas passaria a ser estimada diretamente pelo método de Penman-Monteith, com o emprego de valores adequados para a resistência aerodinâmica e do dossel de cada cultura estudada.

Monteith (1965), supôs um dossel representado por uma grande folha para estimar a evapotranspiração, e esta suposição pode ser aplicada na estimativa da evapotranspiração de referência. Isso significa assumir-se que todas as folhas do dossel estão expostas, da mesma maneira, as mesmas condições ambientais. Esta suposição tem como objetivo estimar a resistência da cobertura vegetal à difusão de vapor d'água. Desta maneira, o autor admite um valor médio representativo do dossel.

O modelo de Penman-Monteith é de fácil entendimento, embora tenha uma formulação teórica rigorosamente física. O método requer, para seu emprego, informações climatológicas, normalmente coletadas em estações meteorológicas padrões. Devido as dificuldades de se obter valores confiáveis e representativos para a resistência da cobertura vegetal, sua aplicação prática tem sido limitada (Monteith, 1985; Villa Nova \& Reichardt, 1989; Oke, 1992). Alguns autores, como Ben-Asher et al. (1989), consideram que o modelo de Penman-Monteith apresentará pouco valor prático, caso a resistência da cobertura vegetal não venha a ser parametrizada a partir de propriedades conhecidas e de fácil mensuração da planta, do solo e da atmosfera.

Devido as dificuldades operacionais, este modelo tem sido utilizado como uma ferramenta para estimar a resistência da cobertura vegetal, quando a evapotranspiração é conhecida. O proposto pelo autor seria o caminho inverso do que vem sendo realizado por diversos pesquisadores (Monteith, 1985). Mas, 
quando são estabelecidos valores adequados para a resistência da cobertura vegetal, o modelo de Penman-Monteith tem se mostrado superior aos demais métodos combinados na estimativa da evapotranspiração, para uma ampla variedade de climas, localidades e culturas (Allen et al., 1989).

Os vários processos que envolvem fluxo de ágụa (infiltração, redistribuição, evaporação e absorção pelas plantas) são processos interdependentes oul, quase sempre, ocorrem simultaneamente. Reichardt (1985), considera que para se estudar o ciclo da água em uma cultura, via de regra, é necessário considerar o balanço hídrico. Este, nada mais é que a somatória das quantidades de água que entram e saem de um elemento de volume de solo e, num determinado intervalo de tempo, o resultado é a quantidade líquida de água que nele permanece disponível às plantas. $\mathrm{O}$ autor, na realidade, iguala o balanço hídrico à própria lei de conservação de massa, tornando-o diretamente relacionado com o balanço de energia, pois os processos envolvidos requerem energia. $\mathrm{O}$ balanço hídrico, do ponto de vista agronômico, é fundamental, pois possibilita o estudo das condições hídricas sob as quais uma cultura se desenvolveu.

Bernardo (1986), dividiu em dois grupos básicos os métodos de balanço hídrico, o primeiro utiliza lisímetros e o segundo um volume de controle de solo para estimar a evapotranspiração. Os lisímetros, quando corretamente instalados, possibilitam estimativas das mais precisas na estimativa da evapotranspiração. Os principais tipos de lisímetros são: de drenagem ou percolação; de pesagem mecânica; \{lutuante e hidráulico. Logicamente, cada tipo apresenta suas vantagens e desvantagens, de acordo com a utilização.

O lisímetro pode apresentar diversos formatos e tamanhos, mas que devem ser baseados no requerimento específico das condições de estudo e de construção, além dos custos envolvidos. Aboukhaled et al. (1982), consideram que o lisímetro permite realizar a estimativa tanto da evaporação de água em solo nu como da evapotranspiração das culturas em seus diversos estágios de desenvolvimento. 
Com os lisímetros de pesagem pode-se obter diretamente a evapotranspiração através do balanço de massa de água, enquanto com os outros tipos de lisímetros a evapotranspiração só pode ser estimada de maneira indireta.

Evapotranspirômetro é, freqüentemente, utilizado para designar qualquer tipo de lisímetro. Por não existirem regras claras, o termo lisímetro é utilizado para todos os tipos de depósitos repletos com solo e empregados na medida ou estimativa da evapotranspiração. Sellers (1975), prefere dividir os lisímetros em dois tipos e usar terminologia diferenciada para designá-los. Assim, os volumétricos são denominados de evapotranspirômetros, enquanto os outros tipos apenas de lisímetros.

As estimativas lisimétricas apresentam algumas imperfeições que podem ser amenizadas ou mesmo evitadas, quando alguns procedimentos são adotados. Essas imperfeições são causadas, em parte, pelas condições artificiais do solo no lisímetro. Outros fatores também podem influir significativamente, como: a descontinuidade entre a vegetação do lisímetro e a da área circundante; a representatividade das medidas obtidas, devido à reduzida dimensão dos lisímetros comumente utilizados e ao regime hídrico diferenciado, muitas vezes encontrado, entre o lisímetro e a área tampão.

A amostragem é de suma importância quando se trabalha com lisímetros, assim como em outras atividades experimentais. Então, deve-se ter bastante atenção na exposição do lisímetro, para que ele represente, o mais fielmente possível, as condições naturais do solo e da vegetação, devendo-se evitar obstáculos que possam interferir na radiação natural ou nos movimentos atınosféricos. Para evitar problemas de advecção, deve-se manter uma área tampão suficientemente grande (Pruitt \& Angus, 1960; van Bavel, 1961; Ritchie \& Burnett, 1968).

A estimativa da evapotranspiração, tanto a potencial, como a real ou de cultivo, quanto a de referência, pode ser extremamente complexa. O 
evapotranspirômetro quindo operado adequadamente, isto é, quando umedecido sem que se permita ocorrer deficiência e/ou excesso de água no tanque e quando exposto homogeneamente dentro de uma área tampão de tamanho adequado para minimizar os efeitos dia advecção, é um instrumento que fornece valores seguros de evapotranspiração. Grande cuidado deve ser tomado na operação do instrumento, reconstituição do solo no tanque, com a vegetação, com o manejo e com as práticas culturais. As irrigações devem ser mantidas nos tanques, de forma que garanta observações que possibilitem comparações entre diferentes instalações (Thornthwaite \& Mather, 1955).

Os principais cuidados para instalação de tanques lisimétricos, segundo Gangopadhyaya et al. (1966), são: utilizar equipamento grande o suficiente para assegurar sua representatividade da cobertura vegetal; manter as condições físicas do interior do aparelho o mais próximo possível das condições da área estudada e instalá-los em locais onde os efeitos advectivos sejam mínimos.

$\mathrm{Na}$ estimativa da evapotranspiração real ou de cultivo, utilizando-se evapotranspirômetro ou lisímetro, a umidade do solo pode ter uma grande amplitude, mas na estimativa da evapotranspiração potencial ou da de referência, Pequeno et al. (1978), recomendam manter a umidade do solo o mais próximo possível a máximo que ele possa armazenar. Para tal, aconselham regas diárias ou a cad: clois dias. Desta maneira, o teor de água no solo não irá influir negativamente nas estimativas.

Ch:ng (1971), aconselha a utilização de lisímetros suficientemente grandes para reduzir os efeitos da adveç̧ão e proporcionar adequado desenvolvimento radicular, sem restrições significativas ocasionadas pelas dimensões do equipamento. Para as culturas de baixo porte, ele sugere que o volume de solo no tanque seja, no mínimo, superior a $1 \mathrm{~m}^{3}$ e considera o volume de $4 \mathrm{~m}^{3}$ como suficiente para a cultura da cana-de-açúcar (Saccharum officinarum, L.). As condições físicas do solo do tanque devem ser compatíveis com as condições do 
solo que circunda o equipamento, devendo-se evitar a formação de lençol d'água no interior do equipamento, e seu cultivo deve possuir porte e manejo semelhantes aos empregados na área tampão.

Os lisímetros de pesagem são considerados como os mais precisos, podendo alcançar precisão de $0,1 \mathrm{~mm}$ em intervalo de integração de um dia, na estimativa da evapotranspiração, sendo também os mais empregados na sua estimativa, em períodos inferiores a um dia (Howell et al., 1992). Outros métodos que apresentam resultados bastante satisfatórios, para períodos inferiores a um dia, são os métodos da correlação de turbilhões, o da razão de Bowen e o de Penman-Monteith.

Vários mecanismos de pesagem podem ser utilizados em lisímetros, sendo os sistemas de células de carga incluídos entre os mais modernos. A acurácia deste sistema depende das características da célula de carga empregada e do sistema de armazenamento e de processamento dos dados. Embora, há quase 30 anos os lisinetros de pesagem estejam sendo utilizados em estudos de ET, ainda não exist uma padronização da estrutura, formato e nem mesmo da nomenclatura. Esta variabilidade estrutural ocorre, principalmente, devido à diversidade dos objetivos de estudo e de melhorias nos sistemas de pesagem, armazenamento e processamento dos dados ocorridas em curto intervalo de tempo (Tanner, I 60; Harrold, 1966). 


\section{MATERIAIS E MÉTODOS}

O experimento foi conduzido em condições de campo, na área experimental de irrigação do Departamento de Engenharia Rural, na Fazenda Areão da Escola Superior de Agricultura "Luiz de Queiroz", situada no município de Piracicaba, estado de São Paulo, com latitude de $22^{\circ} 42^{\prime}$ S, longitude $47038^{\prime}$ W e altitude média de 530 metros.

Segundo a classificação climática de Köeppen, Piracicaba possui clima do tipo Cwa, ou seja, subtropical úmido, com estiagem no inverno, temperatura média no mês mais frio inferior a $18^{\circ} \mathrm{C}$ e no mês mais quente superior a $22^{\circ} \mathrm{C}$. A temperatura média anual é de $21,1^{\circ} \mathrm{C}$ e a precipitação média anual é de aproximadamente $1250 \mathrm{~mm}$ (Ometto, 1989). O solo do local do experimento é classificado como Terra Roxa Istruturada (Alfisol), série Luiz de Queiroz.

Os dados processados e analisados neste trabalho foram os obtidos no período de $1^{\circ}$ de novembro a 10 de dezembro de 1996, utilizando-se de uma estação agrometeorológica automática para coleta de dados climáticos, de um lisímetro de pesagem com princípio de célula de carga e de um sistema automático para estimativa da razão de Bowen. A área experimental (Figura 1) foi vegetada com grama batatais (Paspalum notatum flïgge). Com as informações coletadas na estação pode-se, por diversas metodologias, estimar a evapotranspiração de referência (ETo), e compará-la com os valores obtidos pelo sistema automático da razão de Bowen (Figura 2) e com os obtidos com o lisímetro de pesagem. 


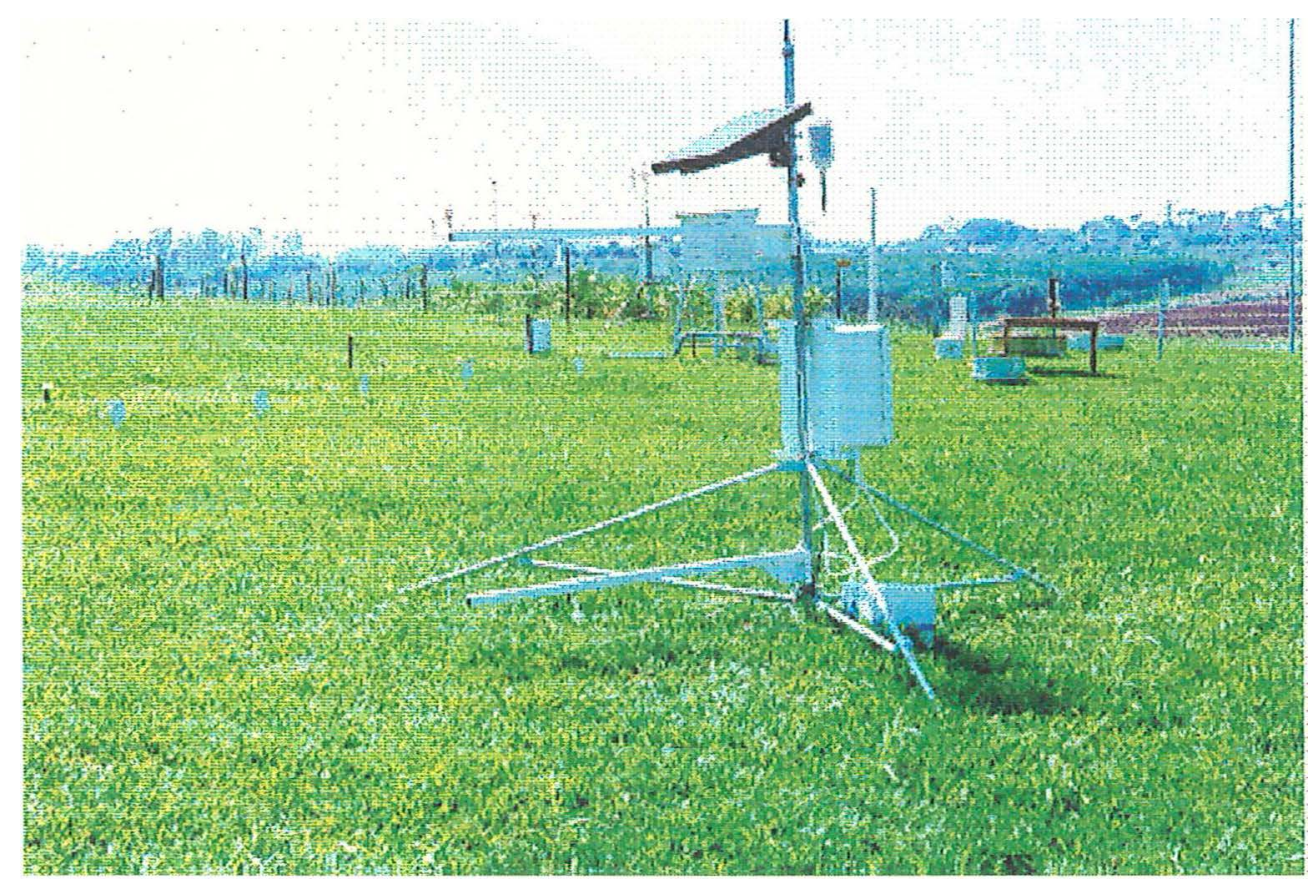

Figura 1 - Área experimental

Os equipamentos da área experimental foram dispostos sobre uma área gramada, com aproximadamente $35 \mathrm{~m}$ de largura por $90 \mathrm{~m}$ de comprimento e com maior declividade média (norte-sul) de 2,5\%, de maneira a obter-se, o ma1s próximo possível, condições potenciais de evapotranspiração. Então, a área cultivada com grama, em volta dos equipamentos, teve como objetivo minimizar as decorrências do efeito oásis. Para tal, toda a área cultivada recebeu o mesmo manejo, exceto no que se referiu ao método de aplicação de água, pois o lisímetro recebeu água através de recipiente de volume aferido e a área tampão através de um sistema de gotejamento enterrado. A condução do experimento foi realizada com manejo adequado e recomendado para gramado. Durante todo o período de coleta de dados, a grama foi mantida com altura de $0,12 \mathrm{~m} \pm 0,03 \mathrm{~m}$ e isenta de competição com plantas daninhas e pragas. 


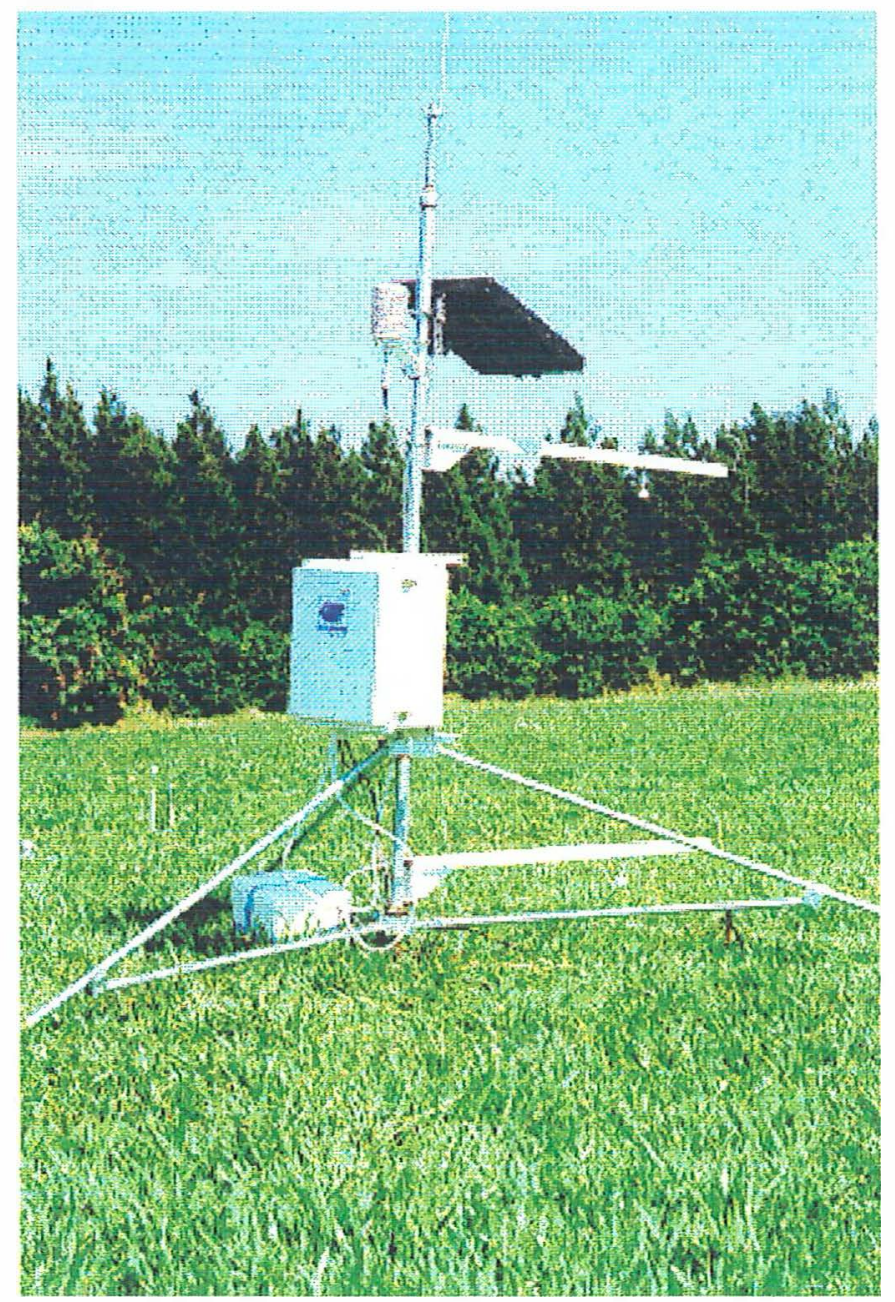

Figura 2 - Equipamento automático da razão de Bowen

O equipamento da razão de Bowen, instalado na área experimental, foi calibrado para fornecer valores médios em intervalos de $20 \mathrm{~min}$, de leituras realizadas a cada segundo, e armazenadas em um sistema de aquisição de dados 21X(L), fabricado pela Campbell Scientific. Entre os principais dados obtidos com o equipamento, estão: radiação líquida (Rn); fluxo de calor no solo (G); gradientes de temperatura $(\Delta T)$ e de tensão de vapor d'água ( $\triangle \mathrm{ea})$ do ar atmosférico. No cálculo do balanço de energia, os fluxos que chegam ao sistema foram considerados como positivos, enquanto os fluxos que saem do sistema 
foram considerados negativos. A seguir, estão apresentadas algumas das especificações de sensores do equipamento da razão de Bowen:

$\Rightarrow 02$ braços metálicos (modelo BRA/UPR e BRA/LWR, Campbell Scientific) com locais para sucção de ar (diâmetro igual a $0,025 \mathrm{~m}$ ) com filtros de teflon (gelınan 66154) para prevenir que líquidos penetrassem no sistema (poros de 1,0 $\mu \mathrm{m}$ de diâmetro) e termopares (Figura 3), instalados de maneira que o local de suç̧ão do ar e os termopares permanecessem a $0,10 \mathrm{~m}$ e $1,50 \mathrm{~m}$ da superfície gramada;

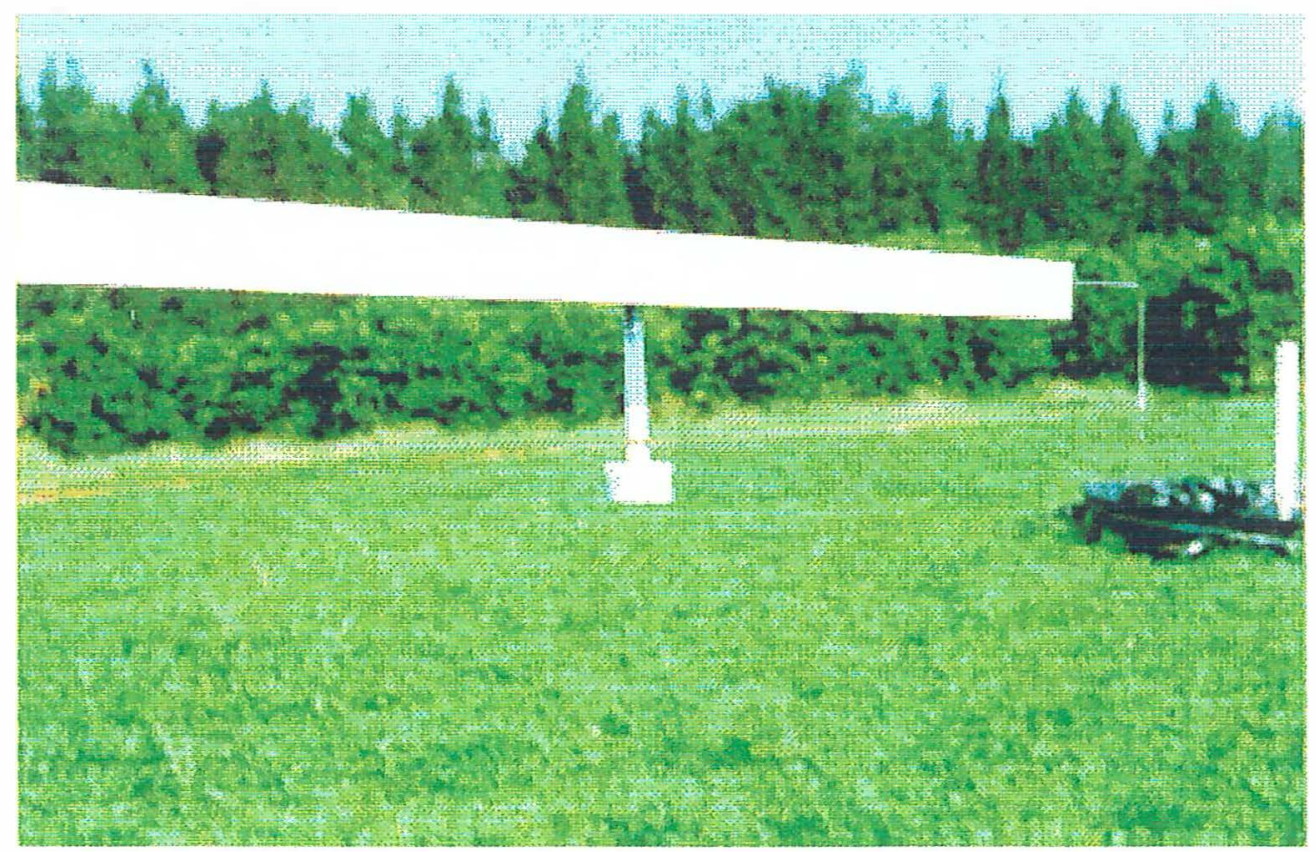

Figura 3 - Braço metálico superior com entrada de ar e termopares do equipamento da razão de Bowen

$\Rightarrow$ Termopares (modelo TCBR-3, Campbell Scientific) com diâmetro de $0,076 \times 10^{-3} \mathrm{~m}$, aproximadamente, resolução de $0,006{ }^{\circ} \mathrm{C}$. O diâmetro reduzido dos termopares tinha como finalidade reduzir, ao máximo, erros provenientes devido sua exposição à radiação solar (Figura 3); 
$\Rightarrow$ Psicrômetro e controlador de fluxo de ar (modelo 023A, Campbell Scientific) com espelho (modelo dew-10, General Eastern Corp.). O fluxo foi mantido, conforme recomendação do fabricante, sempre próximo a $0,024 \mathrm{~m}^{3} \cdot \mathrm{h}^{-1}$ (4 litros / minuto). A temperatura do ponto de orvalho (To) registrada pelo equipamento apresentava uma resolução de $\pm 0,003^{\circ} \mathrm{C}$ no intervalo de temperatura de $\pm 35^{\circ} \mathrm{C}$ e precisão de $0,05^{\circ} \mathrm{C}$, já a pressão do vapor d'água atmosférico foi registrada com precisão de $\pm 0,01 \mathrm{kPa}$ (Figura 4);

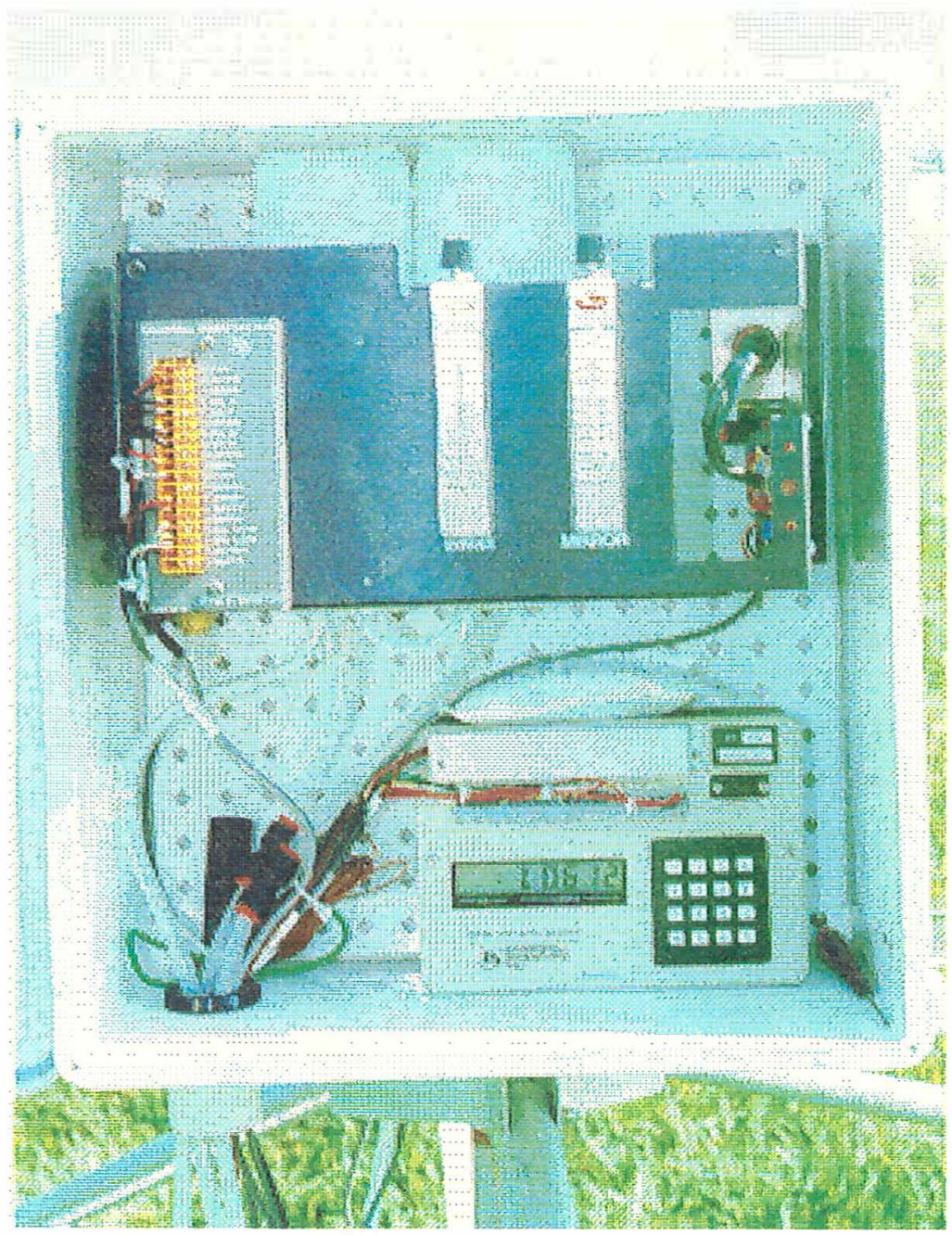

Figura 4 - Psicrômetro, controlador do fluxo de ar e sistema de aquisição de dados 
$\Rightarrow 02$ placas para estimar o fluxo de calor sensível no solo (modelo HFT-3, Campbell Scientific), instaladas a $0,08 \mathrm{~m}$ de profundidade e a $1 \mathrm{~m}$ de distância uma da outra, apresentando sensibilidade de $36 \mathrm{~W} \cdot \mathrm{m}^{-2} / \mathrm{mV}$, com termopares de solo (Figura 5).

$\Rightarrow 02$ termopares de solo, em cromel-constantan, (modelo TCAV, Campbell Scientific) instalados a 0,02 e $0,06 \mathrm{~m}$ da superfície do solo, instalados acima das placas de fluxo de calor de solo (Figura 5).

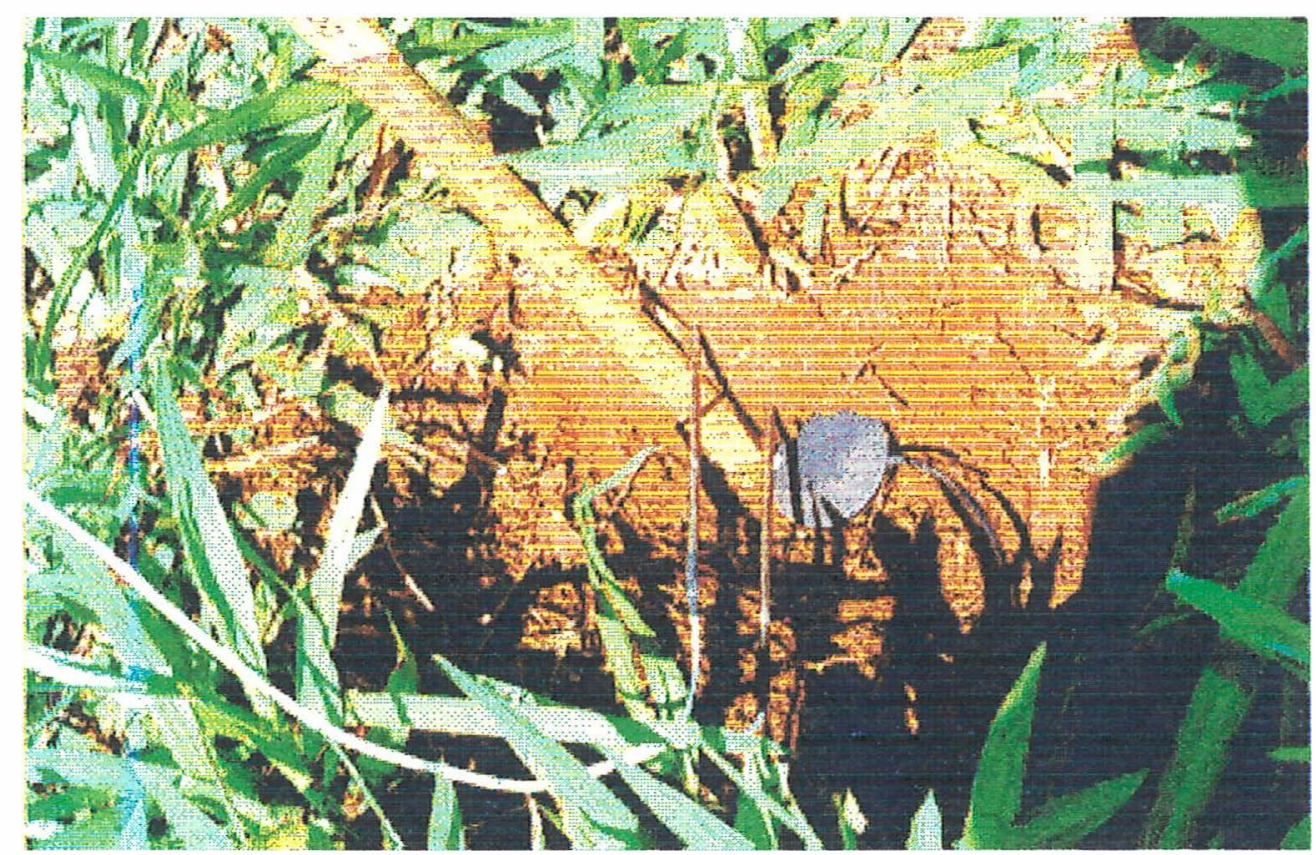

Figura 5 - Instalação da placa de fluxo de calor de solo e termopares de solo

Com os valores dos gradientes de temperatura do ar $(\Delta \mathrm{T})$, dos gradientes de tensão do vapor d'água do ar $(\Delta$ ea $)$ e do coeficiente psicrométrico para equipamento com ventilação forçada, efetuou-se os cálculos para estimativa do valor da razão de Bowen $(\beta)$, com o emprego da equação 08 , para cada intervalo de tempo correspondente a 20 minutos. 
Com os cálculos da razão de Bowen para cada intervalo de tempo, com os valores de radiação líquida $(\mathrm{Rn})$ e fluxo de calor sensível no solo $(\mathrm{G})$, obtidos com o equipamento automático, estimou-se o calor latente de evaporação (LE), através da equação (03) do balanço de energia. Utilizando-se o valor de $\beta$ e LE, calculou-se o fluxo de calor sensível $(\mathrm{H})$ com a equação (01) da razão de Bowen. E, conhecendo-se o valor de LE, foi possível calcular o valor da evapotranspiração de referência (ETo) para cada intervalo de tempo de 20 minutos, em todo o período de tempo estudado.

O lisímetro de pesagem (Figura 6) foi constituído de um tanque interno de cimento amianto com profundidade de $0,65 \mathrm{~m}$, comprimento de $1,20 \mathrm{~m}$ e largura de $0,85 \mathrm{~m}$. Este tanque ficava sobre uma chapa de compensado naval de $0,03 \mathrm{~m}$ de espessura, 1,25 $\mathrm{m}$ de comprimento e $0,90 \mathrm{~m}$ de largura, que, por sua vez, apoiava-se em três células de carga dispostas triangularmente. Foram realizados cálculos para dispor as células de carga, de maneira a se obter uma distribuição homogênea de massa. As células de carga foram apoiadas em pilares de madeira e sob estes pilares foi montada uma placa de cimento armado, este sistema de apoio foi idealizado com o intuito de evitar um possível deslocamento do sistema de pesagem devido às deformações do solo. As paredes do solo foram sustentadas por chapas de compensado naval, formando um tanque externo, pois elas apresentas alta resistência mecânica, sendo também resistentes às variações de temperatura e à umidade, além de apresentar baixo custo.

As células de carga (modelo LCCA-2K, fabricada pela Omega Engineering) apresentam capacidade individual de $910 \mathrm{~kg}$ e acurácia de $0,037 \%$ de sua capacidade. Elas são hermeticamente fechadas e resistentes à corrosão, permitindo o seu uso em ambiente aberto, possuem um extensômetro elétrico interno, ao longo de seu eixo longitudinal e, também, um sistema de compensação automática com finalidade de reduzir a zero os erros ocasionados pelas variações de temperatura durante o período de operação. 


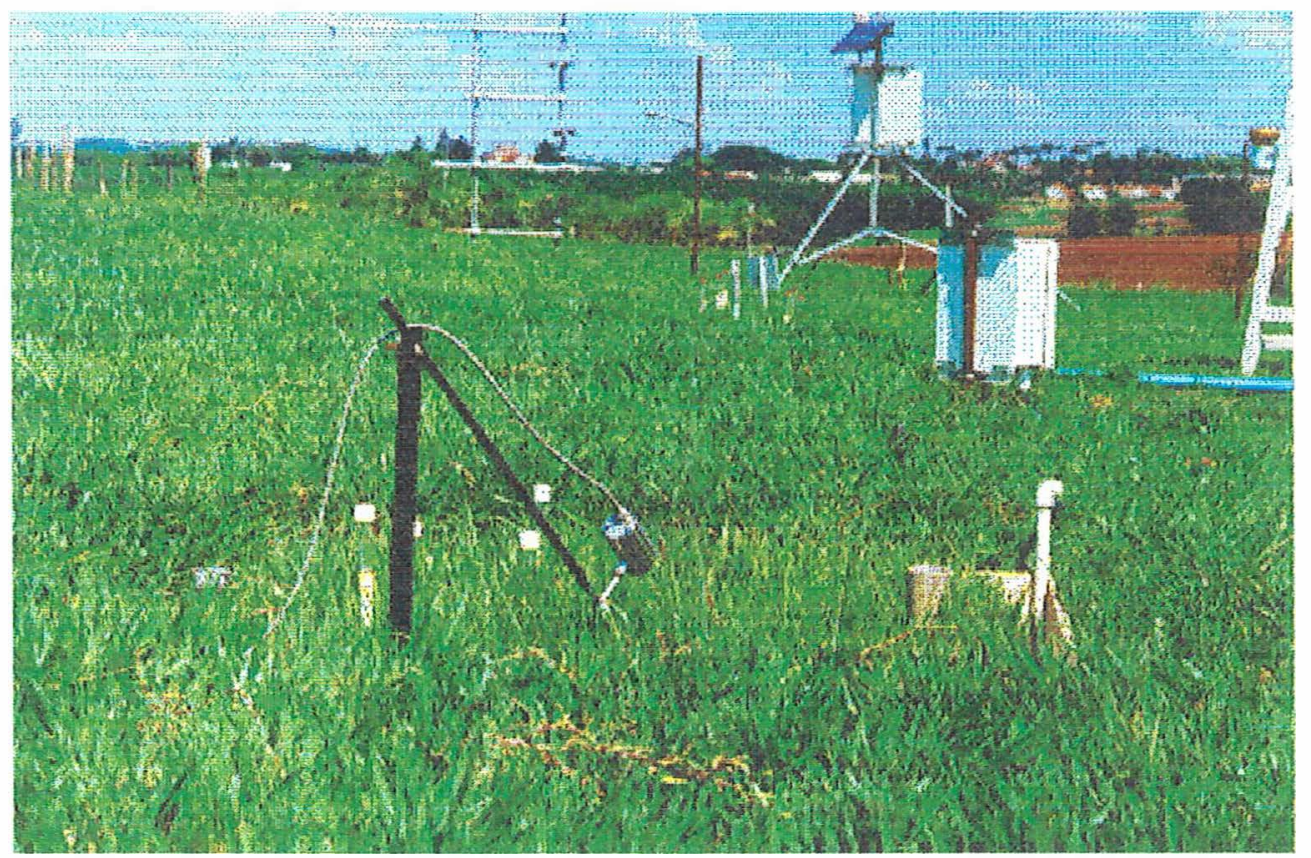

Figura 6 - Vista superior da instalação do lisímetro de pesagem (parte inferior da figura)

O sistema de lisimetria de pesagem foi inicialmente montado em laboratório, onde procederam-se testes de funcionamento do equipamento, estes procedimentos e outras explicações com maior riqueza de detalhes, além da calibração do sistema de pesagem em campo, podem ser obtidos em Silva (1996), responsável pela construção e instalação do equipamento no campo. Estes testes indicaram que o equipamento estava funcionando adequadamente, tanto para decréscimos como para acréscimos de peso no sistema.

No preenchimento do lisímetro foi utilizado solo de cada camada do perfil original, de tal forma que as condições naturais fossem obtidas com maior semelhança possível, ao se realizar a reconstituição do solo no interior do equipamento. Embora a estrutura do mesmo tenha sido deformada, a seqüência e profundidade dos diferentes horizontes originais foram mantidas. 
O processo de drenagem natural no lisímetro, assim como no tanque protetor externo de compensado, era facilitado por uma camada inferior de brita. Um espaço entre os dois tanques foi mantido, de maneira a possibilitar a realização de inspeções visuais no equipamento. Este espaço também tinha a função de evitar impedimento mecânico ao funcionamento do equipamento. Quando ocorriam precipitações excessivas, realizava-se drenagem introduzindo uma mangueira, adaptada a um venturi, através de um tubo de acesso, sendo esta mangueira ligada a uma torneira. Então, com a pressão negativa provocada pelo venturi, a água em excesso no lisímetro e na caixa protetora era succionada para fora através desta mangueira.

O lisímetro possuía 2 tensiômetros instalados nas profundidades de $0,15 \mathrm{~m}$ e $0,30 \mathrm{~m}$, com a finalidade de permitir o monitoramento da tensão da água no solo. Um tensímetro digital de punção foi utilizado para realizar as leituras da tensão da água, que era acompanhada para controlar a umidade no solo do lisímetro. A capacidade de campo foi determinada, no próprio local do experimento, com o auxílio de dois lisímetros de drenagem, também instalados na área. Eles foram irrigados de forma a provocar drenagem, quando esta drenagem cessou, pode-se tomar este valor de tensão como o da capacidade de campo.

As informações climáticas foram obtidas através do uso de uma estação agrometeorológica automática (Figura 7), instalada na própria área experimental. Utilizando-se de um sistema de aquisição de dados (modelo CR 10), fabricado pela Campbell Scientific, foi possível registrar estes dados de forma contínua, permitindo armazenar valores médios das informações climáticas para cada 30 minutos, das leituras realizadas a cada segundo. Outro equipamento semelhante foi empregado para mensurar e armazenar o sinal das células de carga nos mesmos intervalos de tempo. A seguir estão apresentadas algumas das especificações dos sensores da estação agrometeorológica: 


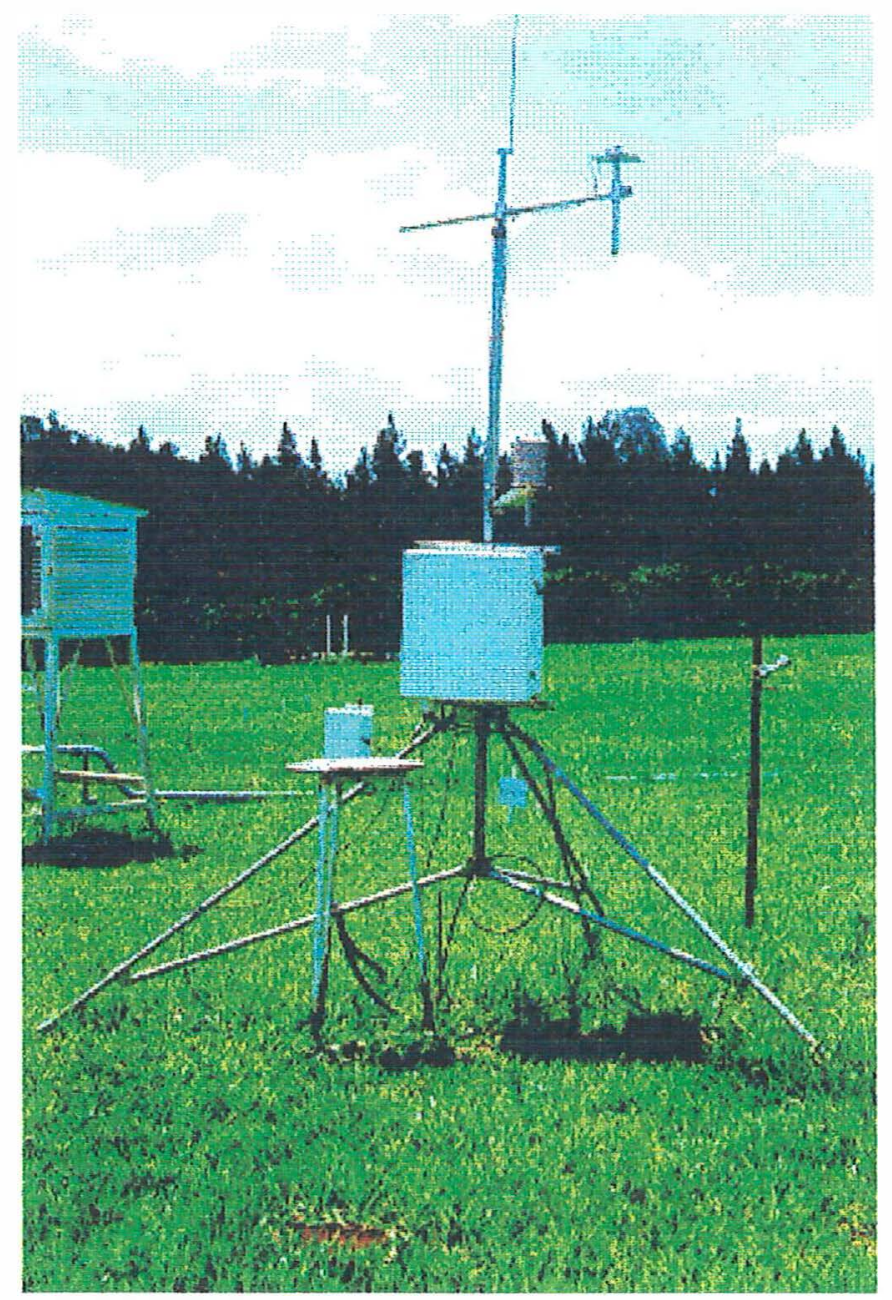

Figura 7 - Estação agrometeorológica

$\Rightarrow$ Temperatura e umidade relativa a $2 \mathrm{~m}$ de altura da superfície gramada (modelo HMP35C temperature/RH Probe-Campbell), com acurácia de $\pm 0,1{ }^{\circ} \mathrm{C}$ para a temperatura e $\pm 3 \%$ para a umidade relativa;

$\Rightarrow$ Radiação global a $3 \mathrm{~m}$ de altura da superfície gramada (modelo LI200X Pyranometer- Li-cor Inc);

$\Rightarrow$ Velocidade do vento a $0,5,1,0,1,5$ e 2,0 metros de altura da superfície gramada (modelo 014A Wind Speed Sensor-Met One Instruments, limiar de medida (threshold) $=0,45 \mathrm{~m} \cdot \mathrm{s}^{-1}$ ); 
$\Rightarrow$ Direção do vento a $2,0 \mathrm{~m}$ de altura da superfície gramada (modelo $024 \mathrm{~A}$ Wind Direction Sensor-Met One lnstruments, com limiar de medida (threshold) de $0,45 \mathrm{~m} \cdot \mathrm{s}^{-1}$ e acurácia de $5 \%$ );

$\Rightarrow$ Precipitação a $1,5 \mathrm{~m}$ de altura da superfície gramada (modelo TE525 Tipping Bucket Rain Gauge-Weather Bureau, precisão de 0,1 mm);

$\Rightarrow$ Radiação líquida a $1 \mathrm{~m}$ de altura da cobertura vegetal (modelo Q7.1 Net Radiometer-REBS; espectro de 0,25 a $60 \mu \mathrm{m}$ ).

Como os dados da estação agrometeorológica e do lisímetro foram armazenados para cada intervalo de 30 minutos e os do equipamento automático da razão de Bowen para intervalos de 20 minutos, foram realizados cálculos de média e de integração de períodos para que os intervalos se igualassem, permitindo comparações entre as estimativas dos diferentes equipamentos. Então, para o lisímetro e para a estação estas operações foram realizadas a cada dois intervalos : no equipamento da razão de Bowen a cada três, assim foram obtidos dados para cada intervalo de 1 hora, para cada um dos 3 sistemas.

Para emprego do método de Penman-Monteith pode-se utilizar a equação proposta por Monteith (1965), que pode ser expressa da seguinte maneira, possibilitando a utilização de unidades internacionais:

$$
L E=\frac{\mathrm{S} \cdot(\mathrm{Rn}-\mathrm{G})+\frac{\rho \cdot c_{p} \cdot \Delta e}{\mathrm{ra}}}{\mathrm{S}+\gamma \cdot\left(1+\frac{\mathrm{rc}}{\mathrm{ra}}\right)}
$$

onde:

$L E=$ fluxo de calor latente de evaporação $\left(W \cdot m^{-2}\right)$;

$R n=$ radiação líquida $\left(W \cdot m^{-2}\right)$;

$\mathrm{G}=$ fluxo de calor sensível no solo $\left(\mathrm{W} \cdot \mathrm{m}^{-2}\right)$; 
$\rho=$ massa especifica do ar atmosférico $\left(\mathrm{kg} \cdot \mathrm{m}^{-3}\right)$;

$\mathrm{c}_{\mathrm{p}}=$ calor específico do ar a pressão constante $\left(\mathrm{J} \cdot \mathrm{kg}^{-1} \cdot{ }^{\circ} \mathrm{C}^{-1}\right)$;

$\Delta \mathrm{e}=$ déficit de vapor d'água a temperatura do ar, es - ea, $(\mathrm{kPa})$;

$\mathrm{rc}=$ resistência da cobertura vegetal $\left(\mathrm{s} . \mathrm{m}^{-1}\right)$;

ra = resistência aerodinâmica à transferência de calor sensível e calor latente de evaporação $\left(\mathrm{s} . \mathrm{m}^{-1}\right)$;

$\gamma=$ coeficiente psicrométrico $\cong 0,0626 \mathrm{kPa} \cdot{ }^{\circ} \mathrm{C}^{-1}$;

$\mathrm{S}=$ inclinação da tangente à curva de pressão de saturação de vapor d'água, no ponto dado pela temperatura do ar $\left(\mathrm{kPa} .{ }^{\circ} \mathrm{C}^{-1}\right)$.

Os parâmetros climáticos foram calculados de acordo com a padronização proposta pela FAO/1991 (Smith, 1991; Pereira et al., 1997), devido sua grande aceitação e facilidade de manipulação. Além disso, alguns parâmetros foram considerados como constantes, embora apresentando alguma variação, graças a aceitação científica e a fraca variabilidade durante o período das estimativas.

Como exemplos, podem ser citados o valor da massa específica do ar atmosférico $(\rho)$ considerada como $1,26 \mathrm{~kg} \cdot \mathrm{m}^{-3}$ e o calor latente de evaporação da água $(\lambda)$ considerado, nesse estudo, igual a $2.450 .000 \mathrm{~J}_{\mathrm{kg}}{ }^{-1}$, visto que $\lambda$ é uma função muito fraca no intervalo de variação da temperatura das condições experimentais. Embora, $\lambda$ possa ser obtido com a equação (10) (Pereira et al., 1997).

$$
\lambda=2.497-2,37 . \mathrm{T}
$$

onde:

$\lambda=$ calor latente de evaporação da água $\left(\mathrm{J} \cdot \mathrm{g}^{-1}\right)$;

$\mathrm{T}=$ temperatura do ar $\left({ }^{\circ} \mathrm{C}\right)$. 
Utilizando a equação 10 e o valor médio da temperatura do ar $\left(23^{\circ} \mathrm{C}\right)$, nos 40 dias estudados, seria obtido um valor de $2.443 \mathrm{~kJ}_{\mathrm{kgg}}{ }^{-1}$ para $\lambda$.

Para calcular a pressão de saturação do vapor d'água em função da temperatura do ar, pode-se utilizar a equação a seguir:

$$
\text { es }=0,6108 \exp \left(\frac{17,27 \cdot T}{T+237,3}\right)
$$

onde:

es = pressão de saturação do vapor de água $(\mathrm{kPa})$;

$\mathrm{T}=$ temperatura do ar $\left({ }^{\circ} \mathrm{C}\right)$.

A equação (12) pode ser empregada no cálculo da pressão atual de vapor d'água.

$$
\mathrm{ea}=\mathrm{es} \cdot \frac{U R}{100}
$$

onde:

ea = pressão parcial do vapor d'água do ar $(\mathrm{kPa})$;

$U R=$ umidade relativa do ar $(\%)$.

O valor da tangente à curva de pressão de saturação de vapor d'água foi calculado pela equação (13):

$$
\mathrm{S}=\frac{4098 \cdot e \cdot s}{(T+237,3)^{2}}
$$

A resistência aerodinâmica a transferência de calor sensível e vapor d'água pode ser estimada pela equação (14), utilizada por Allen (1989). 


$$
\mathrm{ra}=\frac{\operatorname{Ln}\left(\begin{array}{c}
z m-d \\
z o m
\end{array}\right) \cdot \ln \left(\frac{z h-d}{z o h}\right)}{K^{2} \cdot u z}
$$

onde:

ra $=$ resistência aerodinâmica a transferência de calor sensível e vapor d'água $\left(\mathrm{s} . \mathrm{m}^{-1}\right)$;

$z \mathrm{~m}=$ altura de medida da velocidade do vento $(\mathrm{m})$;

$\mathrm{d}=$ deslocamento do plano zero do perfil do vento $(\mathrm{m})$;

zom $=$ comprimento de rugosidade equivalente da cultura para transferência de momento ( $(1 \mathrm{I})$;

$\not h=$ altura de medida da temperatura e da umidade relativa do ar $(\mathrm{m})$;

$\therefore$ oh $=$ comprimento da rugosidade equivalente da cultura para transferência de calor sensível e de calor latente $(\mathrm{m})$;

$\mathrm{K}=$ constante de von Karman $(0,41)$;

$\mathrm{uz}=$ velocidade do vento medida na altura $\mathrm{z}\left(\mathrm{m} \cdot \mathrm{s}^{-1}\right)$.

O valor do deslocamento do plano zero do perfil do vento (d) foi estimado através da equação (15), segundo recomendação de Brutsaert (1982).

$$
\mathrm{d}=\frac{2}{3} \cdot h c
$$

onde:

$\mathrm{c}=$ altura média da vegetação $(\mathrm{m})$.

Já o comprimento de rugosidade equivalente para transferência de momento (zom) foi obtido com o emprego da equação (16). 


$$
\mathrm{zom}=0,123 \cdot \mathrm{hc}
$$

Ele propôs, também, que o valor do comprimento da rugosidade equivalente para transferência de calor sensível e calor latente (zoh) fosse obtido através de uma das relações a seguir:

$$
\begin{aligned}
& \text { zoh }=0,1 . z o m \\
& \text { zoh }=0,0123 \cdot h c
\end{aligned}
$$

A proposta da $\mathrm{FAO} / 1991$, de utilizar a equação de Penman-Monteith para estimar a evapotranspiração diária, requer algumas parametrizações com o intuito de representar uma cultura hipotética. Sendo, então, uma metodologia recomendada para estimar a evapotranspiração na escala diária, diferentemente da proposta original de Monteith (1965). Para a escala recomendada pela FAO/1991, Allen et al. (1989) sugerem que rc seja calculada pela equação:

$$
\mathrm{rc}=\frac{R F}{0,5 \cdot I A F}
$$

onde:

$R F=$ resistência estomâtica média diária de uma folha $\left(\mathrm{s} . \mathrm{m}^{-1}\right)$;

$\mathrm{AF}=$ índice de área foliar (superficie de folhas, $\mathrm{m}^{2} /$ superfície do terreno, $\mathrm{m}^{2}$ ).

Para uma superficie gramada, ao se utilizar a equação (19), pode-se adotar $R F=100 \mathrm{~s}^{-1} \mathrm{~m}^{-1}$. E, se a altura média do gramado (hc) se encontrar no intervalo de 0,10 a $0,15 \mathrm{~m}$, pode-se :ssumir que: 


$$
\mathrm{IAF}=24 . \mathrm{hc}
$$

Considerando uma cultura hipotética com hc $=0,12 \mathrm{~m}$, obtém-se com a equação 20 um valor de $I A F=2,88$. Desta maneira, estima-se, com a equação

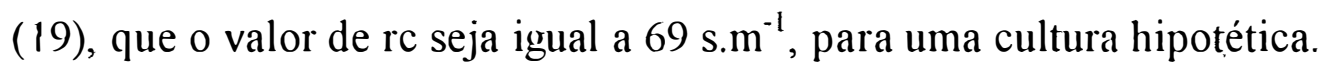

Como a altura média do gramado (hc), no período da coleta de dados, foi de aproximadamente $0,12 \mathrm{~m}$ :

com a equação 15 , obteve-se $\mathrm{d}=0,08 \mathrm{~m}$; com a equação 16 , obteve-se zom $=0,01476 \mathrm{~m}$; com a equação 18 , obteve-se zoh $=0,001476 \mathrm{~m}$.

Substituindo-se estes valores obtidos para d, zom e zoh na equação 14 , obtém-se que:

$$
\mathrm{ra}=\frac{208}{u z}
$$

Através dos valores calculados, verifica-se que a relação rc/ra representa uma função linear da velocidade do vento medido a $2 \mathrm{~m}$ de altura da superfície do solo. A relação toma-se aproximadamente:

$$
\frac{r c}{r a} \cong 0,3317 \cdot 112
$$

Pereira et al. (1997), acreditam que a relação rc/ra assume dois estágios em função da velocidade do vento. A equação 22, proposta pela $\mathrm{FAO} / 1991$, assume que a relação rc/ra é linear em todos os estágios. Eles obtiveram um primeiro 
estágio onde rc/ra foi praticamente constante $(\cong 0,11)$ para $u<1,1 \mathrm{~m} \cdot \mathrm{s}^{-1}$ e um segundo estágio para velocidades do vento superiores ao limite mencionado, onde a relação aumenta rapidamente. Os autores, comparando os valores obtidos com os propostos pela $\mathrm{FAO} / 1991$, encontraram que a relação estudada foi levemente superestimada no primeiro estágio e grosseiramente subestimada no segundo, mas alertam para o fato que a relação obtida por eles, para o segundo estágio, também é uma aproximação, considerando que ra não pode crescer indefinidamente.

Os três métodos de estimativa de ETo foram comparados estatisticamente, entre si, pelo coeficiente de determinação $\left(\mathrm{r}^{2}\right)$ da regressão linear simples. Mas, como a análise isolada de $r^{2}$ pode conduzir à interpretações impróprias, avaliou-se também o índice de concordância (id) obtido com a análise proposta por Willmott (1981).

O valor de id pode variar de 0 , para uma discordância total dos métodos avaliados, até 1 , nesse caso para uma concordância plena. No cálculo de id, foi utilizada a equação 23 , apresentada a seguir:

$$
i d=1-\frac{\sum(P i-O i)^{2}}{\sum(|P i-O|+|O i-O|)^{2}}
$$

onde:

$\mathrm{Pi}=$ evapotranspiração estimada $(\mathrm{mm})$;

$\mathrm{Oi}=$ evapotranspiração observada $(\mathrm{mm})$;

$\mathrm{O}=$ evapotranspiração média observada $(\mathrm{mm})$. 


\section{RESULTADOS E DISCUSSÃO}

A evapotranspiração de referência foi estimada pelo balanço de energia, realizado com os dados obtidos com o equipamento da razão de Bowen $\left(\mathrm{ETo}_{\mathrm{BR}}\right)$, pelo modelo Penman-Monteith (ETo ${ }_{\mathrm{PM}}$ ) padronizado pela FAO/1991, tendo como referência as informações climatológicas da estação agrometeorológica automática e através do lisímetro de pesagem $\left(\mathrm{ETo}_{\mathrm{l}}\right)$. Ela foi estimada, pelos três métodos, no período de 40 dias, compreendidos no período de $1^{\circ}$ de novembro a 10 de dezembro de 1996 (Tabela 1). Para o total deste período estudado, obtevese $\mathrm{ETo}_{\mathrm{L}}=177,37 \mathrm{~mm}, \mathrm{ETo}_{\mathrm{PM}}=172,91 \mathrm{~mm}$ e $\mathrm{ETo}_{\mathrm{BR}}=166,77 \mathrm{~mm}$.

A ETo estimada pelos três métodos selecionados para este trabalho apresentou valores distribuição temporal muito similar em todo o período estudado (Figura 8). Para a soma de ETo nos 40 dias estudados, a maior discrepância observada, entre as metodologias de estimativa, foi de 5,98\%, devido a estimativa de $\mathrm{ETO}_{\mathrm{BR}}$ ter sido equivalente a $94,02 \%$ do valor estimado para $\mathrm{ETo}_{1}$.

A resposta apresentada pelo lisímetro é a diferença de peso entre um intervalo e o anterior, como a evapotranspiração provoca perda de massa, a cada intervalo de tempo é possível obter-se o valor de ETo. Os dados lisimétricos foram analisados cuidadosamente, com a finalidade de eliminar-se todos os valores ocasionados por precipitações, irrigações e drenagens. Então, para efeito de ETo foram considerados apenas os valores negativos dos intervalos de 30 minutos, exceto os ocasionados pelas drenagens realizadas após chuvas excessivas. 
Tabela 1 - Valores da evapotranspiração de referência $(\mathbf{m m})$ estimados para o período de $1^{\circ}$ de novembro a 10 de dezembro de 1996.

\begin{tabular}{|c|c|c|c|c|c|c|c|}
\hline Dia & $\mathbf{E T o}_{\mathrm{L}}$ & ETo $_{P M}$ & $\mathbf{E T o}_{\mathrm{BR}}$ & Dia & $\mathrm{ETo}_{\mathrm{l}}$ & EToPM & $\mathbf{E T o}_{\mathrm{BR}}$ \\
\hline $01 /$ nov & 3,45 & 2,90 & 3,68 & $21 /$ nov & 2,07 & 2,13 & 2,43 \\
\hline $02 /$ nov & 2,16 & 1,69 & 2,14 & $22 /$ nov & 2,71 & 2,12 & 2,31 \\
\hline $03 /$ nov & 2,77 & 2,10 & 3,63 & $23 /$ nov & 4,98 & 4,91 & 4,97 \\
\hline $04 /$ nov & 4,41 & 3,77 & 3,99 & $24 /$ nov & 6,40 & 5,54 & 6,56 \\
\hline 05/nov & 6,37 & 6,19 & 5,77 & $25 /$ nov & 5,98 & 5,98 & 5,35 \\
\hline 06/nov & 6,49 & 5,87 & 5,49 & $26 /$ nov & 5,46 & 6,22 & 5,05 \\
\hline $07 /$ nov & 6,09 & 6,09 & 6,23 & $27 /$ nov & 6,26 & 6,68 & 5,42 \\
\hline 08/nov & 6,50 & 6,05 & 4,71 & $28 /$ nov & 6,10 & 6,63 & 5,40 \\
\hline $09 /$ nov & 6,86 & 6,98 & 5,34 & $29 /$ nov & 5,17 & 5,22 & 5,07 \\
\hline 10/nov & 6,88 & 6,87 & 5,00 & $30 /$ nov & 2,22 & 1,91 & 1,87 \\
\hline $11 /$ nov & 5,32 & 6,06 & 4,04 & $01 / \mathrm{dez}$ & 4,36 & 4,23 & 4,09 \\
\hline $12 /$ nov & 3,55 & 3,47 & 2,43 & 02/dez & 4,87 & 5,04 & 5,30 \\
\hline $13 /$ nov & 1,96 & 2,01 & 1,78 & $03 / \mathrm{dez}$ & 2,84 & 2,42 & 2,58 \\
\hline $14 /$ nov & 1,13 & 1,11 & 1,72 & $04 / \mathrm{dez}$ & 2,60 & 1,85 & 2,72 \\
\hline $15 /$ nov & 4,64 & 2,69 & 1,92 & $05 / \mathrm{dez}$ & 5,78 & 5,71 & 5,85 \\
\hline $16 /$ nov & 3,66 & 3,90 & 5,36 & $06 / \mathrm{dez}$ & 5,77 & 5,23 & 5,26 \\
\hline $17 /$ nov & 3,63 & 4,69 & 4,76 & $07 / \mathrm{dez}$ & 3,65 & 3,82 & 3,77 \\
\hline $18 /$ nov & 5,80 & 5,90 & 6,87 & 08/dez & 3,91 & 3,40 & 3,00 \\
\hline $19 /$ nov & 3,37 & 3,29 & 2,60 & 09/dez & 6,99 & 7,07 & 7,01 \\
\hline $20 /$ nov & 0,22 & 1,38 & 1,70 & $10 / \mathrm{dez}$ & 3,99 & 3,79 & 3,60 \\
\hline
\end{tabular}




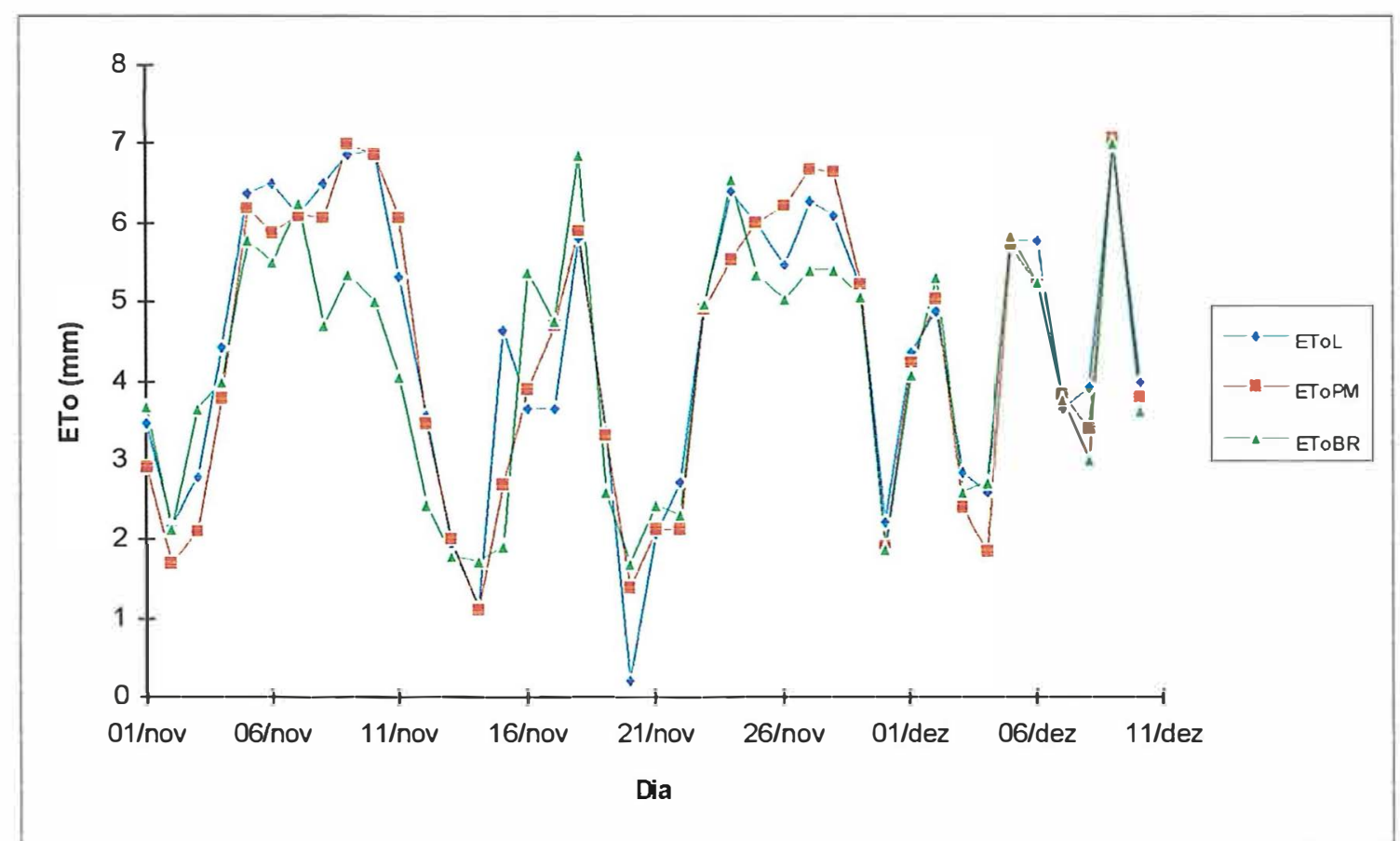

Figura $8-\operatorname{ETo}_{\mathrm{L}}(\mathrm{mm})$ observada no lisímetro de pesagem, ETo ${ }_{\mathrm{BR}}(\mathrm{mm})$ observada no equipamento da razão de Bowen e ETo PM $_{(\mathrm{mm})}$ estimada pela metodologia da FAO/1991, no período de $1^{\circ}$ de novembro a 10 de dezembro de 1996.

Quando comparou-se, pela regressão linear simples e pela análise de concordância de Willmott, pode-se observar (Figura 9) que os valores de $\mathrm{ETo}_{\mathrm{L}}$ ajustaram-se com precisão bastante razoável, quando comparados aos valores estimados para $\mathrm{ETo}_{\mathrm{BR}}$. $\mathrm{O}$ valor alcançado para $\mathrm{r}^{2}$ foi de aproximadamente $0,74 \mathrm{e}$ para id foi obtido um valor de aproximadamente 0,92 . Indicando que os dois modelos de estimativa estão coerentes na estimativa de ETo.

Comparando-se, pelas mesmas metodologias, os valores obtidos para $\mathrm{ETo}_{\mathrm{BR}}$ com os alcançados para $\mathrm{ETO}_{\mathrm{PM}}$ (Figura 10), foi possível observar que os valores calculados para $r^{2}$ e id, 0,79 e 0,93 , respectivamente, superaram os valores de 0,74 e 0,92 obtidos com a comparação entre $\mathrm{ETo}_{\mathrm{L}}$ e $\mathrm{ETo}_{\mathrm{BR}}$. Isto indica que o método de estimativa de ETo com o equipamento da razão de Bowen 
apresentou maior correlação com a estimativa realizada com o método proposto pela $\mathrm{FAO} / 1991$ do que com a estimativa lisimétrica. Entretanto, por estes valores de $r^{2}$ e de id estarem muito próximos, não se justifica uma distinção entre as comparações.

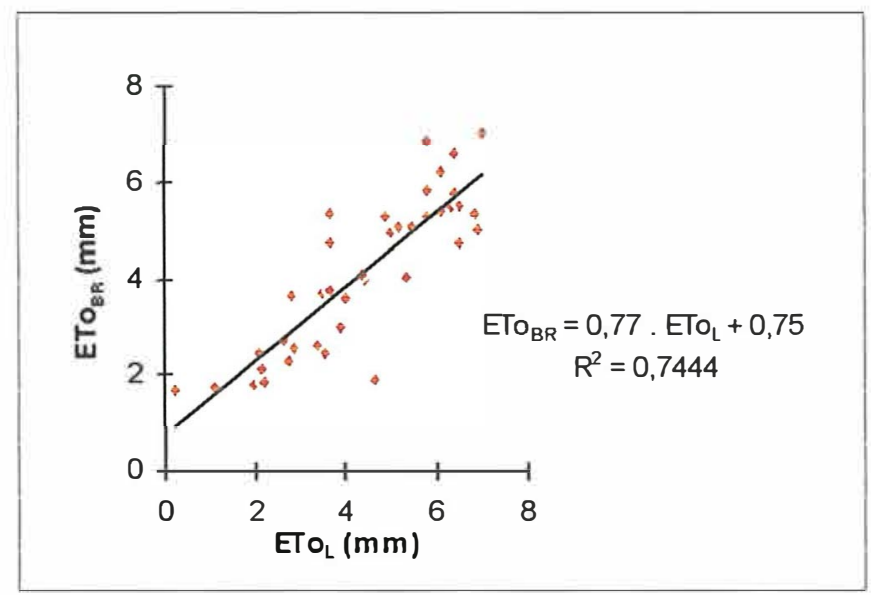

Figura 9 - $\mathrm{ETo}_{\mathrm{BR}}(\mathrm{mm})$ observada no equipamento da razão de Bowen versus $\mathrm{ETo}_{\mathrm{L}}(\mathrm{mm})$ observada no lisímetro de pesagem, no período de $1^{\circ}$ de novembro a 10 de dezembro de 1996.

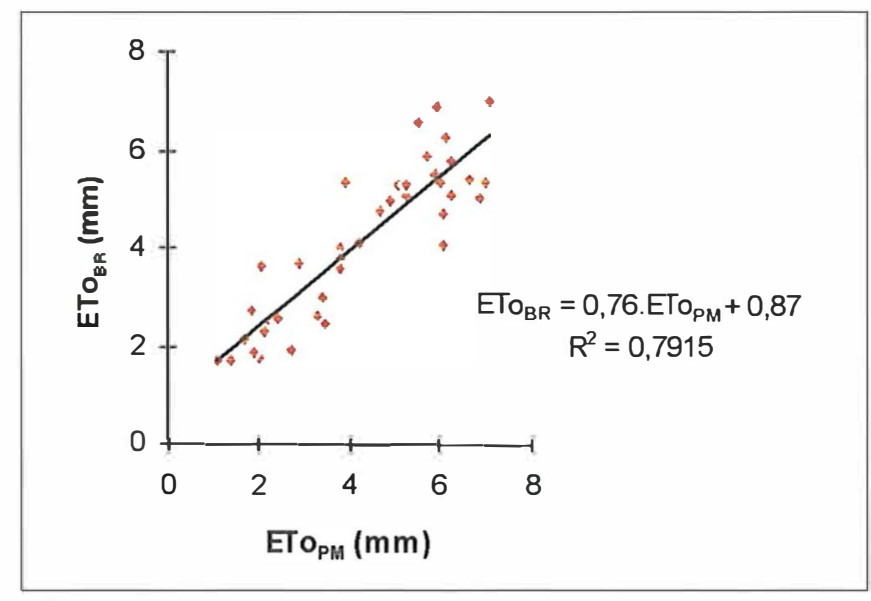

Figura 10 - $\mathrm{ETo}_{\mathrm{BR}}(\mathrm{mm})$ observada no equipamento da razão de Bowen versus ETo $_{\mathrm{PM}}(\mathrm{mm})$ estimada pela metodologia da FAO/1991, no período de $1^{\circ}$ de novembro a 10 de dezembro de 1996. 
Empregando-se as mesmas metodologias, comparou-se os resultados de $\mathrm{ETo}_{\mathrm{L}}$ e ETo $\mathrm{PM}_{\mathrm{PM}}$, obtendo-se os maiores valores para $\mathrm{r}^{2}$ (Figura 11) e id, sendo de aproximadamente 0,91 e 0,97 , respectivamente. Inicialmente, acreditou-se que estes dois métodos foram mais precisos na estimativa de ETo que o método da razão de Bowen, nas condições de estudo. Como os três métodos são considerados padrões no meio científico, acredita-se que desvios provocados pela amostragem possam ter afetado as estimativas do equipamento da razão de Bowen. Algumas suposições explicando que fatores podem justificar tais desvios, encontram-se no transcorrer do texto.

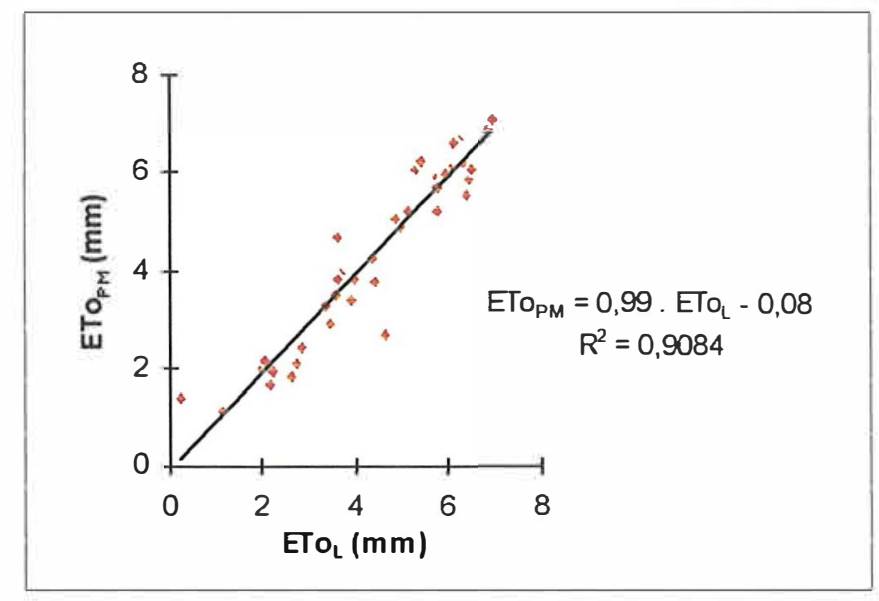

Figura 11 - ETo $_{\mathrm{PM}}(\mathrm{mm})$ estimada pela metodologia da FAO/1991 versus $\mathrm{ETo}_{\mathrm{L}}(\mathrm{mm})$ observada no lisímetro de pesagem, no período de $1^{\circ}$ de novembro a 10 de dezembro de 1996.

$\mathrm{Na}$ metodologia de estimativa de $\mathrm{ETo}_{\mathrm{L}}$, foram considerados apenas os valores das diferenças de peso, entre as médias de dois intervalos consecutivos, que apresentaram valores negativos, excetuando-se os ocasionados por drenagem provocada no equipamento. Sendo assim, todas as respostas positivas não foram computadas para efeito de $\mathrm{ETo}_{\mathrm{L}}$, acreditando-se que foram ocasionadas por 
precipitação, vento, condensação atmosférica (desprezivel) ou por outros fatores que não fossem trocas de água entre o equipamento e a atmosfera.

Após avaliação das informações, observou-se que ao se obter valores positivos como resposta do lisímetro, também se obtinha, de maneira similar, valores positivos como resposta do equipamento da razão de Bowen e da estimativa pela metodologia $\mathrm{FAO} / 1991$. Então, foram selecionados os dias sem ocorrência de precipitação e os dias com baixa intensidade de precipitação (inferior a $1 \mathrm{~mm}$ ). Assim, foram procedidos novos cálculos para estimativa de evapotranspiração de referência do lisímetro, agora considerando-se os valores positivos $\left(\mathrm{ETo}_{\mathrm{L}_{+}^{+}}\right)$, eliminando-se os valores decorrentes das irrigações e das drenagens.

$\mathrm{Na}$ Tabela 2, pode-se observar os valores de $\mathrm{ETo}_{\mathrm{L}^{+}}, \mathrm{ETo}_{\mathrm{PM}}$ e $\mathrm{ETo}_{\mathrm{BR}}$, estimados com o lisímetro de célula de carga, com a metodologia proposta pela FAO/1991 e com o equipamento automático da razão de Bowen, respectivamente, para os 24 dias selecionados, que não ocorreram precipitação superior a $1 \mathrm{~mm}$.

Para os dias 24 sem interferência de precipitações, entre os 40 dias estudados, realizaram-se novas comparações. Quando aplicada a comparação estatística, pela regressão linear simples, entre os valores de $\mathrm{ETo}_{\mathrm{L}+}$ e de $\mathrm{ETo}_{\mathrm{BR}}$ nos dias selecionados, foi possível observar um valor de, aproximadamente, 0,78 para $\mathrm{r}^{2}$ (Figura 12) e com a análise de concordância obteve-se um valor de 0,93 para id. Como pode ser visto, os valores de $r^{2}$ e de id foram superiores aos encontrados quando não se considerou os valores lisimétricos positivos.

Um cuidado muito especial deve ser adotado no procedimento de eliminação dos dados positivos dos lisímetros. Caso este procedimento se torne necessário, deve-se realizar uma análise minuciosa e criteriosa. Pois, foi observado que os valores positivos obtidos como resposta do lisímetro foram superiores aos valores correspondentes às lâminas de precipitação. Com base nessas infornações, pode-se admitir que o impacto da água precipitada com a 
superfície exposta do equipamento provoca um acréscimo de peso no lisímetro superior ao seu peso.

Tabela 2 - Valores de $\mathrm{ETo}_{\mathrm{BR}}(\mathrm{mm}), \mathrm{ETo}_{\mathrm{PM}}(\mathrm{mm})$ e $\mathrm{ETo}_{\mathrm{L}+}(\mathrm{mm})$, nos dias em que ocorreram precipitações inferiores a $1 \mathrm{~mm}$.

\begin{tabular}{|c|c|c|c|c|c|c|c|}
\hline$\overline{\text { Dia }}$ & $\mathbf{E T o}_{\mathrm{L}+}$ & EToPM & $\mathbf{E T o}_{\mathrm{BR}}$ & Dia & $\overline{\text { ETo }_{\mathrm{L+}}}$ & $\mathbf{E T O}_{\mathrm{PM}}$ & $\mathbf{E T o}_{\mathrm{BR}}$ \\
\hline $04 /$ nov & $\overline{4,02}$ & 3,77 & 3,99 & $24 /$ nov & 5,79 & 5,54 & 6,56 \\
\hline $05 /$ nov & 6,12 & 6,19 & 5,77 & $25 /$ nov & 5,27 & 5,98 & 5,35 \\
\hline 06/nov & 5,68 & 5,87 & 5,49 & $26 /$ nov & 5,00 & 6,22 & 5,05 \\
\hline $07 /$ nov & 5,51 & 6,09 & 6,23 & $27 /$ nov & 5,86 & 6,68 & 5,42 \\
\hline 08/nov & 6,10 & 6,05 & 4,71 & $28 /$ nov & 5,62 & 6,63 & 5,40 \\
\hline $09 /$ nov & 6,17 & 6,98 & 5,34 & $30 /$ nov & 1,95 & 1,91 & 1,87 \\
\hline $10 /$ nov & 6,26 & 6,87 & 5,00 & $02 / \mathrm{dez}$ & 4,77 & 5,04 & 5,30 \\
\hline $11 /$ nov & 5,01 & 6,06 & 4,04 & 03/dez & 2,68 & 2,42 & 2,58 \\
\hline $12 /$ nov & 3,40 & 3,47 & 2,43 & 05/dez & 5,46 & 5,71 & 5,85 \\
\hline $18 /$ nov & 5,61 & 5,90 & 6,87 & $06 / \operatorname{dez}$ & 5,53 & 5,23 & 5,26 \\
\hline $22 /$ nov & 2,59 & 2,12 & 2,31 & $08 / \mathrm{dez}$ & 3,38 & 3,40 & 3,00 \\
\hline $23 /$ nov & 4,21 & 4,91 & 4,97 & 09/dez & 6,36 & 7,07 & 7,01 \\
\hline
\end{tabular}

Quando comparou-se os valores de $\mathrm{ETo}_{\mathrm{BR}}$ com os de $\mathrm{ETo}_{\mathrm{PM}}$ (Figura 13), nos dias sem interferência significativa de precipitações, observou-se que os valores alcançados, tanto para $\mathrm{r}^{2}(0,72)$ como para id $(0,90)$, foram um pouco inferiores aos obtidos com as comparações entre os mesmos parâmetros no período total do estudo.

A comparação pela regressão linear simples entre os valores de $\mathrm{ETo}_{\mathrm{L}+}$ e os de ETo $_{\mathrm{PM}}$ (Figura 14) apresentou $\mathrm{r}^{2}(0,92)$ superior, em 0,01 , que o $\mathrm{r}^{2}$ alcançado pela comparação entre $\mathrm{ETo}_{\mathrm{L}}$ e $\mathrm{ETo}_{\mathrm{PM}}$ no período total estudado. Entretanto, o 
valor de id $(0,96)$ decresceu em 0,01 para a mesma comparação. Estas diferenças podem ser consideras insignificantes, e até mesmo nulas, indicando que não houve diferença nos coeficientes para os dois períodos estudados.

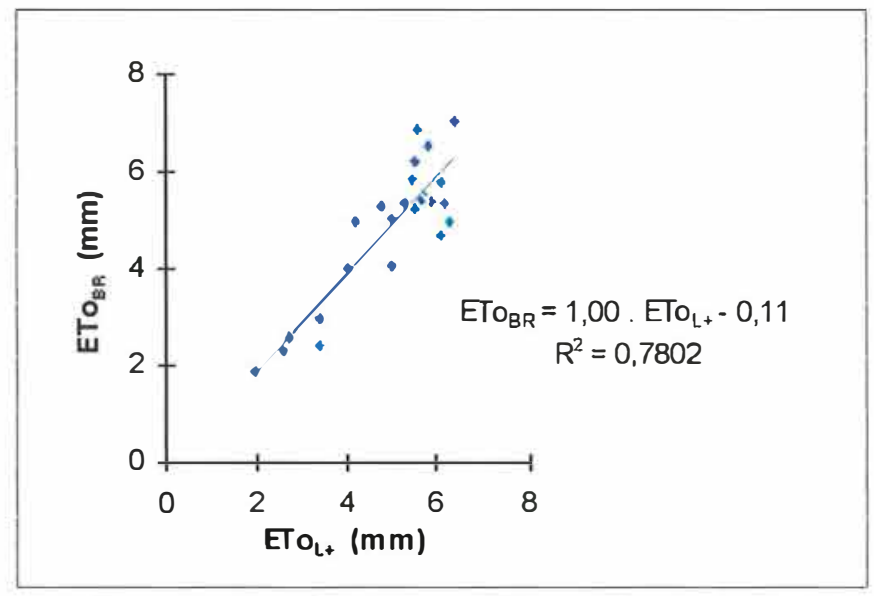

Figura $12-\mathrm{ETo}_{\mathrm{BR}}(\mathrm{mm})$ versus $\mathrm{ETo}_{\mathrm{L}+}(\mathrm{mm})$ considerando os valores positivos, nos dias com precipitação inferior a $1 \mathrm{~mm}$.

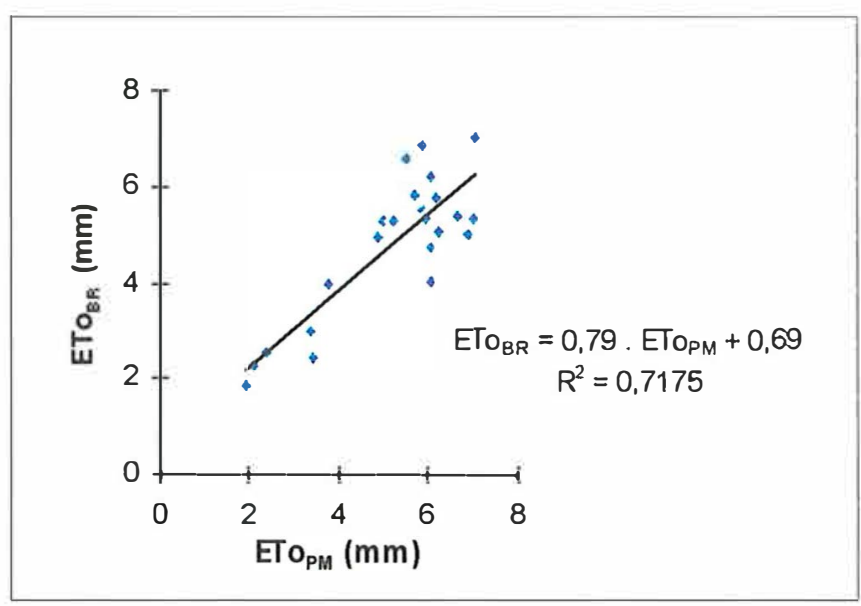

Figura 13 - ETo $\mathrm{ER}_{\mathrm{BR}}(\mathrm{mm})$ observada no equipamento da razão de Bowen versus ETo PM $(\mathrm{mm})$ estimada pela metodologia da FAO/1991, nos dias com precipitação inferior a $1 \mathrm{~mm}$. 
Quando os valores positivos foram considerados no cálculo de ETo do lisímetro, nos dias com precipitação inferior a $1 \mathrm{~mm}$, e comparada por regressão linear simples com os valores de $\mathrm{ETo}_{\mathrm{BR}}$ e ETo $\mathrm{PM}_{\mathrm{PM}}$, observou-se que os valores de $\mathrm{r}^{2}$ foram superiores aos valores de $r^{2}$ quando esta análise não considerava estes valores positivos das respostas lisimétricas, indicando que os valores positivos não devem ser eliminados aleatoriamente. Inclusive, acredita-se que eles podem ser considerados, desde que não representem precipitação.

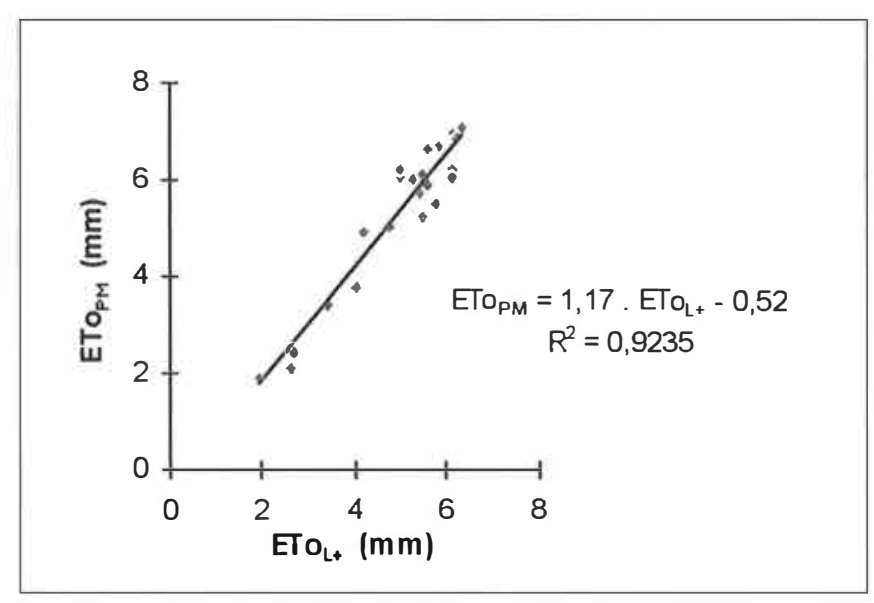

Figura $14-$ ETo $_{\mathrm{Lt}}(\mathrm{mm})$ observada no lisímetro de pesagem considerando os valores positivos versus ETo PM $(\mathrm{mm})$ estimada pela metodologia da FAO/1991, nos dias com precipitação inferior a $1 \mathrm{~mm}$.

Após estudo dos resultados alcançados com as análises estatísticas, nos dias sem interferência de precipitações, acredita-se que as respostas do equipamento da razão de Bowen, também, foram influenciadas nos dias que ocorreram chuvas. Em condições de campo, observou-se que, em alguns dias, o conduto de transporte do ar succionado, para as medidas de conteúdo de vapor d'água no ar atmosférico, apresentava água em seu interior, embora o 
equipamento possuísse um filtro de teflon para evitar a entrada de água no sistema.

Então, sempre que se observava presença de água no sistema, realizava-se secagem manual, de forma a evitar interferências nas respostas do equipamento da razão de Bowen. Mas, como pode ser observado na Figura 8, as diferenças de ETo entre as três metodologias foram maiores no início da coleta de dados, quando este fato ainda não havia sido detectado e a freqüência das coletas era menor, conseqüentemente, é possível admitir-se que no início da coleta de dados o sistema pode ter operado sob influência indevida da presença de água.

Fato semelhante foi observado por Bausch e Bernard (1992), que eliminaram das suas avaliações os intervalos que correspondiam às irrigações, devido as leituras lisimétricas terem sido afetadas pela água de irrigação e pelo problema desta água ser succionada pelo equipamento da razão de Bowen, que não possuía proteção adequada para evitar a entrada de água.

Com o intuito de estudar o fato, foram realizadas análises estatísticas, semelhantes as que foram realizadas para o período total, para os 20 dias finais do experimento (Figura 17) e para os 10 dias finais (Figura 18), de 21 de novembro a 10 de dezembro e de $1^{\circ}$ de dezembro a 10 de dezembro, respectivamente. Como é possível observar na Tabela 3 , os valores de $\mathrm{r}^{2}$ e de id calculados com as comparações estatísticas entre as ETo, estimadas pelos três métodos adotados, do período representado pelos 20 dias finais do estudo foram superiores aos obtidos para o período total. O mesmo comportamento foi observado, quando reduziu-se o período estudado para os 10 dias finais, para as comparações de $\mathrm{ETo}_{\mathrm{L}}, \mathrm{ETO}_{\mathrm{PM}} \mathrm{e}$ ETo $_{B R}$, entre si. Nestas comparações os valores médios de $r^{2}$ e de id foram superiores ou iguais aos valores calculados para os 20 dias finais. Conseqüentemente, eles foram mais elevados que os valores de $r^{2}$ e de id obtidos com as comparações das metodologias no período total de estudo. 
A partir dessas análises, pode-se concluir que os resultados obtidos com o equipamento da razão de Bowen, foram mais consistentes no período final da coleta de dados, devido, possivelmente, ao manejo mais adequado e freqüente aplicado ao equipamento, principalmente no que se refere em evitar, ao máximo, a presença de água nos condutos de ar do sistema. Desta maneira, os três métodos de estimativa de ETo podem ser considerados e adotados no estudo da evapotranspiração como métodos padrões. Vale salientar, que os métodos de Penman-Monteith e os que envolvem balanço de energia são utilizados para estimativa da demanda atmosférica, enquanto os métodos lisimétricos são empregados para estimativa da demanda de uma cultura.

Tabela 3 - Valores de id e de $\mathbf{r}^{2}$ obtidos relacionando-se os valores de ETo $_{\mathrm{L}}$ versus ETo EMM $_{\mathrm{P}}$, ETo $0_{\mathrm{I}}$ versus $\mathrm{ETo}_{\mathrm{BR}}$ e ETo $_{\mathrm{PM}}$ versus $\mathrm{ETo}_{\mathrm{BR}}$, para o período total, para os 20 dias finais e 10 dias finais do experimento.

\begin{tabular}{|c|c|c|c|c|c|c|}
\hline Período & $\begin{array}{c}\text { ETo }_{\mathrm{L}} \\
\mathbf{r}^{2}\end{array}$ & $\begin{array}{c}\text { ETo }_{\mathrm{PM}} \\
\text { id }\end{array}$ & $\begin{array}{c}\mathbf{E T o}_{\mathrm{L}} \\
\mathbf{r}^{2}\end{array}$ & $\begin{array}{c}\mathbf{E} \mathbf{E T}_{\mathrm{BR}} \\
\text { id }\end{array}$ & $\begin{array}{c}\text { ETopM } \\
\mathbf{r}^{2}\end{array}$ & 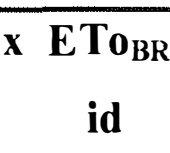 \\
\hline $1 \% /$ nov a $10 /$ dez & 0,91 & 0,97 & 0,74 & 0,92 & 0,79 & 0,93 \\
\hline $21 /$ nov a $10 /$ dez & 0,95 & 0,98 & 0,94 & 0,98 & 0,88 & 0,96 \\
\hline $1 \% /$ dez a $10 /$ dez & 0,97 & 0,98 & 0,93 & 0,98 & 0,95 & 0,99 \\
\hline
\end{tabular}

Segundo Ritchie \& Burnett (1968), a interferência do vento pode limitar a sensibilidade dos equipamentos lisimétricos, baseados em células de carga, em até 0,02 mm. Então, era esperado que os maiores valores positivos ocorressem nos dias de maiores intensidades de vento. Portanto, realizou-se análise estatística para verificar a correlação da velocidade média do vento com as respostas positivas do lisímetro. Através de regressão linear verificou-se, nos dias 
selecionados onde não ocorreram precipitações ou drenagens (Tabela 4), que o total diário dos valores positivos não apresentou correlação positiva com a velocidade média diária do vento, pelo contrário apresentaram correlação negativa, que pode ser representada pela seguinte equação:

$$
\mathrm{L}+=-0,1559 . \mathrm{u}+0,8497
$$

onde:

$\mathrm{L}+=$ soma diária dos valores positivos obtidos através da diferença de peso do lisímetro em dois intervalos consecutivos $(\mathrm{mm})$;

$\mathbf{u}=$ velocidade do vento medida 2 metros acima da superfície do solo $(\mathrm{m} / \mathrm{s})$.

Tabela 4 - Valores positivos das respostas lisimétricas $(\mathrm{mm})$ e velocidade média diária do vento $(\mathrm{m} / \mathrm{s})$ a $2 \mathrm{~m}$ de altura.

\begin{tabular}{cccccccccc}
\hline Dia & $\mathbf{0 4 / 1 1}$ & $\mathbf{0 5 / 1 1}$ & $\mathbf{0 6 / 1 1}$ & $\mathbf{0 7 / 1 1}$ & $\mathbf{0 8 / 1 1}$ & $\mathbf{0 9 / 1 1}$ & $\mathbf{1 0 / 1 1}$ & $\mathbf{1 1 / 1 1}$ & $\mathbf{1 2 / 1 1}$ \\
\hline $\mathbf{u}(\mathbf{m} / \mathbf{s})$ & 2,51 & 3,01 & 1,92 & 1,65 & 2,30 & 1,98 & 2,04 & 2,50 & 1,64 \\
$\mathbf{L}+(\mathbf{m m})$ & 0,39 & 0,25 & 0,80 & 0,58 & 0,40 & 0,68 & 0,62 & 0,30 & 0,15 \\
\hline Continuação da Tabela $\mathbf{4}$ & & & & & & & & \\
\hline Dia & $\mathbf{2 2 / 1 1}$ & $\mathbf{2 3 / 1 1}$ & $\mathbf{2 4 / 1 1}$ & $\mathbf{2 5 / 1 1}$ & $\mathbf{2 6 / 1 1}$ & $\mathbf{2 7 / 1 1}$ & $\mathbf{2 8 / 1 1}$ & $\mathbf{0 8 / 1 2}$ & $\mathbf{0 9 / 1 2}$ \\
\hline $\mathbf{u}(\mathbf{m} / \mathbf{s})$ & 3,79 & 2,22 & 1,47 & 2,17 & 3,16 & 3,20 & 2,65 & 1,28 & 1,66 \\
$\mathbf{L}+(\mathbf{m m})$ & 0,12 & 0,77 & 0,61 & 0,71 & 0,46 & 0,40 & 0,48 & 0,53 & 0,63 \\
\hline
\end{tabular}

Além disso, o valor de correlação calculado entre os valores de velocidade média diária do vento $(\mathrm{m} / \mathrm{s})$ e a soma diária dos valores positivos obtidos com as respostas lisimétricas em dois intervalos de tempo consecutivos, para a equação (24), foi muito baixo, sendo obtido o valor para $r^{2}$ de aproximadamente 0,27 , como pode ser visto na Figura 15. Indicando que, para períodos de um dia, a 
velocidade do vento não correlacionou-se com os valores positivos de maneira direta e proporcional, para as condições do estudo.

Salienta-se, que nos dias sem precipitação pluviométrica e com maiores intensidades de vento são esperados maiores valores de evapotranspiração, então como a ETo é considerada um valor negativo e como ela tende a crescer nos dias analisados, pode-se supor que os valores positivos foram diminuídos pela ETo. Sendo assim, seria necessário um estudo mais específico para inferir sobre a influência da velocidade do vento sobre os valores positivos das respostas lisimétricas, possivelmente com intervalos bem menores que os estudados.

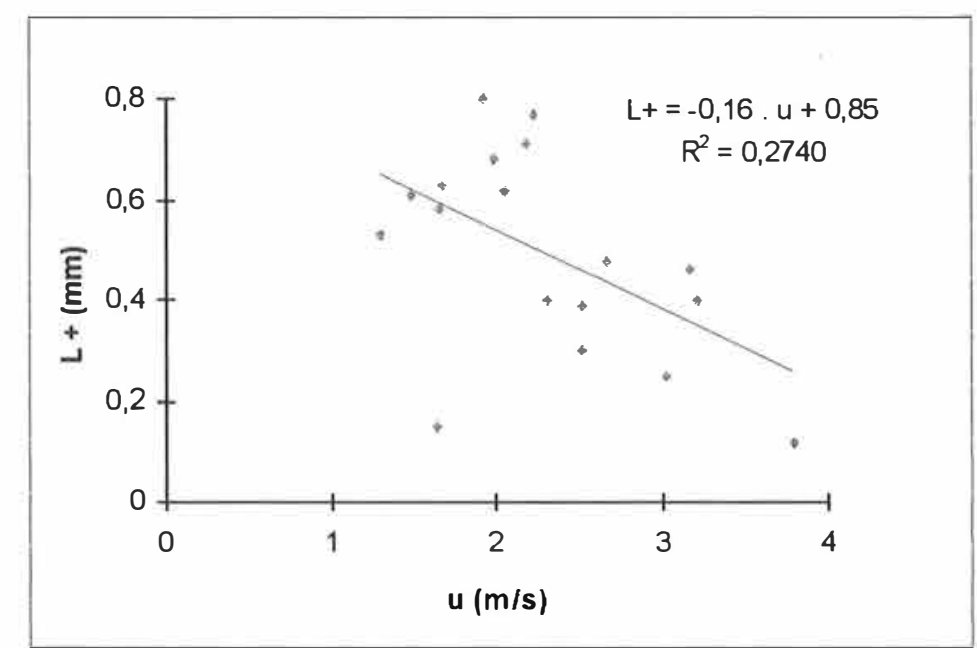

Figura 15 - Velocidade média diária do vento $(\mathrm{m} / \mathrm{s})$ versus total diário das respostas lisimétricas positivas $(\mathrm{mm})$.

A distribuição dos valores de evapotranspiração ao longo de um dia, também, foi avaliado. Nesse estudo avaliou-se a correlação entre os métodos na estimativa de ETo em períodos menores que um dia. Foram selecionados os dias do período de $1^{\circ}$ a 10 de dezembro, onde os equipamentos trabalharam com a menor interferência possível de fatores externos, principalmente de precipitações. 
Foram selecionados os dias 02, 05, 06, 08 e 09 de dezembro, divididos em intervalos de 1 hora.

As análises estatísticas, regressão linear simples e índice de concordância de Willmott, entre os três métodos de estimativa de ETo estudados, demonstraram que todos os métodos foram muito efícientes na estimativa horária de ETo (Figuras 19, 20, 21, 22 e 23). Pois, os valores calculados para $r^{2}$ e id foram bastante significativos (Tabela 5). Na comparação entre $\mathrm{ETo}_{\mathrm{L}}$ e ETopM, o menor valor alcançado para $\mathrm{r}^{2}$ foi de aproximadamente 0,83 e atingiu um valor máximo de aproximadamente 0,93 , com média para os 5 dias analisados de 0,89 . E, o valor de id apresentou-se no intervalo de 0,95 a 0,98 , com a média sendo 0,97 .

Já, na comparação entre os valores de $\mathrm{ETo}_{\mathrm{L}}$ e $E \mathrm{ETo}_{\mathrm{BR}}$, os valores de $\mathrm{r}^{2}$ e de id foram um pouco inferiores aos obtidos na análise anterior, embora eles possam ser considerados muito bons, considerando que a estimativa foi realizada a cada hora do dia, $\mathrm{r}^{2}$ variou de 0,70 a 0,89 , e teve média de 0,83 , aproximadamente. $\mathrm{O}$ id teve 0,94 como valor médio, e manteve-se no intervalo de 0,90 a 0,97 .

Tabela 5 - Valores de id e de $\mathbf{r}^{2}$ calculados com a comparação de $\mathrm{ETo}_{\mathrm{L}}$ versus $\mathrm{ETo}_{\mathrm{PM}}, \mathrm{ETo}_{\mathrm{L}}$ versus $\mathrm{ETo}_{\mathrm{BR}}$ e ETo $\mathrm{EM}_{\mathrm{PM}}$ versus $\mathrm{ETo}_{\mathrm{BR}}$, nos dias 02, 05, 06, 08 e 09 de dezembro de 1996.

\begin{tabular}{|c|c|c|c|c|c|c|}
\hline \multirow[b]{2}{*}{ Dia } & \multicolumn{2}{|c|}{$\mathrm{ETo}_{\mathrm{L}} \times \mathrm{ETo}_{\mathrm{PM}}$} & \multicolumn{2}{|c|}{$\mathrm{ETo}_{\mathrm{L}} \times \mathrm{ETo}_{\mathrm{BR}}$} & \multirow{2}{*}{$\begin{array}{c}\text { ETo }_{\mathrm{PM}} \\
\mathrm{r}^{2}\end{array}$} & \multirow{2}{*}{$\begin{array}{c}\mathbf{x} \mathbf{E T o}_{\mathrm{BR}} \\
\text { id }\end{array}$} \\
\hline & $\mathbf{r}^{2}$ & id & $\mathbf{r}^{2}$ & id & & \\
\hline $02 / \mathrm{dez}$ & 0,93 & 0,98 & 0,86 & 0,95 & 0,95 & 0,98 \\
\hline $05 / \mathrm{dez}$ & 0,93 & 0,98 & 0,86 & 0,95 & 0,96 & 0,99 \\
\hline 06/dez & 0,90 & 0,97 & 0,89 & 0,97 & 0,97 & 0,99 \\
\hline 08/dez & 0,83 & 0,95 & 0,70 & 0,90 & 0,96 & 0,98 \\
\hline 09/dez & 0,88 & 0,97 & 0,83 & 0,95 & 0,94 & 0,98 \\
\hline Média & 0,89 & 0,97 & 0,83 & 0,94 & 0,96 & 0,98 \\
\hline
\end{tabular}


Os resultados mais significativos foram obtidos com a comparação entre os valores de $\mathrm{ETo}_{\mathrm{PM}}$ e $\mathrm{ETo}_{\mathrm{BR}}$, demonstrando grande aderência dos processos de estimativas proposto pela $\mathrm{FAO} / 1991$ e do equipamento da razão de Bowen, obtendo-se valores de $\mathrm{r}^{2}$ no intervalo de 0,94 a 0,97 , a média alcançada foi de 0,96. O id, também, apresentou valores altíssimos $(0,98$ e 0,99$)$, sendo seu valor médio igual a 0,98 , aproximadamente.

Como foi mencionado, os três métodos se apresentaram de maneira efíciente na estimativa horária de ETo, mas vale salientar que os dias foram selecionados de forma a evitar, ao máximo, as influências externas. Quando esta mesma comparação foi realizada para os dias onde ocorreram precipitações (Figuras 24, 25, 26 e 27), do mesmo período de $1^{\circ}$ a 10 de dezembro, foi observado que os valores de $\mathrm{r}^{2}$ e de id (Tabela 6) foram inferiores aos dos dias com baixa influência pluviométrica, embora não tenham sido baixos o suficiente para invalidar as estimativas propostas, mesmo nos dias com precipitações. Foram analisados os dias $1^{\circ}, 3,7$ e 10 de dezembro.

Tabela 6 - Valores de id e de $\mathbf{r}^{2}$ calculados com a comparação de $E^{2} o_{L}$ versus

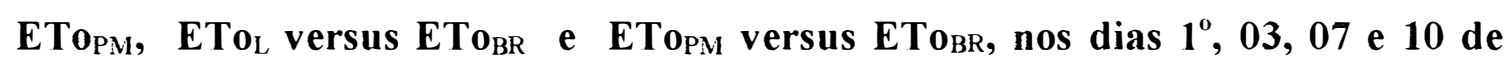
dezembro de 1996.

\begin{tabular}{|c|c|c|c|c|c|c|}
\hline \multirow[b]{2}{*}{ Dia } & \multicolumn{2}{|c|}{$E T o_{L} \times E T o_{P M}$} & \multicolumn{2}{|c|}{$\mathrm{ETo}_{\mathrm{L}} \times \mathrm{ETo}_{\mathrm{BR}}$} & \multicolumn{2}{|c|}{$\mathrm{ETo}_{\mathrm{PM}} \times \mathrm{ETo}_{\mathrm{BR}}$} \\
\hline & $\mathbf{r}^{2}$ & id & $\mathbf{r}^{2}$ & id & $\mathbf{r}^{2}$ & id \\
\hline $1^{\circ} / \mathrm{dez}$ & 0,78 & 0,94 & 0,62 & 0,88 & 0,93 & 0,98 \\
\hline $03 / \mathrm{dez}$ & 0,71 & 0,91 & 0,43 & 0,81 & 0,69 & 0,90 \\
\hline 07/dez & 0,71 & 0,91 & 0,59 & 0,87 & 0,88 & 0,97 \\
\hline $10 /$ dez & 0,87 & 0,96 & 0,71 & 0,92 & 0,92 & 0,98 \\
\hline Média & 0,77 & 0,93 & 0,59 & 0,87 & $0, \overline{86}$ & 0,96 \\
\hline
\end{tabular}


Analisando-se os valores médios de $\mathrm{r}^{2}$ e de id, nos dias com precipitação, observou-se que o comportamento das comparações manteve-se o mesmo de quando considerou-se apenas os dias sem chuvas. Ou seja, os menores valores de $\mathrm{r}^{2}$ e de id foram obtidos com a comparação entre $\mathrm{ETo}_{\mathrm{L}} \times \mathrm{ETo}_{\mathrm{BR}}$, apresentando média de 0,59 e 0,87 , respectivamente. A comparação entre $E \mathrm{To}_{\mathrm{L}}$ e EToPM apresentou comportamento central, apresentando 0,77 como valor médio para $\mathrm{r}^{2} \mathrm{e}$ 0,93 para id.

A maior aderência, novamente, foi obtida comparando-se ETopM com $\mathrm{ETo}_{\mathrm{BR}}$, que apresentou valores de $\mathrm{r}^{2}$ no intervalo de 0,69 a 0,93 , alcançando média igual a 0,86 , maior que a média de $r^{2}(0,83)$ obtida com a comparação de $\mathrm{ETo}_{\mathrm{L}} \times \mathrm{ETo}_{\mathrm{BR}}$, nos dias sem chuvas. Tendência semelhante foi observada para id, que apresentou valor médio igual a 0,96. Demonstrando que a metodologia FAO/1991 e o equipamento da razão de Bowen, desde que manuseado adequadamente, foram eficientes não só na estimativa diária de ETo, mas também apresentaram excelente eficiência na estimativa da evapotranspiração em intervalos de tempo de 1 hora.

Para melhor compreensão e ilustração da forma como os resultados foram avaliados, os dados horários do dia 05 de dezembro estão apresentados na Figura 16 e na Tabela 8. Alguns dos resultados (tabelas e gráficos) não estão apresentados com o intuito de sintetizar a apresentação e por não prejudicarem a compreensão das análises.

É possível verificar na Figura 16, que os valores estimados para ETo pelos três métodos, para o dia 05 de dezembro de 1996, foram bastante similares. As três estimativas apresentaram o mesmo comportamento de variação ao longo do dia, com baixíssimas distorções em um ou outro ponto, mas sem afetar o contexto geral, como já foi demonstrado nas análises previamente apresentadas e discutidas. A Figura 16 apresenta, além das linhas representativas da variação diária de $\mathrm{ETo}_{\mathrm{L}}, \mathrm{ETo}_{\mathrm{PM}}$ e $\mathrm{ETo}_{\mathrm{BR}}$, a linha que representa a variação da estimativa 
lisimétrica considerando os valores positivos $\left(\mathrm{ETo}_{\mathrm{L}_{+}}\right)$não provenientes de precipitação ou irrigação. Por tal motivo, esta curva também representa, em alguns trechos, a $\mathrm{ETo}_{\mathrm{L}}$. Logicamente, estes são os intervalos do dia onde não se verificou a ocorrência de valores positivos, por isso $\mathrm{ETo}_{\mathrm{L}}$ e $\mathrm{ETo}_{\mathrm{L}^{+}}$podem ser representados pela mesma linha.

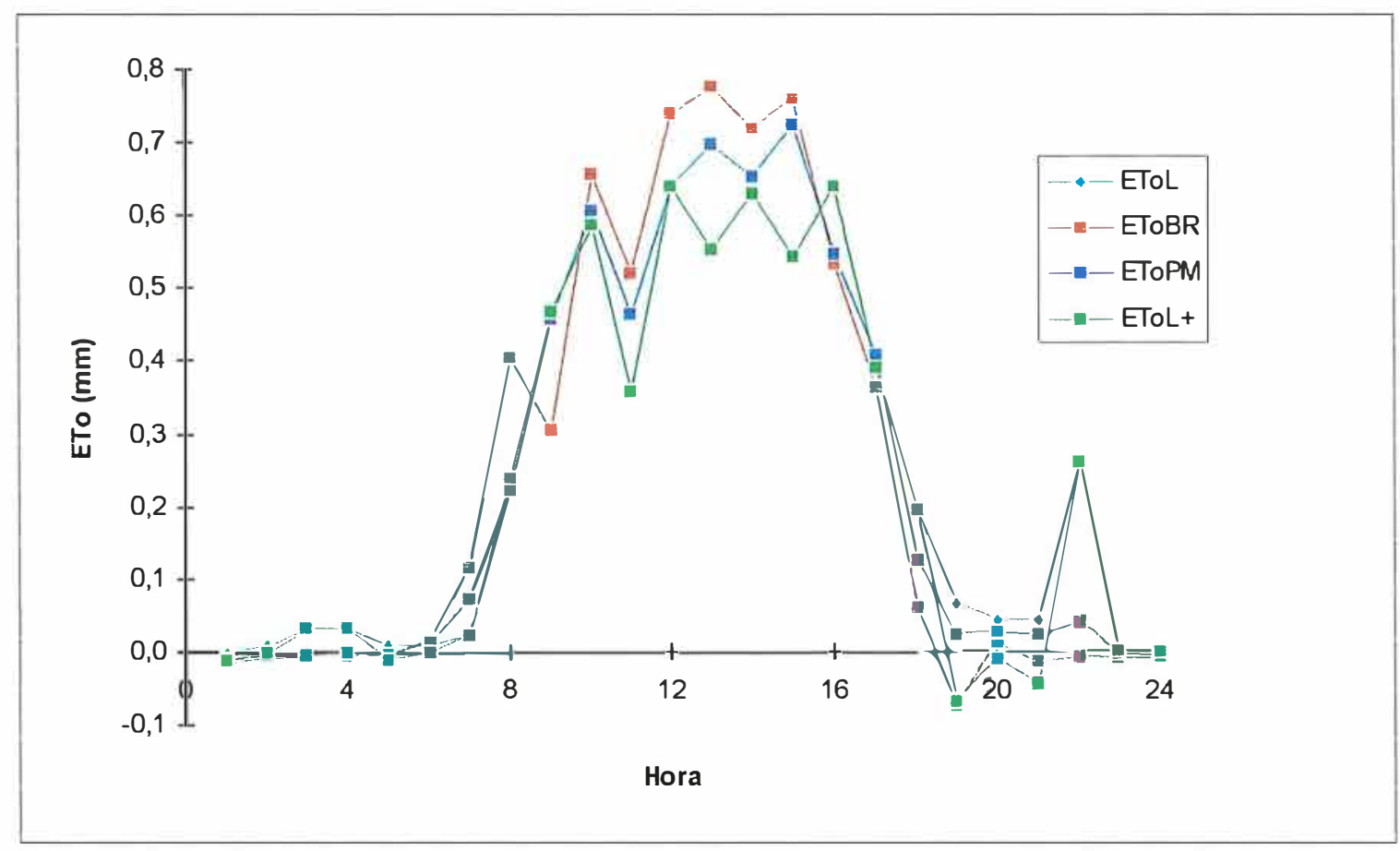

Figura 16 - Variação de $\mathrm{ETo}_{\mathrm{L}}, \mathrm{ETo}_{\mathrm{L}+}$, ETo $\mathrm{ER}_{\mathrm{BR}}$ e ETo $\mathrm{PM}_{\mathrm{PM}}$ no dia 05 de dezembro de 1996, em mm.

A influência da eliminação dos dados positivos das respostas do lisímetro, também, foi avaliada na escala horária. Foram utilizadas as mesmas metodologias empregadas no estudo da escala diária. Para possibilitar comparações, analisou-se estatisticamente $\mathrm{ETo}_{\mathrm{L}^{+}}$versus $\mathrm{ETo}_{\mathrm{PM}}$ e $\mathrm{ETo}_{\mathrm{L}^{+}}$versus $\mathrm{ETo}_{\mathrm{BR}}$ (Figuras 28, 29, 30, 31 e 32) nos dias do intervalo de $1^{\circ}$ a 10 de dezembro de 1996, quando não houve 
interferência significativa de precipitação pluviométrica. Foram selecionados os dias 2, 5, 6, 8 e 9 de dezembro de 1996.

Os valores $\mathrm{r}^{2}$ e de id alcançados com as comparações da $\mathrm{ETo}_{\mathrm{L}_{+}}$com a $E \mathrm{PO}_{\mathrm{PM}}$ e com a $\mathrm{ETO}_{\mathrm{BR}}$ foram muito semelhantes aos obtidos com as comparações destes com as respostas do lisímetro sem considerar os valores positivos (Tabela 7). Embora muito semelhantes, pode-se observar (Tabela 7) que os valores de $r^{2}$ e de id obtidos com a comparação de $\mathrm{ETo}_{\mathrm{L}_{+}}$versus ETopM foram, de maneira geral, um pouco menores que os calculados através da comparação de $\mathrm{ETo}_{\mathrm{L}}$ versus ETopm, a maior diferença observada foi de 0,04 e de 0,02 para $r^{2}$ e id, respecitvamente.

Tabela 7 - Valores de id e de $\mathrm{r}^{2}$ para as comparações de $\mathrm{ETo}_{\mathrm{L},+}$ versus $\mathrm{ETo}_{\mathrm{PM}}$, $\mathrm{ETo}_{\mathrm{L}}$ versus $\mathrm{ETo}_{\mathrm{PM}_{\mathrm{M}}}, \mathrm{ETo}_{\mathrm{I}++}$ versus $\mathrm{ETo}_{\mathrm{BR}}$ e $\mathrm{ETo}_{\mathrm{L}}$ versus $\mathrm{ETo}_{\mathrm{BR}}$, nos dias 02, 05, 06, 08 e 09 de dezembro de 1996.

\begin{tabular}{|c|c|c|c|c|c|c|c|c|}
\hline Dia & $\begin{array}{c}\mathrm{ETo}_{\mathrm{L+}} \\
\mathbf{r}^{2}\end{array}$ & $\begin{array}{l}\text { ETo }_{P M} \\
\text { id }\end{array}$ & $\begin{array}{c}\mathrm{ETo}_{\mathrm{L}} \mathrm{x} \\
\mathrm{r}^{2}\end{array}$ & $\begin{array}{c}\text { EToPM } \\
\text { id }\end{array}$ & $\begin{array}{c}\mathrm{ETo}_{\mathrm{L}+} \\
\mathbf{r}^{2}\end{array}$ & $\begin{array}{c}\mathbf{E T} \mathbf{B}_{\mathrm{BR}} \\
\text { id }\end{array}$ & $\begin{array}{c}\mathrm{ETo}_{\mathrm{L}} \mathrm{x} \\
\mathrm{r}^{2}\end{array}$ & $\begin{array}{c}\text { ETo }_{\mathrm{BR}} \\
\text { id }\end{array}$ \\
\hline 02/dez & 0,93 & 0,98 & 0,93 & 0,98 & 0,85 & 0,95 & 0,86 & 0,95 \\
\hline $05 / \mathrm{dez}$ & 0,92 & 0,98 & 0,93 & 0,98 & 0,87 & 0,96 & 0,86 & 0,95 \\
\hline 06/dez & 0,89 & 0,97 & 0,90 & 0,97 & 0,89 & 0,97 & 0,89 & 0,97 \\
\hline $08 / \mathrm{dez}$ & 0,79 & 0,94 & 0,83 & 0,95 & 0,70 & 0,89 & 0,70 & 0,90 \\
\hline 09/dez & 0,85 & 0,95 & 0,88 & 0,97 & 0,83 & 0,94 & 0,83 & 0,95 \\
\hline média & 0,88 & 0,96 & 0,89 & 0,97 & 0,82 & 0,94 & 0,83 & 0,94 \\
\hline
\end{tabular}

Quando analisou-se $\mathrm{ETo}_{\mathrm{L} .+}$ versus $\mathrm{ETo}_{\mathrm{BR}}$, verificou-se, também, que os valores de $r^{2}$ e de id foram muito próximos dos valores de $r^{2}$ obtidos com a comparação de $\mathrm{ETo}_{\mathrm{L}}$ versus $E \mathrm{To}_{\mathrm{BR}}$, sendo de 0,03 a maior diferença encontrada em $r^{2}$ e de 0,01 em id. Para os cinco dias analisados, a média de $r^{2}$ foi apenas 0,01 
menor que a média da mesma comparação sem considerar os valores positivos como resposta do lisimetro. Estas duas últimas análises indicam que os valores lisimétricos positivos podem ser considerados insignificantes no estudo da ETo, na escala horária, para os dias com precipitação inferior a $1 \mathrm{~mm}$.

Após analisar todos os resultados, pode-se afirmar que o equipamento da razão de Bowen pode ser empregado, com sucesso, na estimativa de rc de muitas espécies vegetais agricultáveis, em seus variados estágios de desenvolvimento vegetativo, fornecendo valores confiáveis para serem aplicados na equação de Penman-Monteith. E, que esta metodologia, assim como a FAO/1991, pode, perfeitamente, ser utilizada na estimativa da evapotranspiração, substituindo os lisímetros de pesagem, que são equipamentos de custos elevados e baixa mobilidade.

As parametrizações propostas por Allen et al. (1989) e Smith (1991) para a metodologia de Penman-Monteith foram realizadas com o uso de simplificações e aproximações, que, muitas vezes, podem provocar divergência na estimativa de ETo. Mas, como pode-se observar ao longo de todo o trabalho, a metodologia $\mathrm{FAO} / 1991$ foi a que apresentou maior aderência nos resultados, tanto para a escala horária como na escala diária, assim como nos dias com precipitação e com precipitaçĩo inferior a $1 \mathrm{~mm}$, então, mesmo com as aproximações, pode-se recomend sua utilização. 


\section{CONCLUSÕES}

No período de 40 dias, compreendidos de $1^{\circ}$ de novembro a 10 de dezembro de 1996, foram obtidos os seguintes valores para a evapotranspiração de referência (ETo): com o lisímetro de pesagem a $E^{r} \mathrm{O}_{\mathrm{L}}$, foi de $177,37 \mathrm{~mm}$; empregando-se a parametrização proposta pela $\mathrm{FAO} / 1991$ para a equação de Penman-Monteith alcançou-se um valor de $172,91 \mathrm{~mm}$ para a ETopM e com o equipamento automático razão de Bowen a $\mathrm{ETo}_{\mathrm{BR}}$ foi estimada em 166,77 mm.

Analisando-se os resultados alcançados para ETo diária, entre si, através da regressão linear simples e da análise de concordância de Willmott, é possível afirmar que a maior correlação foi obtida quando se comparou a ETo estimada pela metodologia FAO/1991 com a estimativa lisimétrica. O coeficiente de determinação $\left(\mathrm{r}^{2}\right)$ médio dessa análise foi de 0,91 e o índice de concordância de Willmott (id) médio foi de $\bullet, 97$.

$\mathrm{Na}$ escala horária, as maiores correlações foram obtidas quando se comparou a ETo estimada pela metodologia $\mathrm{FAO} / 1991 \mathrm{com}$ a estimativa realizada com o equipamento da razão de Bowen. O valor médio para $r^{2}$ da análise dos dias 02, 05, 06, 08 e 09 de dezembro de 1996, foi de 0,96 e a média para id foi de 0,98 . Demonstrando elevada correlação entre as metodologias, portanto suas estimativas podem ser aplicadas em pesquisas científicas como padrão na estimaliva de ETo.

O sistema automático da razão de Bowen teve desempenho adequado na estimativa da ETo tanta na escala diária como na horária, apresentou baixa manutenção e fácil manuseio. Podendo ser recomendado para diversos estudos em 
substituição aos lisímetros, que são equipamentos de baixíssima mobilidade em campo.

Os valores de $r^{2}$ e de id alcançados com as comparações estatísticas entre as ETo estimadas pelos três métodos, para os 20 dias finais e para os 10 dias finais do estudo, foram maiores que os obtidos para o período total. Com esses resultados, pode-se afirmar que a estimativa de ETo realizada com o equipamento da razão de Bowen foi mais consistente no período final da coleta de dados, tendo em vista o manejo mais adequado aplicado ao equipamento, principalmente no que se refere a evitar ao máximo a presença de água nos condutos de ar do sistema.

As três metodologias adotadas na estimativa de ETo, metodologia FAO/1991 (Penman-Monteith), lisímetro de célula de carga e o equipamento da razão de Bowen, podem ser consideradas e adotados no estudo da evapotranspiração como padrões, tanto na escala diária como para intervalos de 1 hora. 
ANEXOS 
商

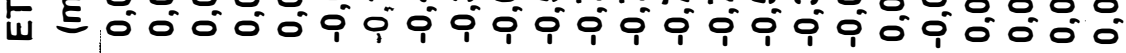

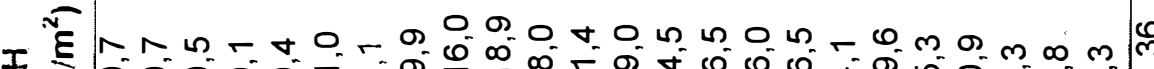

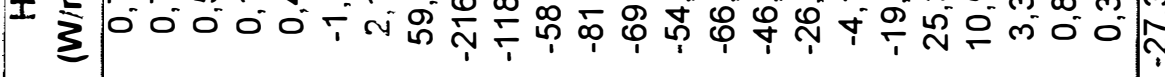

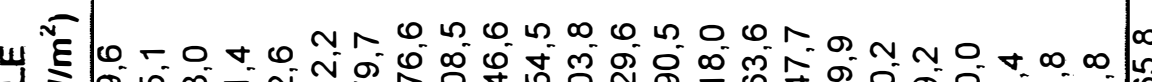

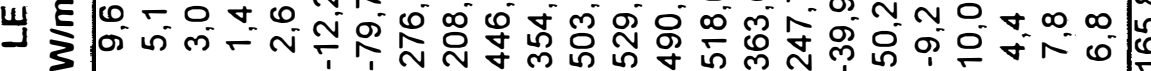
3 ฮ

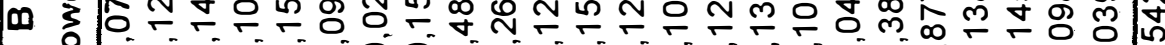

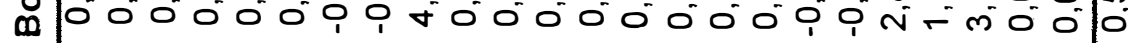

=

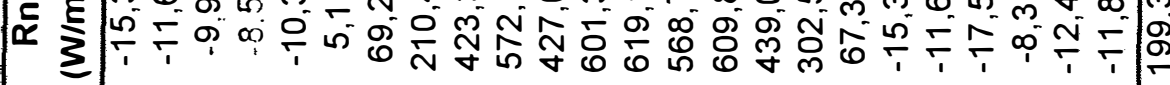

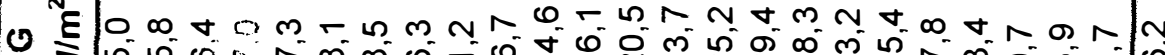
3 ஸ

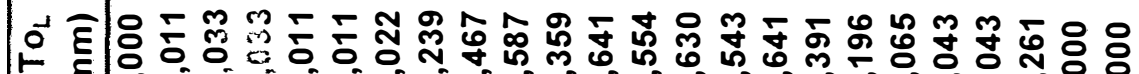

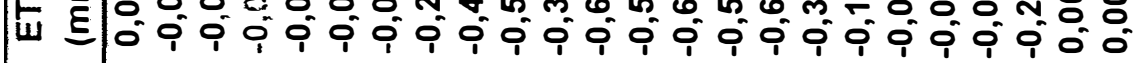
$\pm \widehat{\varepsilon}$

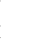

5 ह 000000000000000000000000 Q ह

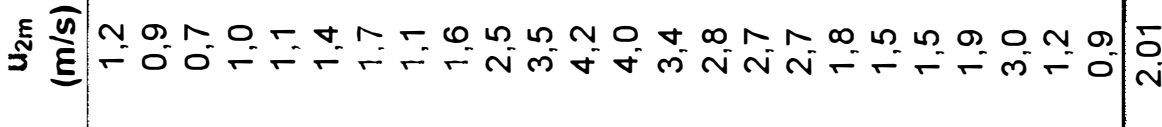

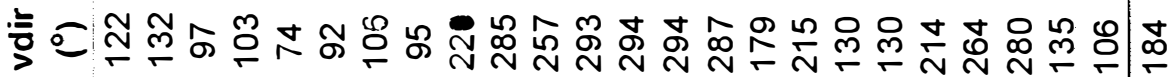

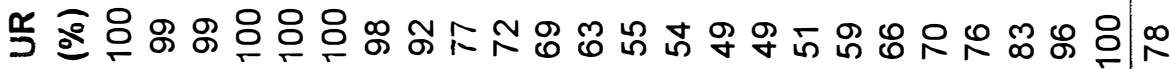

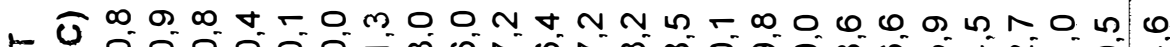

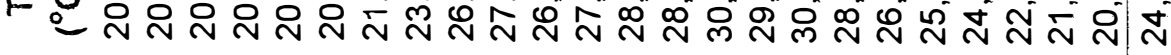

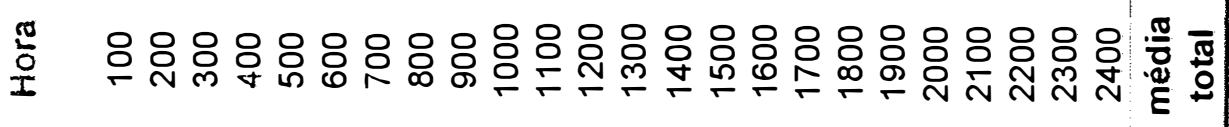



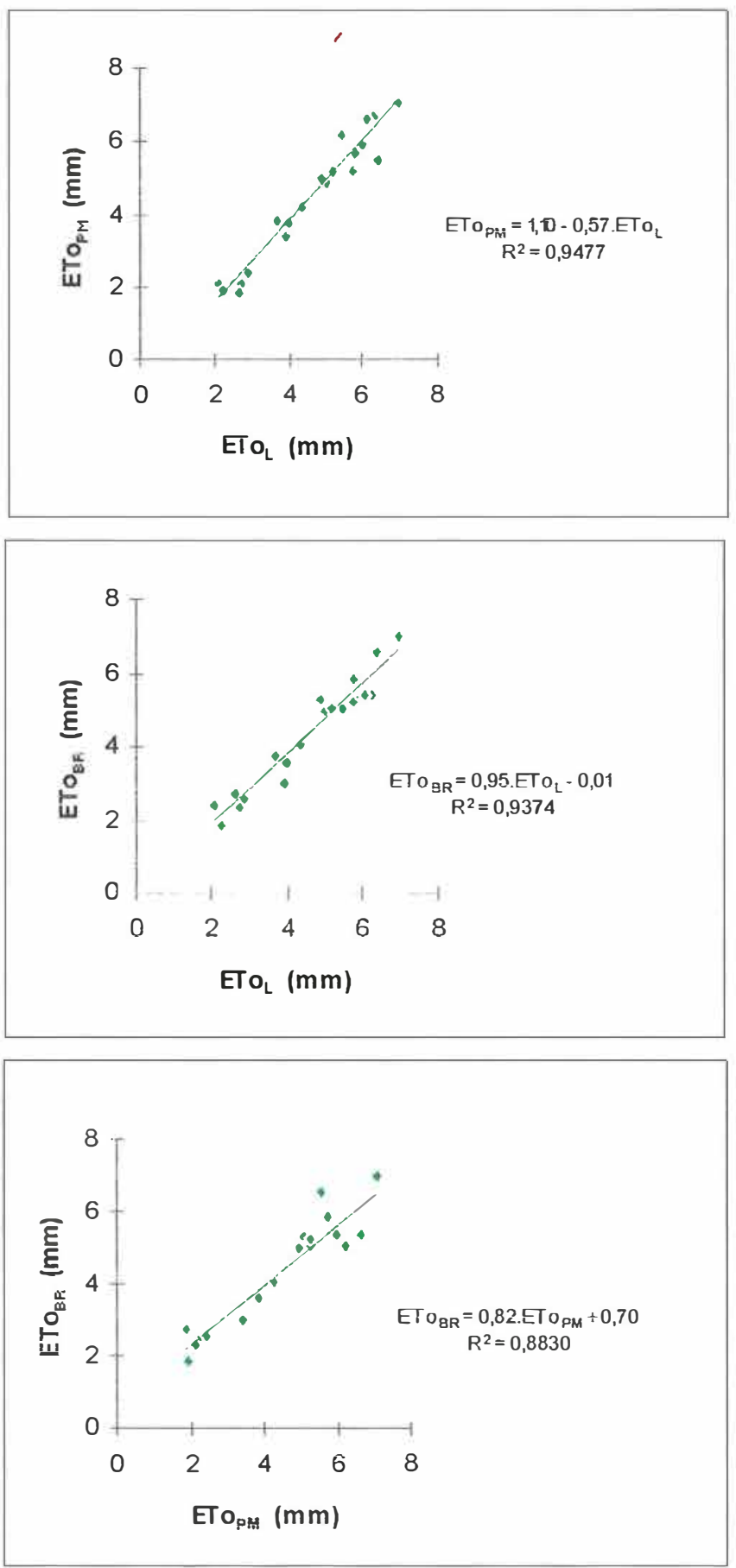

Figura 17 - Valores de ETo $_{\mathrm{L}}$ versus EToPM, ETo Eersus $_{\mathrm{L}} \mathrm{ET}_{\mathrm{BR}}$ e ETo $_{\mathrm{PM}}$ versus ETo $_{\mathrm{BR}}$, estimadas no período de 21 de novembro a 10 de dezembro de 1996. 

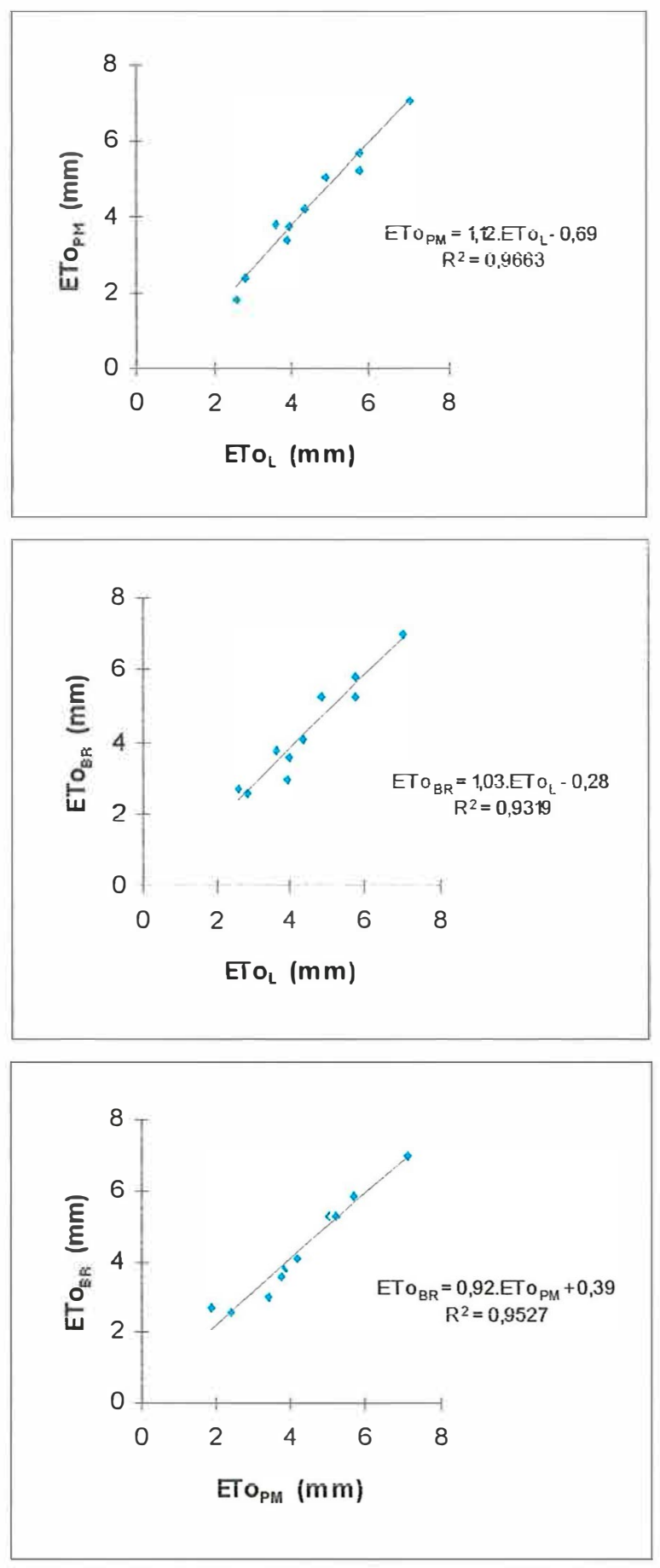

Figura 18 - Valores de ETo $_{\mathrm{L}}$ versus EToPM, ETo ET $_{\mathrm{L}}$ versus ETo $_{\mathrm{BR}}$ e ETopm versus ETo ${ }_{\mathrm{BR}}$, estimadas no período de $1^{\circ}$ a 10 de dezembro de 1996. 

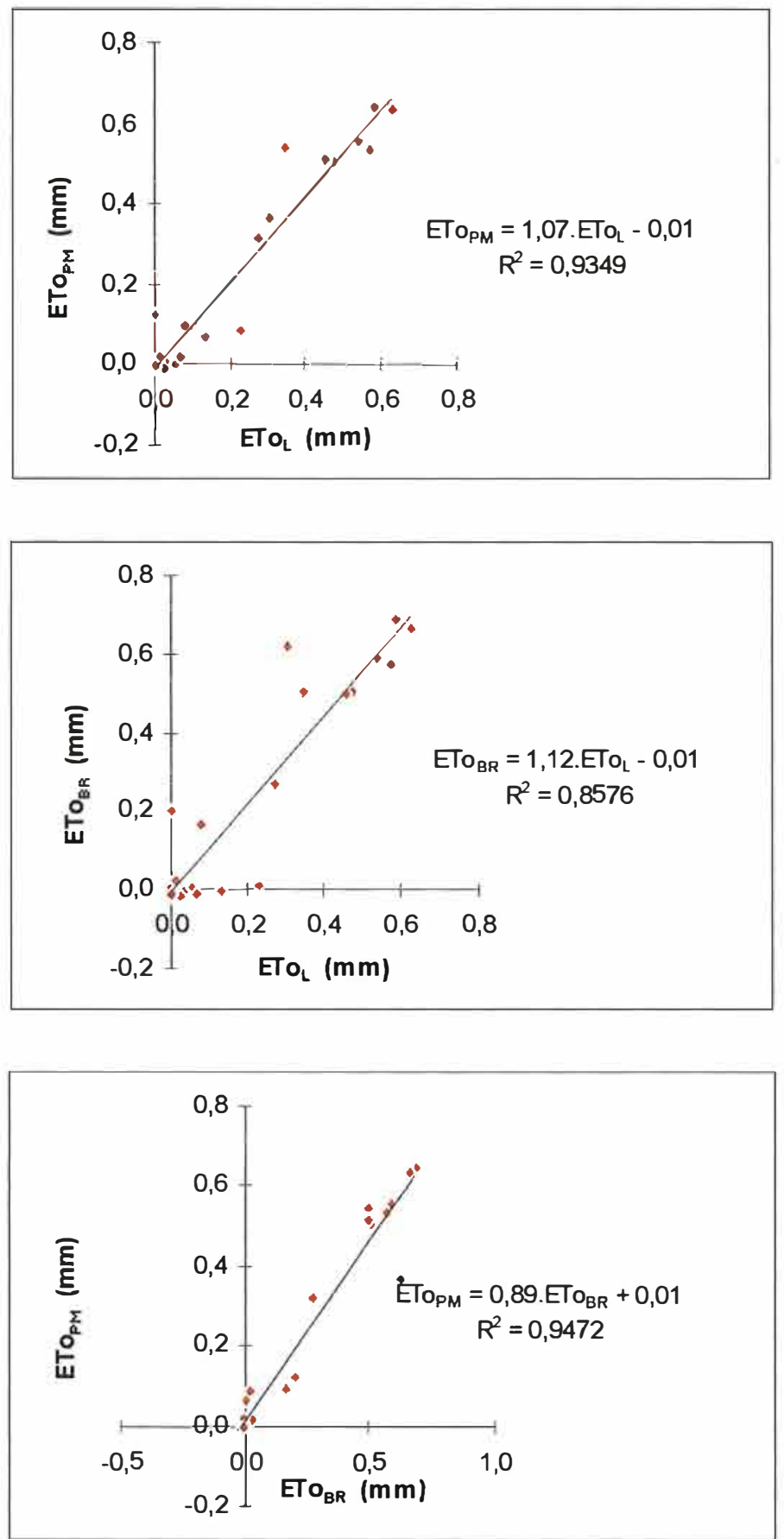

Figura 19 - Valores de ETo $_{\mathrm{L}}$ versus ETo PMM, $_{\text {ETo }}$ versus ETo ETR $_{\mathrm{B}}$ e ETo $_{\mathrm{PM}}$ versus $\mathrm{ETo}_{\mathrm{BR}}$, estimadas para o dia 2 de dezembro de 1996. 

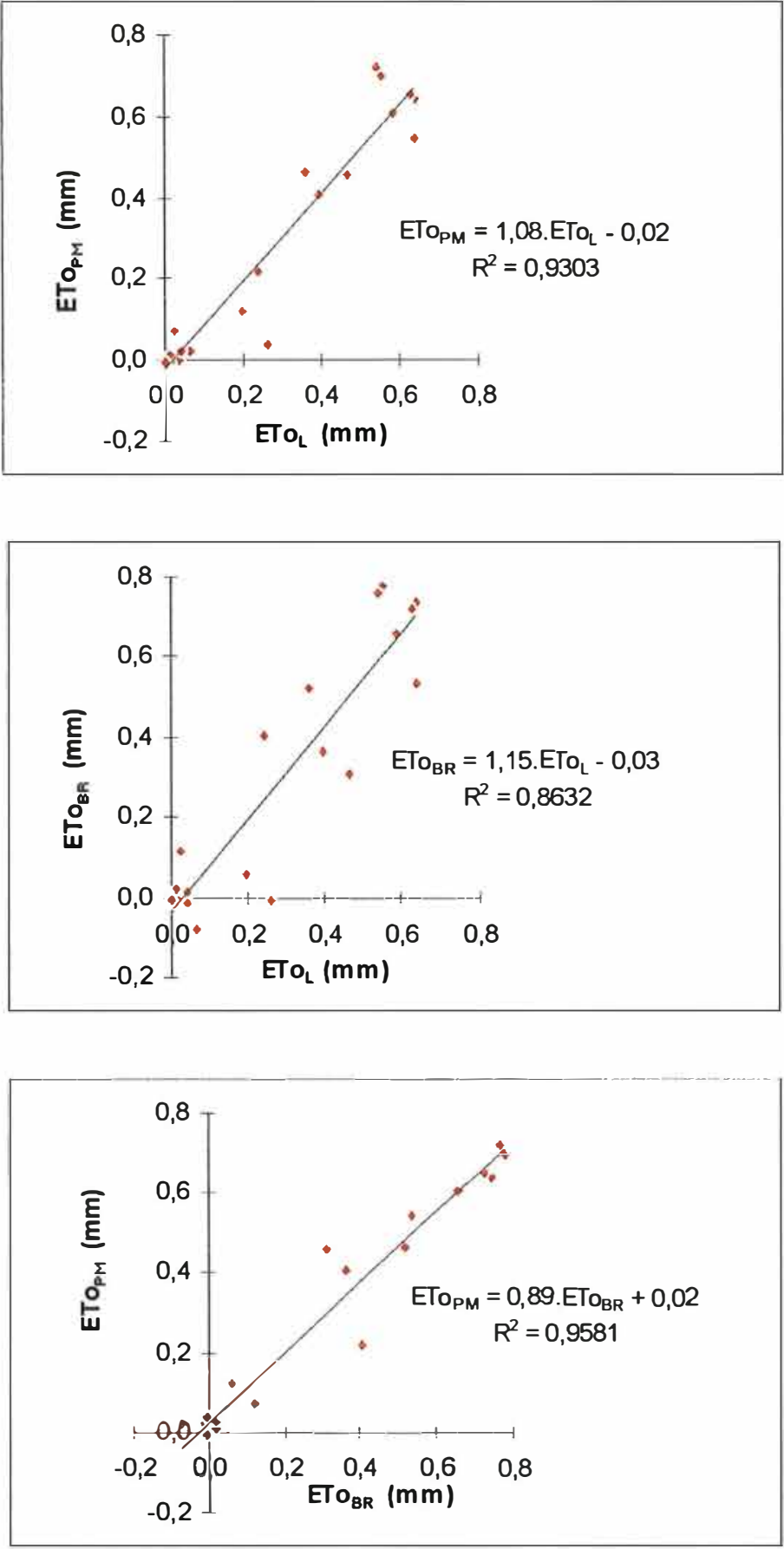

Figura 20 - Valores de ETo $_{\mathrm{L}}$ versus ETo PMM, ETo $_{\mathrm{L}}$ versus ETo ETR $_{\mathrm{BR}}$ e ETo $_{\mathrm{PM}}$ versus ETo ${ }_{\mathrm{BR}}$, estimadas para o dia 5 de dezembro de 1996. 

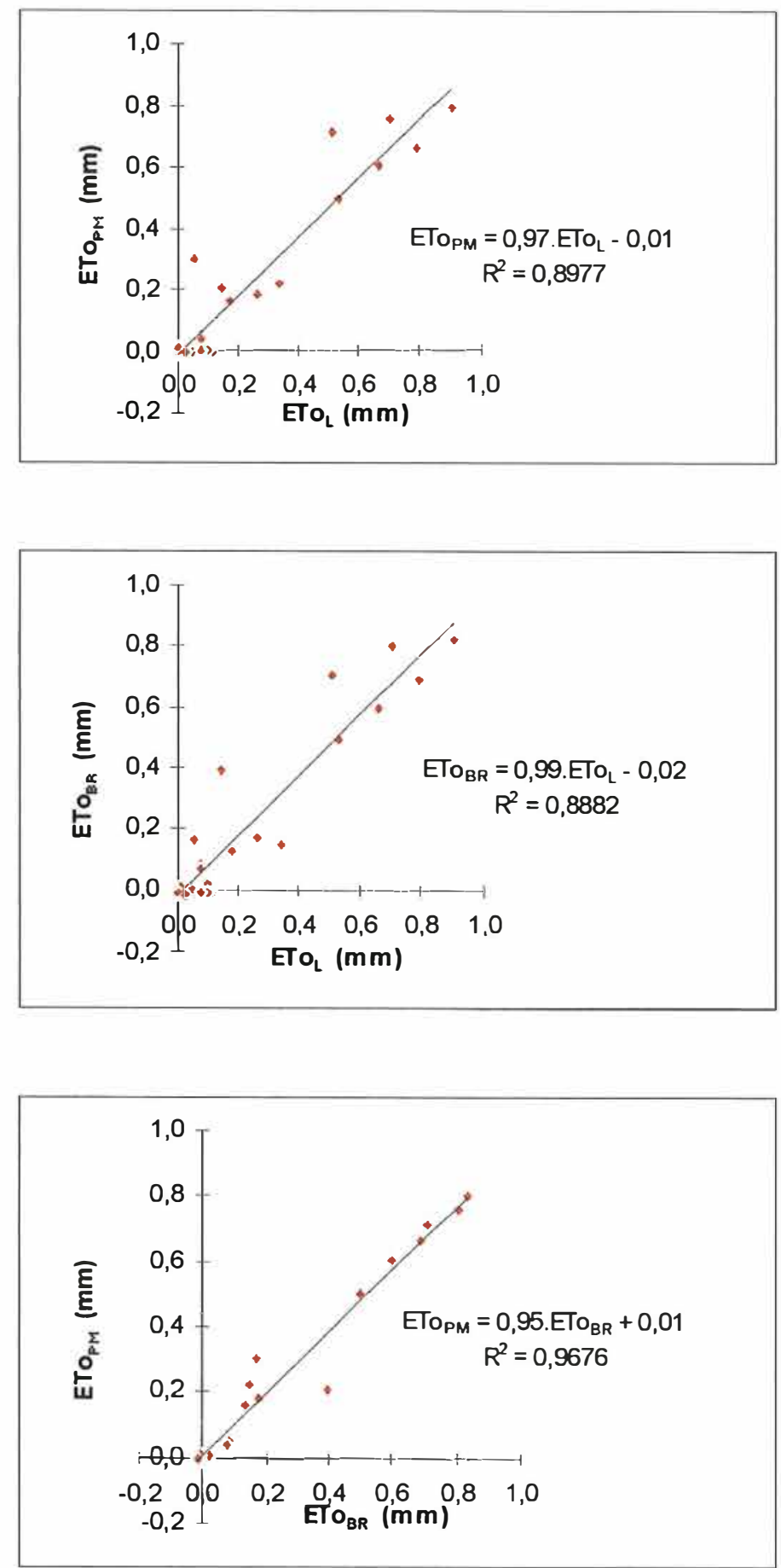

Figura 21 - Valores de ETo E versus ETo $_{\mathrm{PM}}$, ETo $\mathrm{E}_{\mathrm{L}}$ versus ETo $\mathrm{BR}_{\mathrm{BR}}$ e ETo $_{\mathrm{PM}}$ versus ETo $_{\mathrm{BR}}$, estimadas para o dia 6 de dezembro de 1996. 

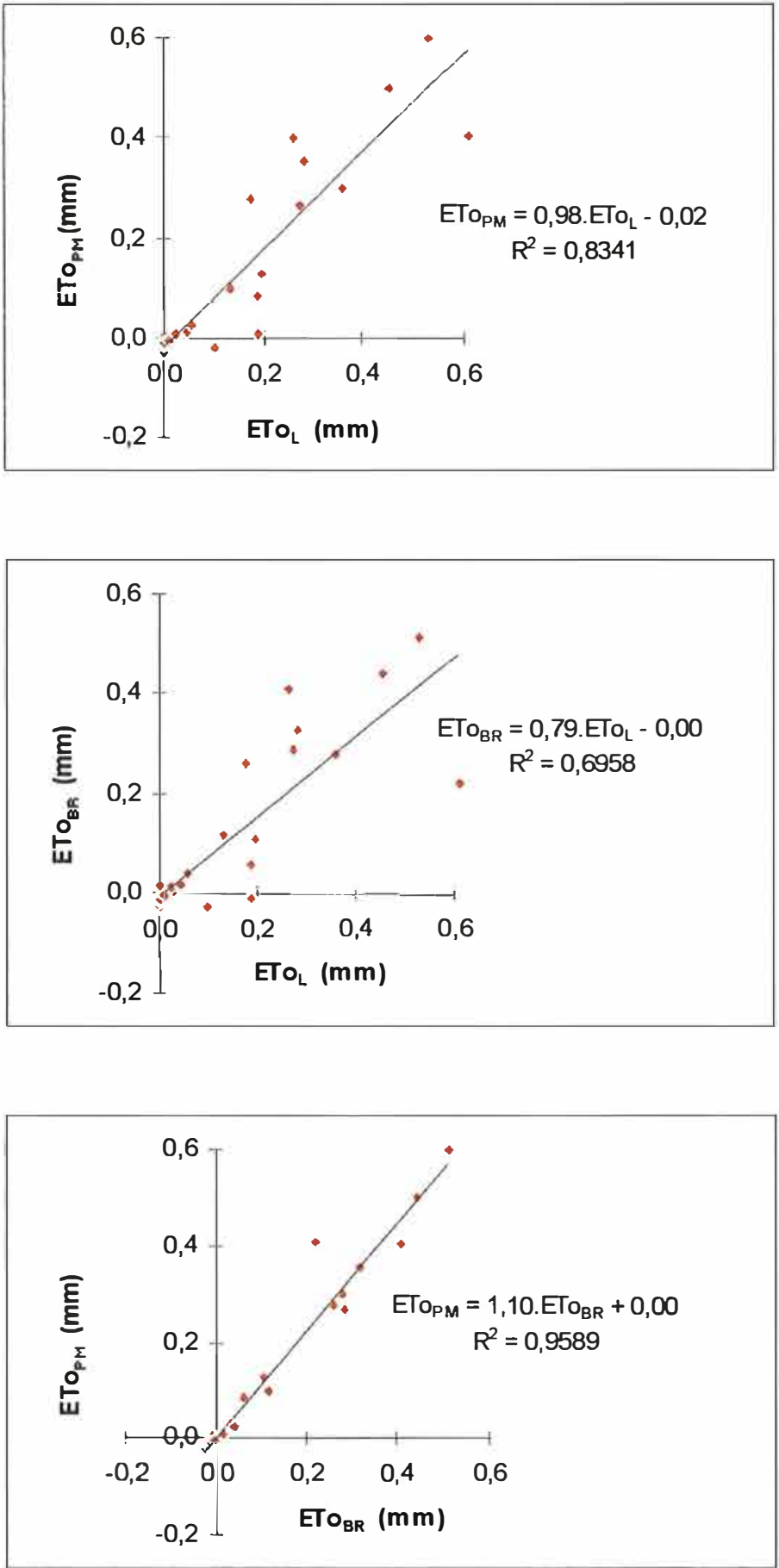

Figura 22 - Valores de ETo $_{\mathrm{L}}$ versus ETo $\mathrm{PM}_{\mathrm{PM}}$ ETo Eersus $_{\mathrm{L}} \mathrm{ET}_{\mathrm{BR}}$ e ETopm versus ETo ${ }_{\mathrm{BR}}$, estimadas para o dia 8 de dezembro de 1996. 

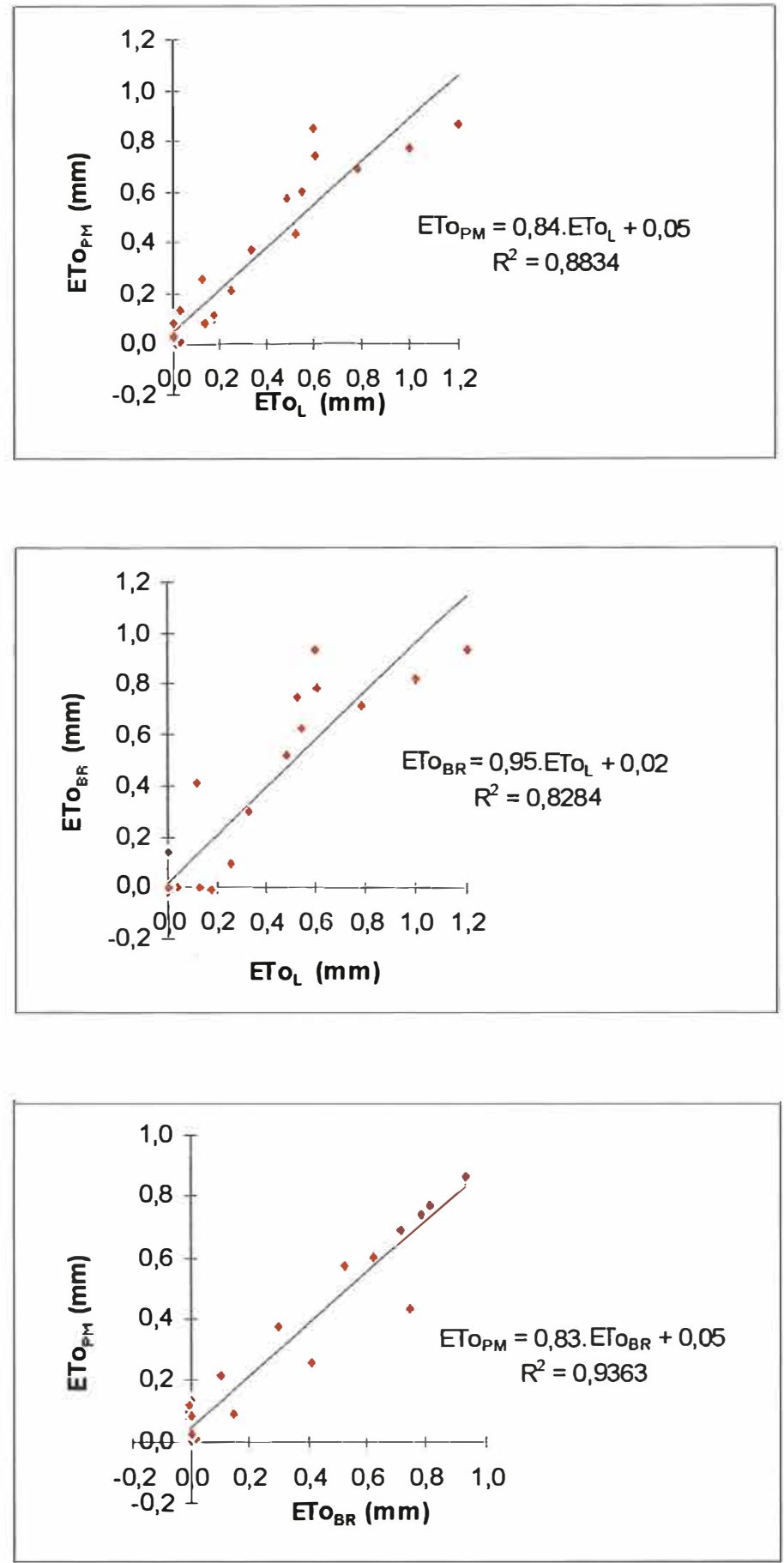

Figura 23 - Valores de ETo Lersus ETopM, ETo $_{\mathrm{L}}$ versus ETo ETR $_{\mathrm{BR}}$ e ETo $_{\mathrm{PM}}$ versus ETo $\mathrm{BR}_{\mathrm{BR}}$, estimadas para o dia 9 de dezembro de 1996. 

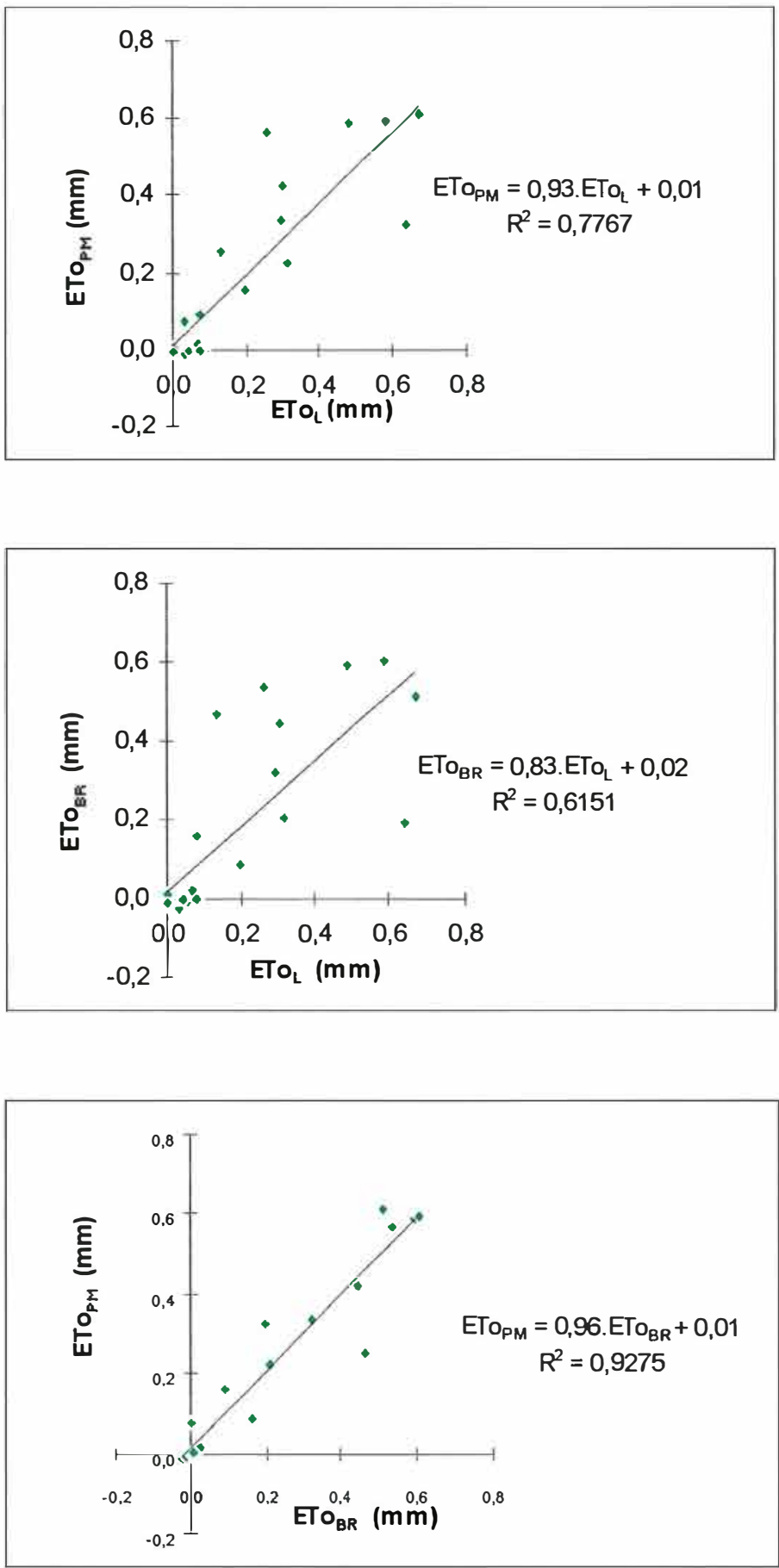

Figura 24 - Valores de ETo $_{\mathrm{L}}$ versus EToPM, ETo ET $_{\mathrm{L}}$ versus ETo BR $_{\mathrm{BR}}$ e ETop $_{\mathrm{PM}}$ versus ETo $_{\mathrm{BR}}$, estimadas para o dia $1^{\circ}$ de dezembro de 1996. 

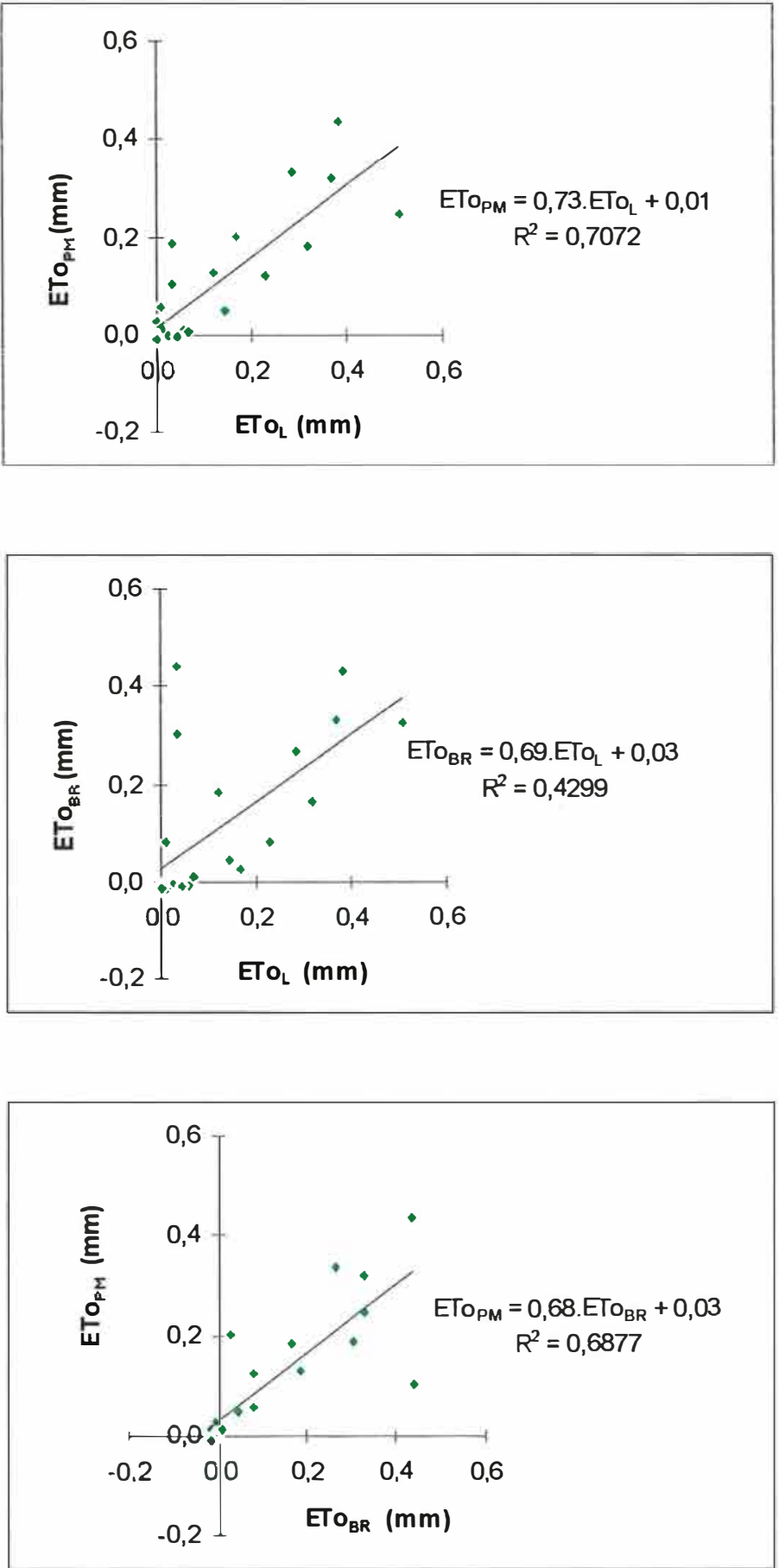

Figura 25 - Valores de ETo $_{\mathrm{L}}$ versus ETo ${ }_{\mathrm{PM}}$, ETo $\mathrm{E}_{\mathrm{L}}$ versus ETo $\mathrm{BR}_{\mathrm{BR}}$ e ETo $_{\mathrm{PM}}$ versus ETo ${ }_{\mathrm{BR}}$, estimadas para o dia 3 de dezembro de 1996. 

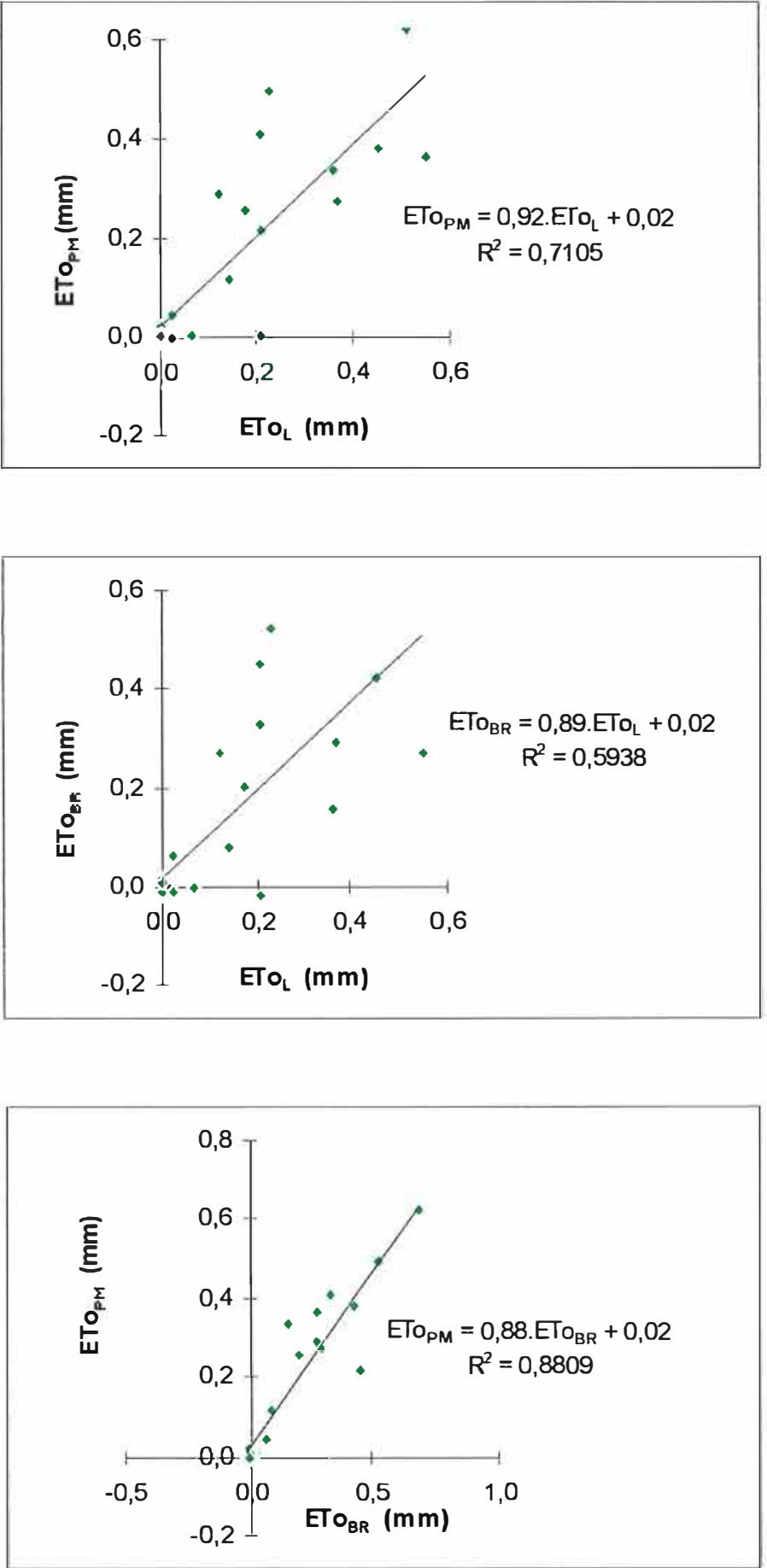

Figura 26 - Valores de ETo $_{\mathrm{L}}$ versus ETo ${ }_{\mathrm{PM}}$, ETo $\mathrm{E}_{\mathrm{L}}$ versus ETo $_{\mathrm{BR}}$ e ETo $_{\mathrm{PM}}$ versus ETo $_{\mathrm{BR}}$, estimadas para o dia 7 de dezembro de 1996. 

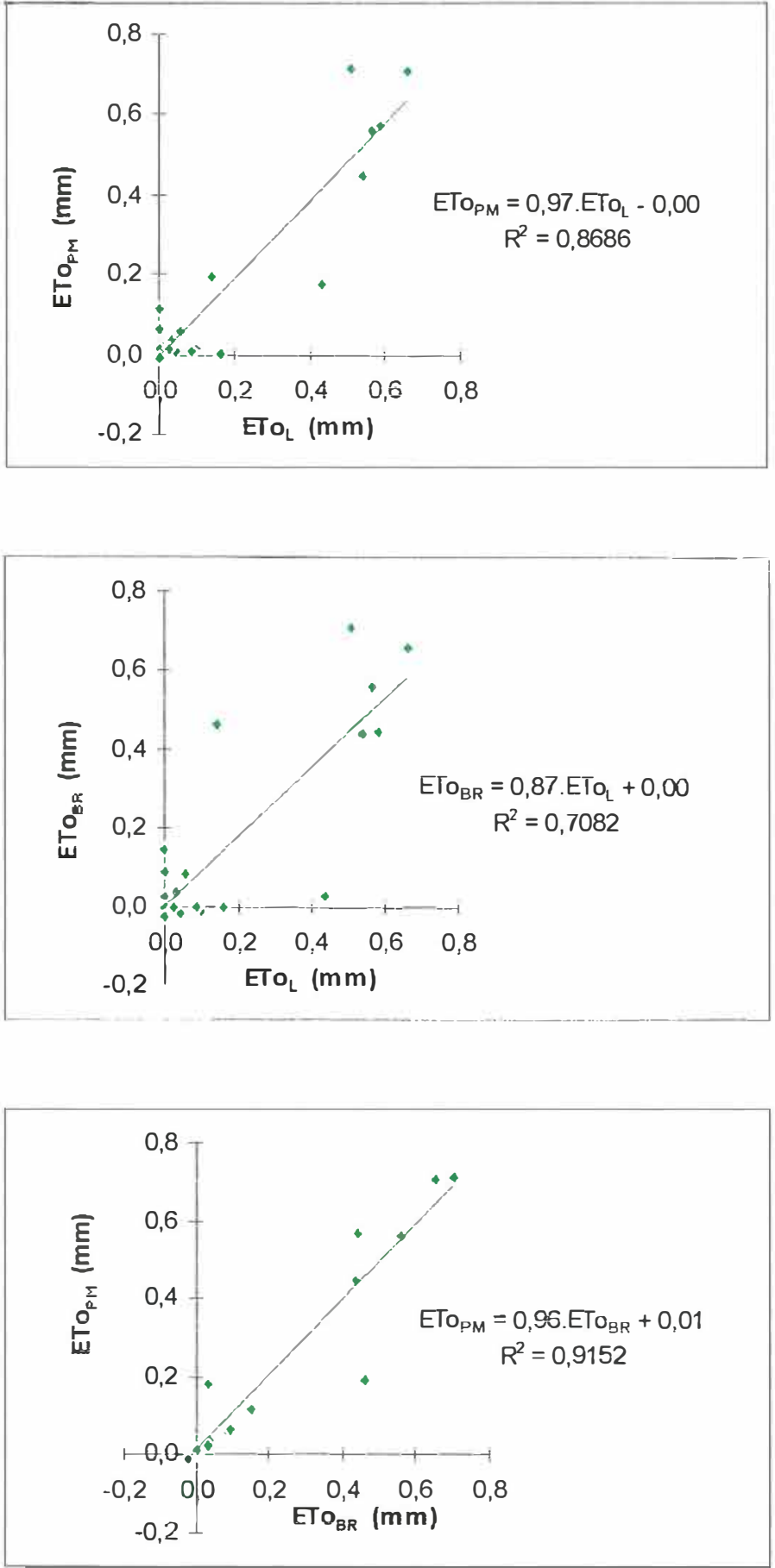

Figura 27 - Valores de ETo $_{\mathrm{L}}$ versus EToPM, ETo E $_{\mathrm{L}}$ versus ETo BR $_{\mathrm{BR}}$ e EToPM versus $_{\text {ETo }}$ BR, estimadas para o dia 10 de dezembro de 1996. 

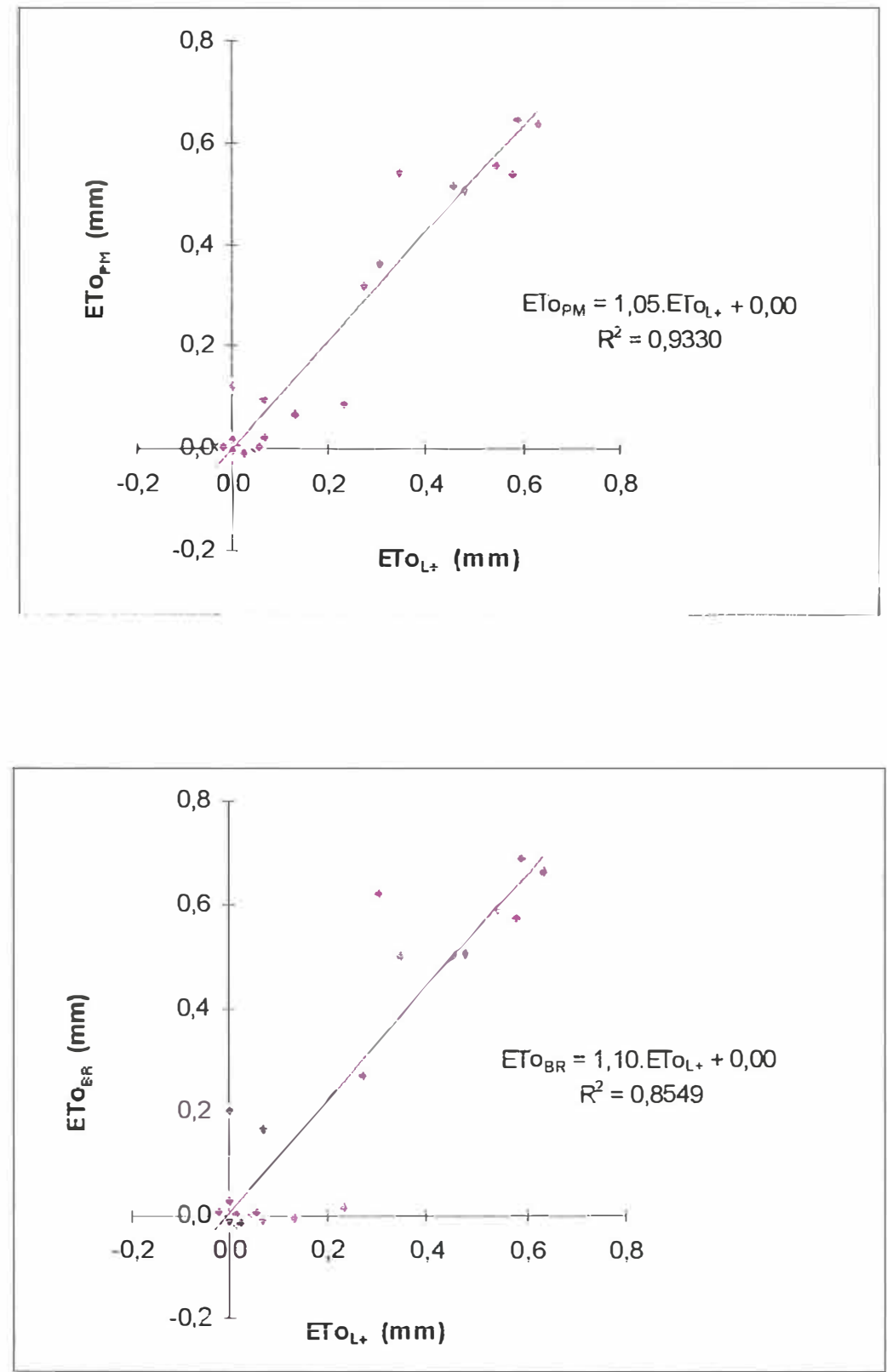

Figura 28 - Vaiores de ETo $_{\mathrm{L}+}$ versus $\mathrm{ETo}_{\mathrm{PM}}$ e $\mathrm{ETo}_{\mathrm{L}+}$ versus $\mathrm{ETo}_{\mathrm{BR}}$, estimadas para o dia 2 de dezembro de 1996. 

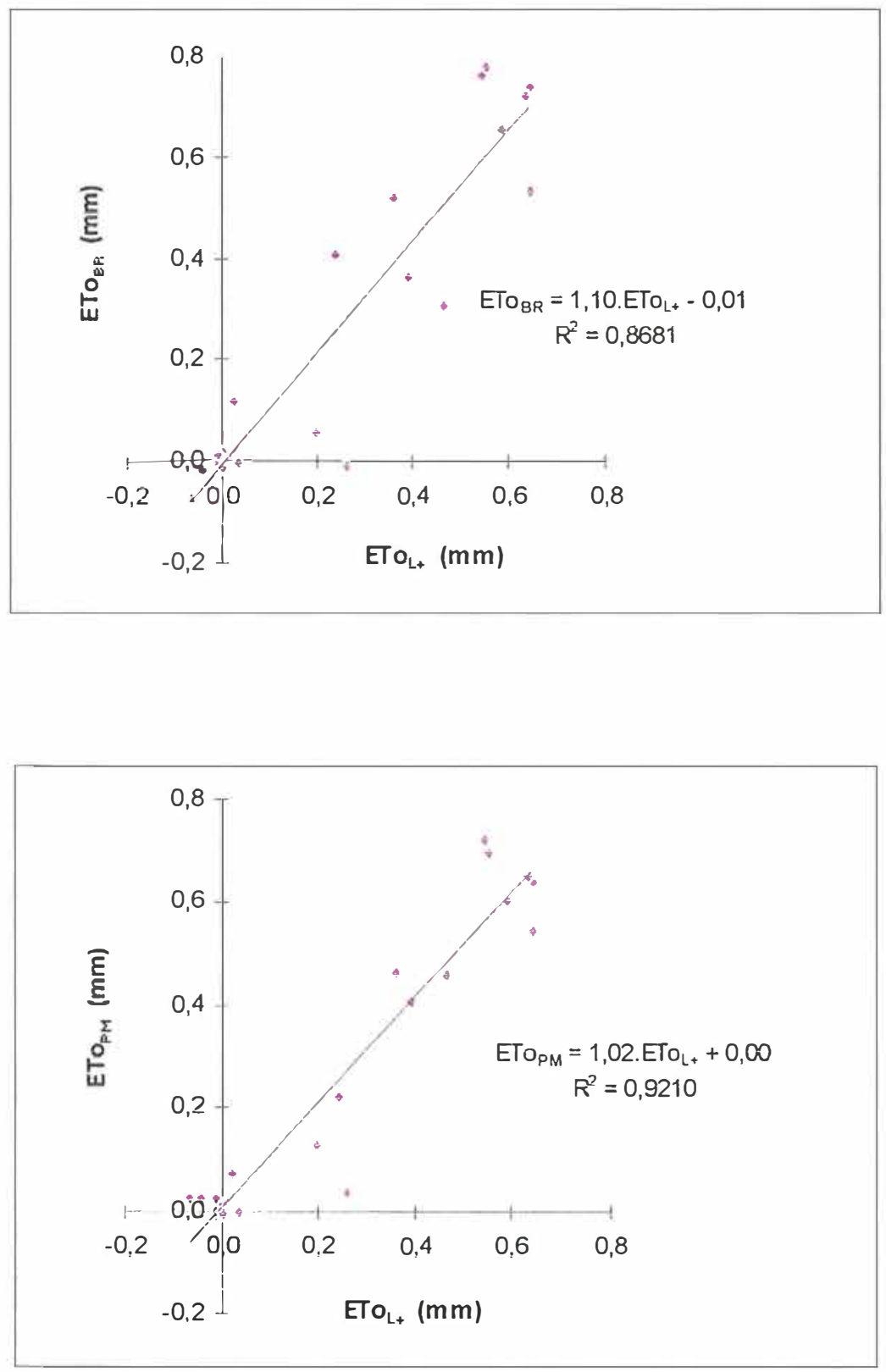

Figura 29 - Valores de ETo $\mathrm{L}_{+}$versus ETo $\mathrm{PM}_{\mathrm{P}}$ e ETo $\mathrm{E}_{\mathrm{L}}$ versus ETo $\mathrm{BR}_{\mathrm{BR}}$, estimadas para o dia 5 de dezembro de 1996. 

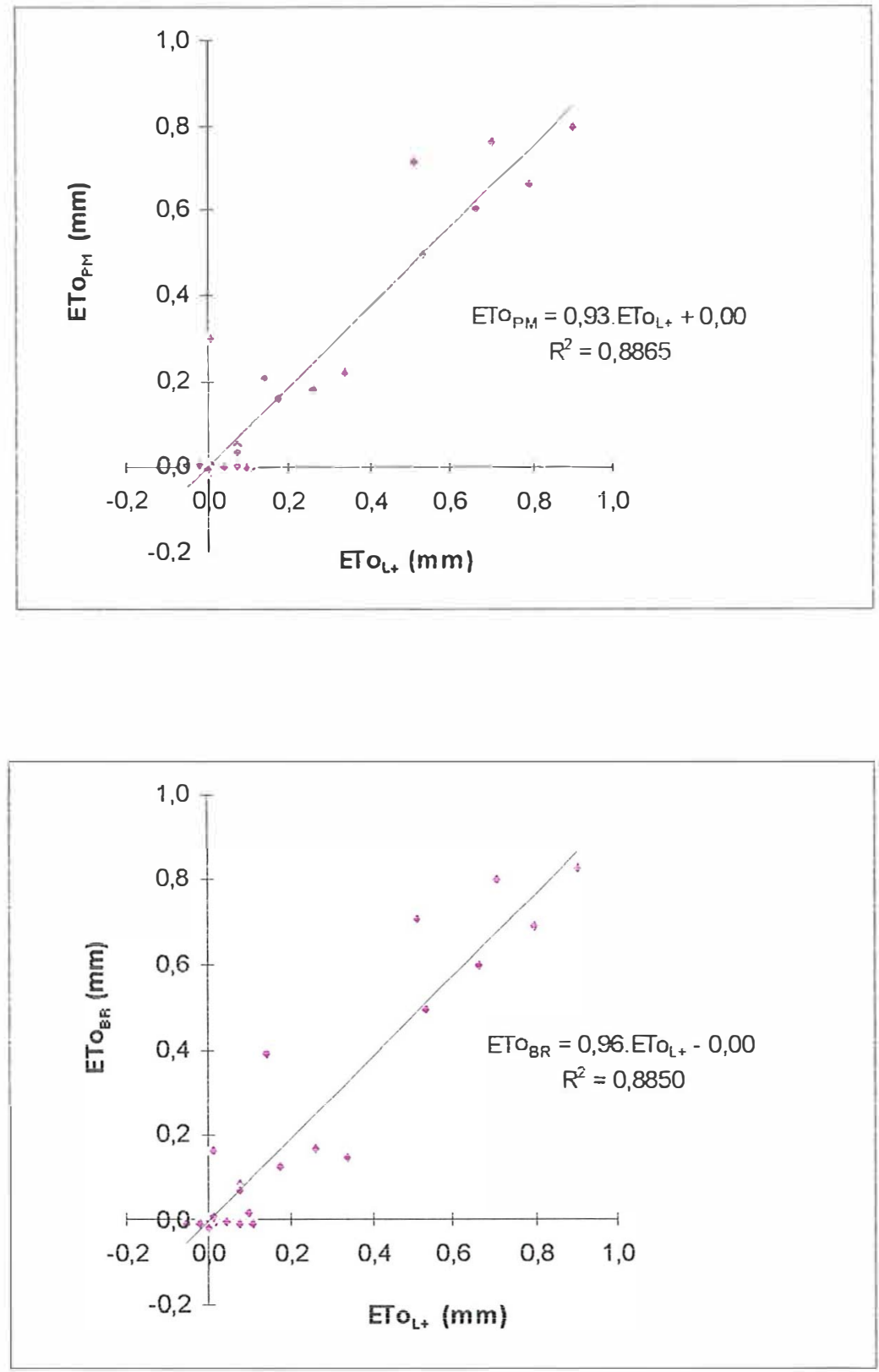

Figura 30 - Valores de $\mathrm{ETo}_{\mathrm{L}+}$ versus ETopM e ETo $\mathrm{L}_{\mathrm{L}}$ versus $\mathrm{ET}_{\mathrm{BR}}$, estimadas para o dia 6 de dezembro de 1996. 

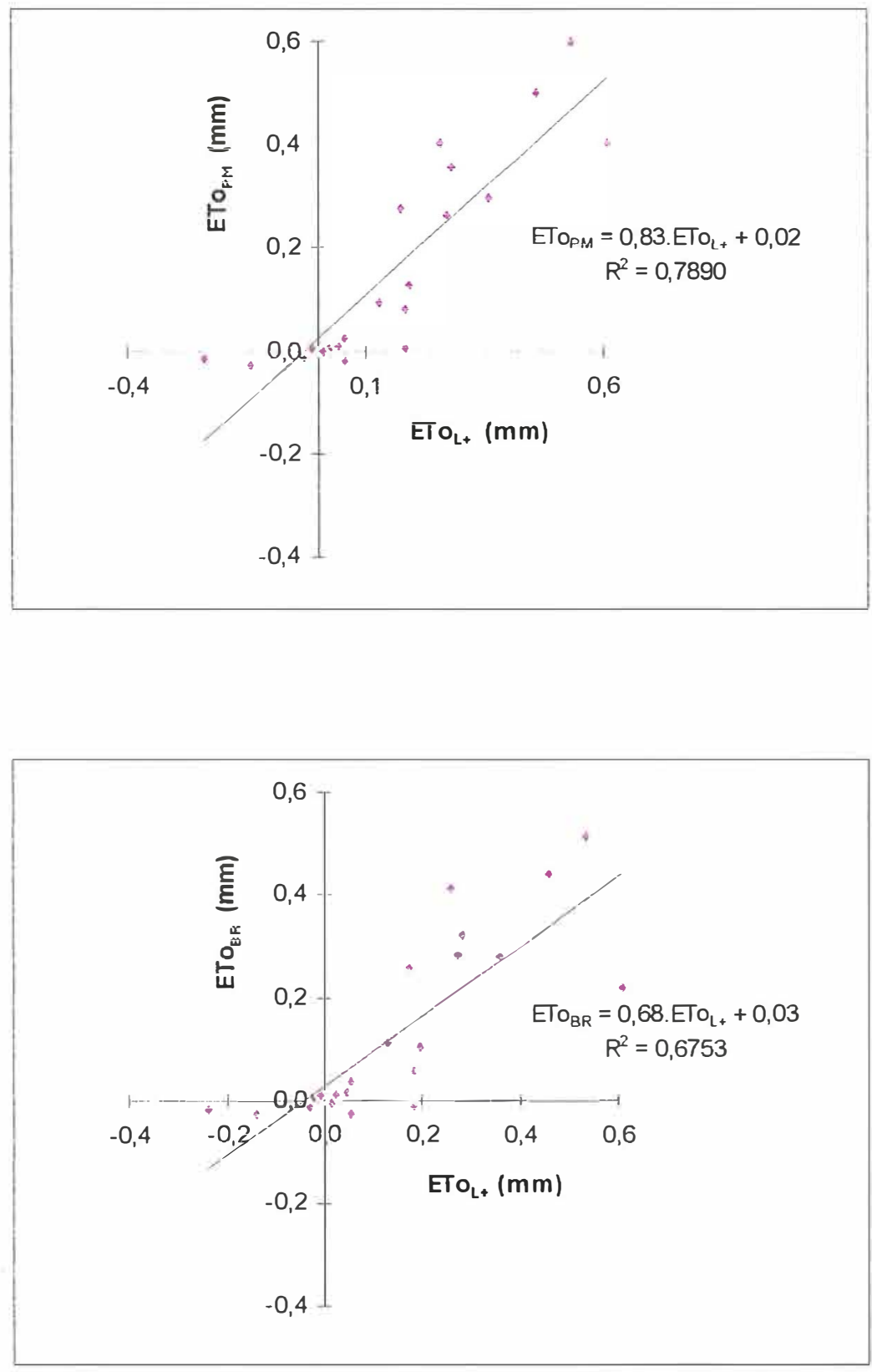

Figura 31 - Valores de $\mathrm{ETo}_{\mathrm{L}+}$ versus $\mathrm{ET}_{\mathrm{PM}_{\mathrm{P}}}$ e $\mathrm{ET}_{\mathrm{L}+}$ versus $\mathrm{ETo}_{\mathrm{BR}}$, estimadas para o dia 8 de dezembro de 1996. 

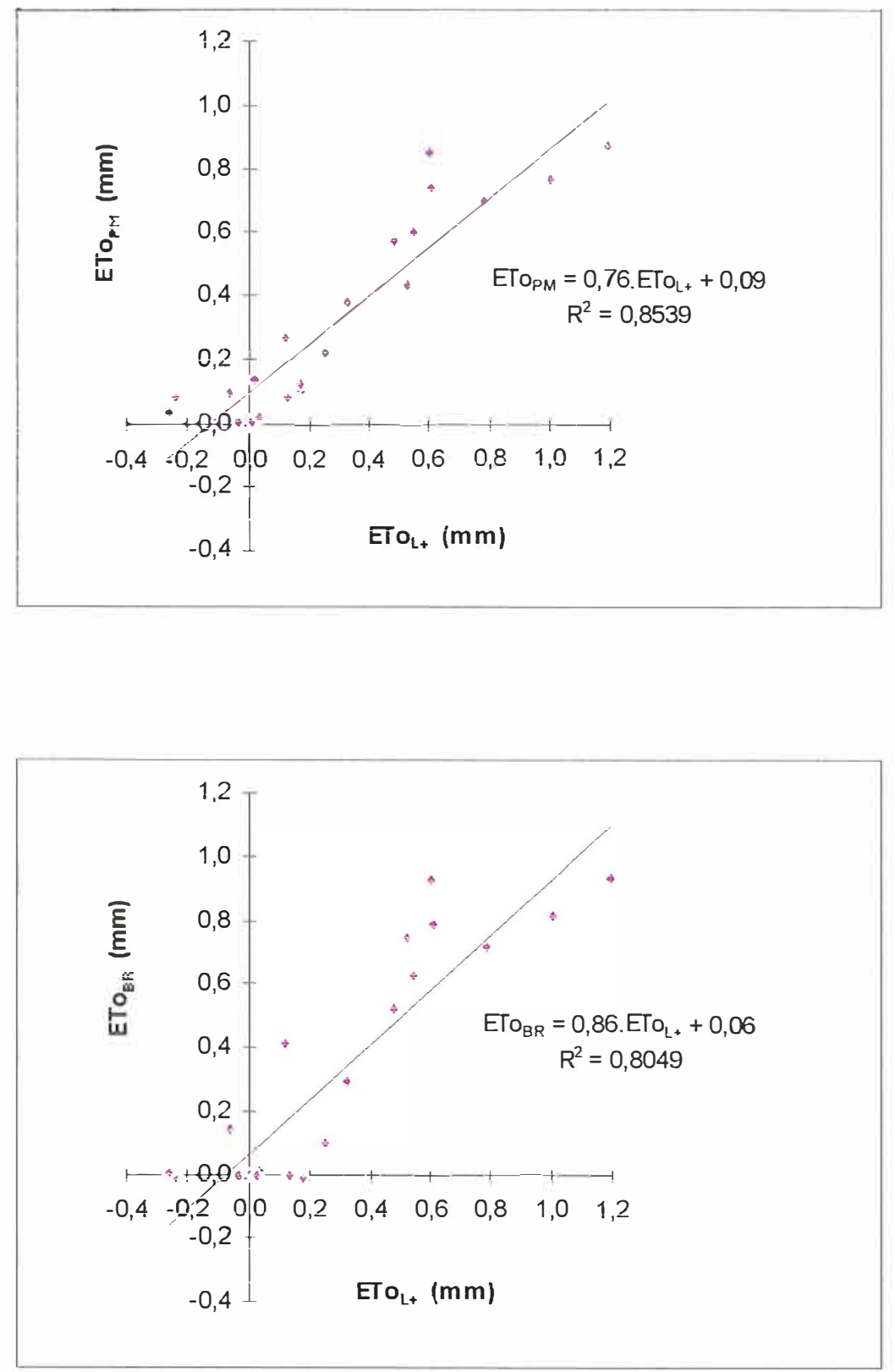

Figura 32 - Valores de ETo $\mathrm{L}_{+}$versus ETo $\mathrm{PM}_{\mathrm{P}}$ e ETo $_{\mathrm{L}+}$ versus ETo $\mathrm{BR}_{\mathrm{B}}$, estimadas para o dia 9 de dezembro de 1996. 


\section{REFERÊNCIAS BIBLIOGRÁFICAS}

ABOUKHALED, A; ALFARO, A.; SMITH, M. Lysimeters. Rome: FAO, 1982. 68 p. (Irrigation and Drainage Paper, 39)

ALFONSI, R. R.; SANTOS FILHO, B. G.; PEDRO JÚNIOR, M. J.; BRUNINI, O.; CAmargo, M. B. P. Balanço de energia em milho. Brasília: Pesquisa Agropecuária Brasileira, v. 12, n. 21, p. 1233-1235, 1986.

ALLEN, R. G.; PRUEGER, J. R.; HILL, R. W. Evapotranspiration from isolated stands of hydrophytes: cattail and bulrush. Transactions of the ASAl, v. 35, n. 4, p. 1191-1198, July/Aug. 1992.

ALLEN, R. G.; ILNSEN, M. E.; WRIGHT, J. L.; BURMAN, R. D. Operational estimates of reference evapotranspiration. Madison: Agronomy Journal, v. 81, n. 4, p. 650-662, July/Aug. 1989.

ANDRÉ, R. G. B. Aspectos energéticos e hídricos da cultura do milho (Zea moxys, L.) na regiào de Jaboticabal. Jaboticabal, 1996. 96p. Tese (Livre Docência) - Faculdade de Ciências Agrárias e Veterinárias, Universidade Estadual Paulista. 
AUBERTINI, G. N.; PE:TER, D. B. Net radiation determination in a cornfield. Madison: Agronomy Journal, v. 53, p. 269-272, 1961.

BAUSCH, W. C.; BERNARD, T. M. Spatial averaging bowen ratio system: description and lysimeters comparison. Chicago: Transactions of the ASAE, v. 35, n. 1, p. 121-128, 1992.

BAVEL, C. H. M. van Lysimetric measurements of evapotranspiration in the Eastern United States. Soil Science Society of America Journal, v. 25, p. 138-141, 1961.

BEN-ASHER, I.; MEEK, D. W.; HUTMACHER, R. B.; PHENE, C. J. Computational approach to assess actual transpiration from aerodynamic and canopy resistance. Madison: Agronomy Journal, v. 81, n. 5, p. 776-782, Sept./Oct. 1989.

BERLATO, M. A.; MOLION, L. C. B. Evaporação e evapotranspiração. Porto Alegre: IPAGRO, 1981. 95 p. (IPAGRO, Boletim Técnico, 7)

BERNARDO, S. Manual de irrigação. 4. ed., Viçosa: Universidade Federal de Viçosa, 1986. 488 p.

BLAD, B. L.; ROSENBERG, N. J. Lysimetric calibration of the Bowen ratioenergy balance method for evapotranspiration estimation in the central great plains. Chicago: Journal of Applied Meteorology, v. 13, p. 227-236, 1974. 
BLANEY, H. F.; CRIDDLE, W. D. Determining water requirements in irrigated areas from climatological and irrigation data. Washington: USDA, SCS, 1952. $96 \mathrm{p}$.

BOWEN, I. S. The ratio of heat losses by conduction and by evaporation from any water surface. Ithaca: Physical Review, v. 2, n. 27, p.779-787, 1926.

BRUTSAERT, W. Evaporation into the atmosphere: theory, history and applications. Dordreclit: Kluver Academic, 1982. 299 p. (Environmental Fluid Mechanics, 1)

CHANG, J. Climate and agriculture: an ecological survey. 2. ed., Chicago: Aldine Publishing Company, 1971. 269 p.

DOORENBOS, J.; PRUIT"T, W. O. Las necessidades de agua de los cultivos. 5. ed., Roma: FAO, 1990. 194 p. (Estudios FAO, Riego y Drenage, 24)

FONTANA, D. C.; BERlato, M. A.; BERGAMASCHI, H. Balanço de energia em soja irrigada e não irrigada. Brasília: Pesquisa Agropecuária Brasileira, v. 3, n. 26, p. 403-410, 1991.

FUCHS, M.; TANNER, C. D. Error analysis of Bowen ratios measured by differential psychrometry. Agricultural Meteorology, v. 7, p. 329-334, 1970.

GANGOPADHYAYA, M.; HARBECK Jr., G. E.; NORDENSON, T. J.; OMAR, M. H.; URYVAEV, V.A. Measurement and estimation of evaporation and 
evapotraspiration. Geneva: WMO, 1966. 121 p. (WMO, Technical Note. 83)

HARGREAVES, G. H. Potential evapotranspiration and irrigation requeriments for Northeast Brazil. Logan: Utah State University, USA Agency for International Development, 1974. 55 p.

HARROLD, L. L. Measuring evapotranspiration by lisimetry. In: EVAPOTRANSPIRATION AND ITS ROLE IN WATER RESOURCES MANAGEMENT, Chicago, 1966. Proceedings. Saint Joseph: ASAE, 1966. p. 28-33.

HOWELL, T. A. McCORMICK, R. L.; PHENE, C.J. Design and installation of large weighing lysimeters. Transactions of the ASAE, v. 35, n. 4, p. 1191-1198, 1992.

LUCHIARI Jr., A. Measurements and predictions of evapotranspiration rates from irrigated wheat in the Cerrado region of Central Brazil. Ithaca, 1988. 171p. Thesis (PhD) - Cornell University.

MONTEITH, J. L. Evaporation and environment. Symposium of the Society for Experimental Biology, v. 19, p. 205-234, 1965.

MONTEITH, J. L. Evaporation from lands surfaces: progress in analysis and prediction since 1948. In: NATIONAL CONFERENCE ON ADVANCES IN EVAPOTRANSPIRATION, Chicago, 1985. Proceedings. Saint Joseph: ASAE, 1985. p. 4-12. 
MONTEITH, J. L. The development and extension of Penman's evaporation formula. In: HILLEL, D. (Ed.) Applications of soil physics. New York: Academic Press, 1980. cap. 10, p. 247-253.

MONTEITH, J. L.; SZEICZ, G. Radiative temperature in the heat balance of natural surfaces. London: Quarterly Journal of Royal Metereological Society, v. 88, n. 378, p. 496-507, Oct. 1962.

MOTHA, R. P.; VERMA, S. B.; ROSENBERG, N. J. Exchange coefficients under sensible heat advection determined by eddy correlation. Agricultural Meteorology, v. 20, p. 273-280, 1979.

OKE, T. R. Boudary layer climates. 2. ed., London: Routledge, 1992. 435 p.

OMETTO, J. C. Bioclimatologia vegetal. São Paulo: Editora Agronômica Ceres, 1981. $440 \mathrm{p}$.

OMETTO, J. C. Registros e estimativas de parâmetros meteorológicos da região de Piracicaha, SP. Piracicaba: FEALQ, 1989. 76 p.

PEQUENO, H. C.; CAMPOS, J. L. D.; SILVA, Z. R. Meteorologia e climalologia agrícolas. Fortaleza: Universidade Federal do Ceará, 1978. $2 v$.

PEREIRA, A. R. Análise do modelo de Priestley-Taylor para estimativa da evapotranspiração potencial. Piracicaba, 1990. 78p. Tese (Livre Docência) - 
Escola Superior de Agricultura "Luiz de Queiroz", Universidade de São paulo.

PEREIRA, A. R. Introdução a micrometeorologia. Piracicaba: ESALQ / USP, 1996. $70 \mathrm{p}$.

PEREIRA, A. R.; VIlla NOVA, N. A.; SEDyiamA, G. C. Evapo(transpi)ração. Piracicaba: FEALQ/ USP, 1997. 183 p.

PRIESTLEY, C. H. B.; TAYLOR, R. J. On the assessment of surface heat flux and evaporation using large-scale parameters. Washington: Monthly Weather Review, n. 100, p. 81-92, 1972.

PRUITT, W. O.; ANGUS, D. E. Large weighing lysimeters for measuring evapotranspiration. Transactions of the ASAE, v. 3, n. 2, p. 13-18, 1960.

RI:ICHARDT, K. Processos de transferência no sistema solo-plantaatmosfera. 4. ed., Campinas: Fundação Cargill, 1985. 445 p.

RITCHIE, J. T.; BURNETT, E. A. A precision weighing lysimeters for row crop water use studies. Agronomy Journal, v. 60, p. 545-549, 1968.

ROSENBERG, J. P. Microclimate: the biological enviroment. New York: Jonh Wiley, 1974. $315 \mathrm{p}$. 
SÃO PAUlO (Estado). Coordenadoria de Açào Regional. Divisào de Geografia. Plano cartográfico do Estado de São Paulo: reambulação de campo 1978/79, foto de 1978. São Paulo, 1979. Escala 1:10.000.

SEDIYAMA, G. C. Necessidades de água para os cultivos. Brasília: ABEAS, 1988. $143 \mathrm{p}$.

SELLERS, W. D. Physical climatology. 3. ed., Chicago: University of Chicago Press, 1975. 272 p.

SILVA, A. A. G. Avaliação da eficiência dos métodos de estimativa da evapotranspiração de referência para o município de Parnaíba-PI. Piracicaba, 1989. 81p. Dissertação (Mestrado) - Escola Superior de Agricultura "Luiz de Queiroz", Universidade de São Paulo.

SMITH, M. Report on the expert consultation on procedures for revision of FAO guidelines for prediction of crop water requirements. Rome: FAO, 1991. $45 \mathrm{p}$.

TANNER, B. D. Use requirements for Bowen ratio and eddy correlation determination of evapotranspiration. In: PLANNING NOW FOR IRRIGATION AND DRAINAGE IN THE 21st CENTURY, New York, 1988. Proceedings. New York: ASCE, 1988. p. 605-616.

TANNER, C. B. Energy balance approach to evapotranspiration from crops. Soil Science Society of America Journal. v. 24, p. 1-9, 1960. 
THOM, A. S.; OLIVER, H. R. On Penman's equation for estimating regional evaporation. London: Quarterly Journal of Royal Meteorogy Society, v. 103, p. 345-357, 1977.

THORNTHWAITE, C. W. An approach toward a raional classification of climate. Geographical Rewiew, v. 38, p. 55-94, 1948.

THORNTHWAITE, C. W.; MATHER, J. R. The water balance. Centerton: Drexel Institute of Technology, 1955. $104 \mathrm{p}$.

VERMA, S. B.; ROSENBERG, N. J.; BLAD, B. L. Turbulent exchange coefficients for sensible heat and water vapor under advective conditions. Chicago: Journal of Applied Meteorology, v. 17, p. 330-338, 1978.

VILLA NOVA, N. A. Estudos sobre o balanço de energia em cultura de arroz. Piracicaba, 1973. 78p. Tese (Livre Docência) - Escola Superior de Agricultura “Luiz de Queiroz", Universidade de São Paulo.

VILLA NOVA, N. A.; REICHARDT, K. Evaporação e evapotranspiração. In: RAMOS, F.; OCCHIPINTI, A. G.; VILLA NOVA, N. A.; REICHARDT, K.; MAGAlhÃES, P. C.; CLEARY, R. W. Engenharia hidrológica. Rio de Janeiro: ABRH, 1989. cap. 3, p. 145-197. (Coleção ABRH de Recursos Hídricos, 2)

WEBB, E. K. Aerial microclimate. Meteorology Monography. v. 6, n. 28, p. 27-58, 1965. 
WILLMOTT, C. J. On the validation of models. Physical Geography, v. 2, p. $184-194,1981$. 